Florida International University

FIU Digital Commons

FIU Electronic Theses and Dissertations

University Graduate School

$7-2-2020$

\title{
A Comprehensive Analysis of Balance, Symmetry, and Center of Mass in the Gait Cycle of Transfemoral Amputees
}

Kayla T. Etienne

Florida International University, ketie004@fiu.edu

Follow this and additional works at: https://digitalcommons.fiu.edu/etd

Part of the Biomechanical Engineering Commons, Biomechanics and Biotransport Commons, Computer-Aided Engineering and Design Commons, Game Design Commons, Orthotics and Prosthetics Commons, Other Biomedical Engineering and Bioengineering Commons, and the Other Mechanical Engineering Commons

\section{Recommended Citation}

Etienne, Kayla T., "A Comprehensive Analysis of Balance, Symmetry, and Center of Mass in the Gait Cycle of Transfemoral Amputees" (2020). FIU Electronic Theses and Dissertations. 4469.

https://digitalcommons.fiu.edu/etd/4469

This work is brought to you for free and open access by the University Graduate School at FIU Digital Commons. It has been accepted for inclusion in FIU Electronic Theses and Dissertations by an authorized administrator of FIU Digital Commons. For more information, please contact dcc@fiu.edu. 


\title{
FLORIDA INTERNATIONAL UNIVERSITY
}

Miami, Florida

\section{A COMPREHENSIVE ANALYSIS OF BALANCE, SYMMETRY, AND CENTER OF MASS IN THE GAIT CYCLE OF TRANSFEMORAL AMPUTEES}

\author{
A thesis submitted in fulfillment of \\ the requirements for the degree of \\ MASTER OF SCIENCE \\ in \\ MECHANICAL ENGINEERING \\ by \\ Kayla T. Etienne
}


To: Dean John L. Volakis

College of Engineering and Computing

This thesis, written by Kayla T. Etienne, and entitled A Comprehensive Analysis of Balance, Symmetry, and Center of Mass in the Gait Cycle of Transfemoral Amputees, having been approved in respect to style and intellectual content, is referred to you for judgment.

We have read this thesis and recommend that it be approved.

Dwayne McDaniel

Alexandra Strong

Benjamin Boesl, Major Professor

Date of Defense: July 2,2020

The thesis of Kayla T. Etienne is approved.

Dean John L. Volakis College of Engineering and Computing

Andrés G. Gil Vice President for Research and Economic Development and Dean of the University Graduate School

Florida International University, 2020 


\section{DEDICATION}

I would like to dedicate this to my parents, because without them I would not have had the courage to make it this far into my education and career. They are my rock and biggest supporters because they always encourage me to try new things, to continue to grow, and to follow all my dreams, no matter how bizarre. I love you both with everything I have, Mom and Dad. 


\section{ACKNOWLEDGMENTS}

I would like to acknowledge and thank Dr. Benjamin Boesl, Dr. Dwayne McDaniel, and Dr. Alexandra Strong for their guidance and support with this thesis and throughout my academic career at FIU Mechanical Engineering. Thank you to my advisor and committee for hearing and believing in this outrageous vision I had for this thesis and encouraging me to push forward with the uncanny topic of combining engineering and animation. I would also like to thank Dr. Ibrahim Tansel for being my original, unofficial advisor when I first started at this university. Lastly, I would thank you Dr. Christopher Bennett from the University of Miami for starting me on this path of biomedical engineering in prosthetics research and for his continued support and guidance. 
ABSTRACT OF THE THESIS

A COMPREHENSIVE ANALYSIS OF BALANCE, SYMMETRY, AND CENTER OF

MASS IN THE GAIT CYCLE OF TRANSFEMORAL AMPUTEES

by

Kayla T. Etienne

Florida International University, 2020

Miami, Florida

Professor Benjamin Boesl, Major Professor

The purpose of this thesis is to create a framework that assists in the transfemoral prosthesis fitting process by calculating balance and symmetry to quantify patient comfort with an understanding of bipedal locomotion and human anatomy. Three different software applications were used to compare (1) the body position during gait cycle, (2) the natural and amputee anatomies, (3) the natural and prosthetic legs, and (4) the equilibrium and torque movements of the hip, knee, and ankle joints. Models were created in Maya for analysis in Solidworks and MEL code evaluation with MatLab. The MatLab code tested combinations of joint degrees and identified stability leg rotations. Additionally, the center of mass (COM) analysis demonstrated that the 3rd combination of materials for the prosthetic leg proved to be closest in COM position to the natural leg $(\mathrm{COM}$ NLratio $=0.6241)$ with a COM ratio $=0.5972 . \mathrm{COM}$ determination assists in establishing symmetry in the prosthesis and amputee relationship. The (COM) alteration contributors were established as the stump length, prosthesis weight, and body position and anatomy. 


\section{TABLE OF CONTENTS}

CHAPTER

PAGE

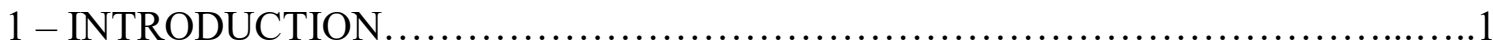

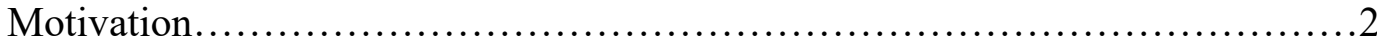

Research Objectives.........................................................

2 - LITERATURE REVIEW...........................................................

Biomechanics...........................................................

Transfemoral Amputation, Prosthetics, and the Fitting Process ................. 10

Gait analysis - Natural Bipedal vs Amputee Locomotion........................14

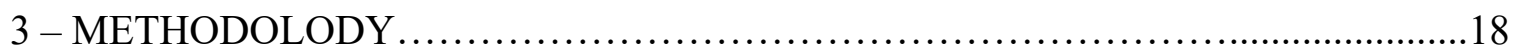

Test Preparation.............................................................

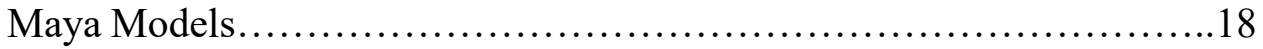

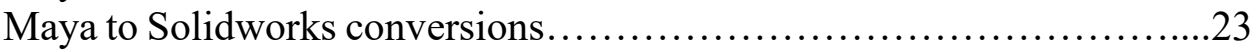

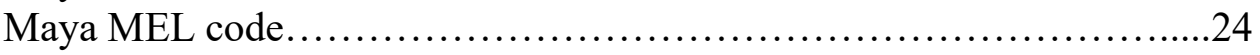

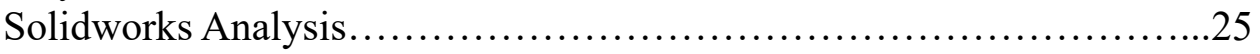

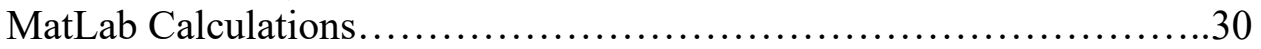

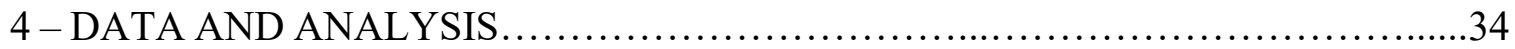

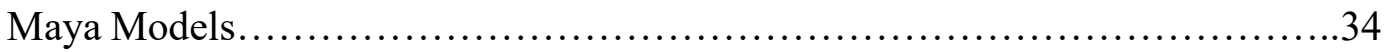

Maya MEL Code Output................................................43

Solidworks Analysis....................................................... 48

Natural Bipedal Locomotion.........................................48

Natural Bipedal vs Amputee Anatomies..................................54

Natural vs Prosthetic Legs..............................................60

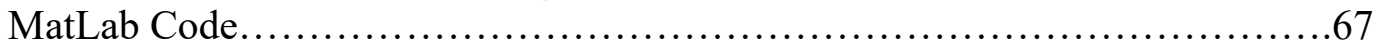

Center of Mass Percentages.........................................67

Equilibrium and Rotational Torque.................................. 71

Input Maya Output Data......................................73

Given Data: Test Joint Angles.................................75

Input Patient Data and Inverse Dynamics Method................76

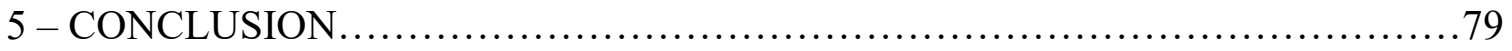

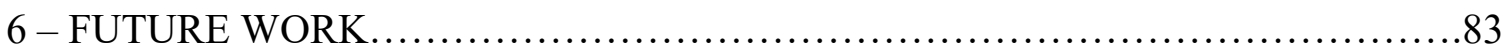

Maya Models and MEL code............................................. 83

Other Studies............................................................... 83

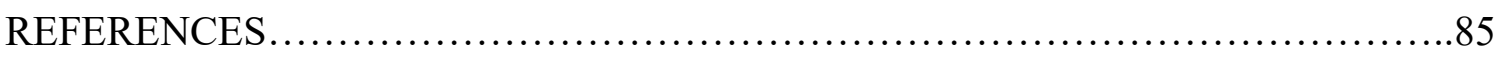

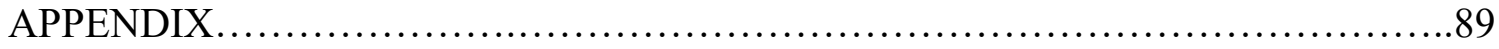




\section{LIST OF TABLES}

TABLE

PAGE

1. Maya Process - Modeling, Rigging, and Animating.............................. 19

2. Converts a. ma file to a. stp file in Maya.......................................... 3

3. Human body center of mass analysis - natural bipedal and amputee male anatomy.....25

4. Prosthetic leg material assignment, parts assembly, and center of mass analysis........28

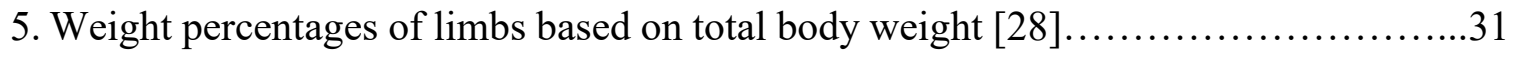

6. Length percentages of limbs based on total body height [29] ..................... 32

7: MEL code output of the joint rotations in the $\mathrm{z}$ directions of the lower limb joints in degrees..................................................... 43

8. Center of mass location data from Solidworks for natural and amputee anatomy...... 57

9. Center of mass location data from Solidworks for different stump lengths.............60

10. Prosthesis center of mass locations for bill of material combinations...............67

11. Center of mass and total body dimensions of male figure in anatomical position.......68

12. Given data, in degrees, from a previous gait study shown in Figure $55 \ldots \ldots \ldots \ldots \ldots . .72$

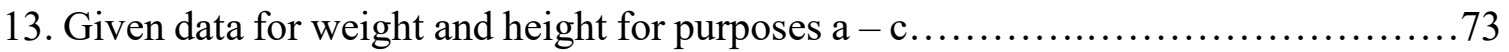

14. MatLab output for Maya joint $\mathrm{z}$ direction rotations for set keyframes from Table 7

15. MatLab torque calculations for Table 12 joint angles.............................75

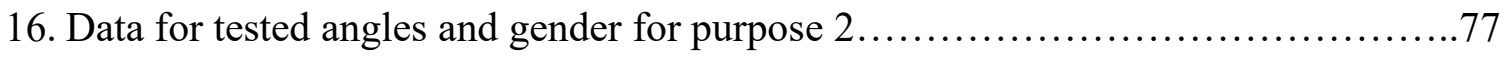




\section{LIST OF FIGURES}

FIGURE

PAGE

1. The identification of the translational and rotational movements on three axes with six degrees of freedom for joint functions as shown on this joint

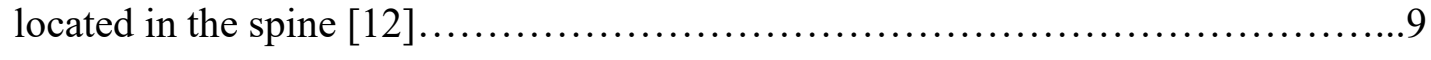

2. A transfemoral prosthetic breakdown of parts, information for patients $[10] \ldots \ldots \ldots . .11$

3. Ottobock catalog order example based on the given patient measurements [13] ....... 12

4. Double pendulum created by the hip-leg relationship during the gait cycle [2]........14

5. Natural Bipedal locomotion: seven main motion phases $[2] \ldots \ldots \ldots \ldots \ldots \ldots \ldots \ldots \ldots \ldots$

6. Leg amputee walking cycle, with a visual representation of how a leg

prosthesis impacts the gait cycle....................................... 16

7. Maya mesh model with skeleton (the colorful system within the gray body).........21

8. Maya bound mesh model with control splines (the blue, green and pink lines)..............21

9. The outliner of the control system (spline curves and IK handles) $\ldots \ldots \ldots \ldots \ldots \ldots \ldots . .22$

10. Solidworks assembly of prosthetic limb parts with assigned materials..............29

11. Maya rendition of walking cycle step 1, heel strike (initial contact), as

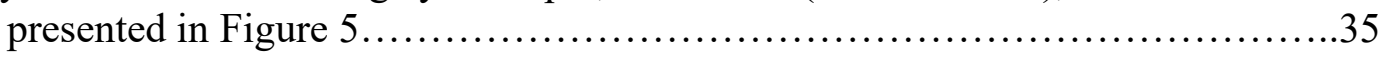

12. Maya rendition of walking cycle step 2, loading response (foot flat), as

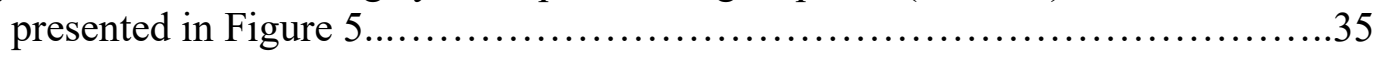

13. Maya rendition of walking cycle step 3, midstance, as presented in Figure 5........36

14. Maya rendition of walking cycle step 4, terminal stance (heel off), as

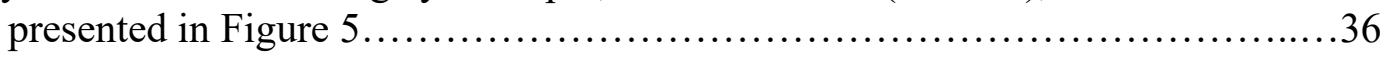

15. Maya rendition of walking cycle step 5, pre-swing (toe off), as presented in Figure 5

16. Maya rendition of walking cycle step 6, initial and mid-swing, as presented in Figure 5. 
17. Maya rendition of walking cycle step 7, terminal swing, as presented in Figure 5 .....

18. Maya rendition of walking cycle step 1 , heel strike (initial contact), as presented in Figure 6.

19. Maya rendition of walking cycle step 2, loading response (foot flat), as presented in Figure 6.

20. Maya rendition of walking cycle step 3, midstance, as presented in Figure 6

21. Maya rendition of walking cycle step 4, terminal stance (heel off), as presented in Figure 6.

22. Maya rendition of walking cycle step 5, pre-swing (toe off), as presented in Figure 6.

23. Maya rendition of walking cycle step 6, initial and mid-swing, as presented in Figure 6.

24. Maya rendition of walking cycle step 7, terminal swing, as presented in Figure 6.

25. Traditional animation walk cycle guidelines [30]....

26. Joint angle data (degrees) of lead leg, where solid line $=$ hip, dashed line $=$ knee, and dotted line $=$ ankle [35]

27. Left leg (lead leg) joint movements, z-axis, of Maya model using MEL code output from Table 7

28. Right leg joint movements, z-axis, of Maya model using MEL code output from Table 7

29. Hips/pelvis rotation, z-axis, of Maya model using MEL code output from Table 7.

30. Hip rotation data, where solid black line $=$ hip rotation, solid grey lines $=$ interval of rotation, and the dotted lines = maximum and minimum rotation locations. [42].

31. Solidoworks 3D model of walking cycle step 1, heel strike (initial contact) with center of mass, as presented in Figure 5

32. Solidoworks drawing of walking cycle step 1, heel strike (initial contact) with center of mass location, as presented in Figure 5. 
33. Solidworks 3D model of walking cycle step 2, loading response (foot flat)

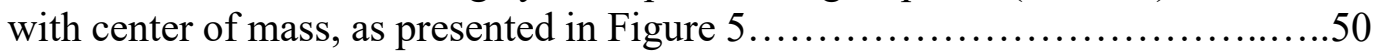

34. Solidworks drawing of walking cycle step 2, loading response (foot flat)

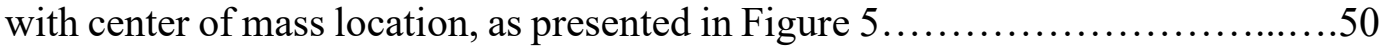

35. Solidworks 3D model of walking cycle step 3, midstance, with center of mass, as presented in Figure 5

36. Solidworks drawing of walking cycle step 3, midstance, with center of mass location, as presented in Figure 5.

37. Solidworks 3D model of walking cycle step 4, terminal stance (heel off), with center of mass, as presented in Figure 5

38. Solidworks drawing of walking cycle step 4, terminal stance (heel off),

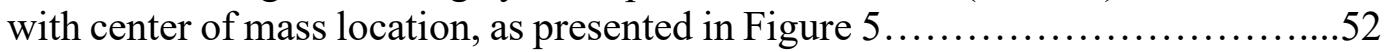

39. Solidworks 3D view of natural anatomy and center of mass location................55

40. Solidworks drawing of natural anatomy with center of mass and the respective dimensions................................................... 55

41. Solidworks 3D view of amputee anatomy with medium sized stump and center of mass location.

42. Solidworks drawing of amputee anatomy, medium stump, with center of mass and the respective dimensions.

43. Solidworks 3D view of amputee anatomy with small sized stump and center of mass location.

44. Solidworks drawing of amputee anatomy, small stump, with center of mass and the respective dimensions

45. Solidworks 3D view of amputee anatomy with large sized stump and center of mass location.

46: Solidworks drawing of amputee anatomy, large stump, with center of mass and the respective dimensions.

47. Solidworks $3 \mathrm{D}$ view of the natural leg and center of mass.

48: Solidworks drawing of natural leg with center of mass and leg dimensions

49. Solidworks 3D view of the prosthetic leg and center of mass location 
50. Solidworks drawing of prosthetic leg with center of mass and leg

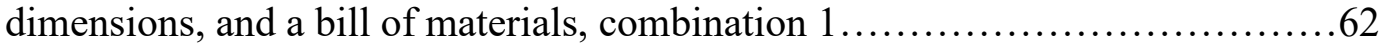

51. Solidworks drawing of prosthetic leg with center of mass and leg

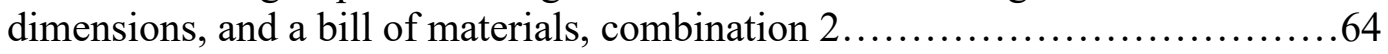

52. Solidworks drawing of prosthetic leg with center of mass and leg

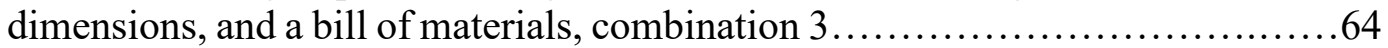

53. Solidworks Mass Properties analysis results for COM percentages...................68

54. Solidworks Mass Properties analysis results, close-up of the engineering

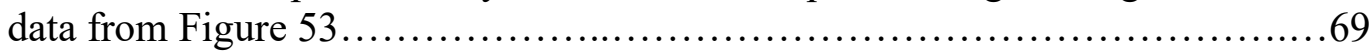

55. Joint moments data, where solid line $=$ hip, dashed line $=$ knee, and dotted line $=$ ankle - moment of inertia $\left(\mathrm{N}^{*} \mathrm{~m}\right)$, joint angle (degrees), and GFR (ground reaction forces in Newtons) ........................................ 72

56. Sample MatLab output for one set of joint rotations in the $\mathrm{z}$ direction.................78

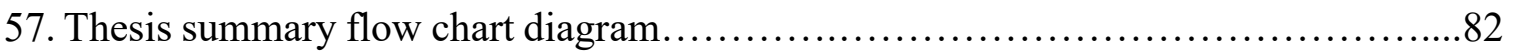




\section{CHAPTER 1 - INTRODUCTION}

Prosthesis and orthotics have proven capable of improving the quality of life and create a sense of normalcy for those that have malformed or missing limbs [1]. In the context of leg prosthesis, the use and production of prosthesis is greatly dependent on the comprehension of the complicated method of bipedal locomotion. Human gait evaluation has been a topic of discussion and analysis in the medical world over the years and has contributed to the advancement of developments in human aid. However, gait differs from person to person, and even within an individual's own gait pattens over time. Traditionally, the prosthesis fitting process is not only dependent on the benchmark standards, but is also dependent on the patient comfort levels and the fitter's observed gait to obtain the "perfect fit" [3-4]. These unique human qualities thus make the scripted benchmark process difficult to model to each patient without individualizing the process.

The use and observance of balance and symmetry, in addition to the current fitting methods, could be used to assist in obtaining an ideal fit of the prosthesis and enhance the relationship between the prosthetic and the wearer. Quantifying balance and symmetry could reduce some of the guess work that is currently a part of modern prosthesis fitting methods and ease the process for not only the technicians, but also the patients. The quantification of balance and symmetry has a potential impact on the current fitting process, but it is vital to first comprehend and identify the relationship between the elements within bipedal anatomy and locomotion. As a result, this thesis will focus on the use and comprehension of the relationship between symmetry, balance, and gait to possibly improve the fitting process with the aid of the computational analysis of torque, equilibrium, and center of mass. 


\section{Motivation}

In modern day prosthesis clinics, the leg fitting process is a method that follows strict benchmark guidelines and is reliant on the fitter's trained eye for additional adjustments. This method has been essential in the prosthesis environment over the years since the benchmark requirements regulate the process to ensure the "ideal" outcome. Given the physical differences among people, especially in their presented gait patterns, the strict, rigid benchmark guidelines constrict the ability to create an individualized and unique fit that varies from patient to patient. To compensate, the current method of fitting relies on the fitter's experience to make the required adjustments accordingly to individualize the process [4]. The prosthetics assembler's seasoned view is meant to gauge and assess the patient's gait onsite and adjust accordingly. Depending on the fitter's experience makes this process susceptible to fitting inconsistencies and patient discomfort.

Patient comfort is deemed as the relationship between the wearer and the prosthetic and is also known as "the comfort to wear" [7]. The fit of a prosthetic is often compared to that of shoes, and like shoes, the comfort to wear could exist within the moment and may diminish over time as the item is continually worn. In transfemoral prosthetics, the interaction between the stump and the socket is the most vital to determine the patient's comfort level. Patient comfort then represents how a patient feels while wearing their prosthetic, an unquantified assessment of the stump socket interaction.

Current prosthesis analysis methods focus mainly on gait analysis and patterns, but none focus on the quantifying and achieving balance and symmetry when comparing 
the right and left side of the body's structure. The ability to obtain a numerical value for balance and symmetry will allow for a more appropriate comprehension of bipedal anatomy and locomotion. A comprehension that will positively influence the fitting process adjustments and potentially quantify the definition of patient comfort.

\section{Research Objectives}

The overall objective of this thesis research is to create a framework that assists in the transfemoral prosthesis fitting process by calculating balance and symmetry to help quantify patient comfort. This research will be conducted using established gait data, as well as information gained through modeling software applications. The objective will be accomplished with the following tasks:

Task 1: Calculation for natural bipedal structure

a) Identify center of mass calculations and ratio formulas for human body

b) Identify the relationships between the hip, knee, and ankle joints during gait

c) Quantify symmetry and balance using torque and equilibrium

Task 2: Calculation for bipedal transfemoral amputee and prosthetic

a) Compare center of mass variables to that of the natural bipedal structure

b) Determine the symmetry and equilibrium using natural and prosthetic leg center mass measurements

c) Determine relationship between material of prosthetic and its center of mass

The main aim of these tasks is to determine the relationships between gait, balance, and symmetry with quantified data. To test the gait values of rotation for the leg 
functions, Maya (an Autodesk 3D animation software) will be used to model human replicas of natural bipedal and transfemoral amputee structures. With this software, it will be possible to manipulate polygons to the ideal shape of a human, as well as create a walk cycle animation for analysis. In conjunction with Maya, Solidworks would be used to verify center of mass alterations throughout the gait cycle. Lastly, MatLab will provide the platform for calculations that will allow for the creation of an algorithm that can be adjusted in accordance to the presented patient. With these three software products working in conjunction with each other, the above two tasks can be accomplished.

The first task focuses on gaining baseline data of the human body in anatomical positionings as well as during natural gait. This baseline data will focus on the legs and the correlated rotations and forces that contribute to equilibrium, balance, and symmetry. The second task focuses on using the data collected from Task 1 and comparing it the new collected information from the transfemoral amputee model. The baseline data from Task 1 will allow for a more in-depth comprehension of how the equilibrium, balance, and symmetry are altered with an amputation and how the prosthetic may be most effectively utilized to regain the most "normal" equilibrium measurements. 


\section{CHAPTER 2 - LITERATURE REVIEW}

\section{Biomechanics}

Biomechanics is known as the application of physics, such as Newton's Laws of Motion, torque, equilibrium, and the center of gravity, to the living structures, like the human body [14]. The study of biomechanics is divided into two major forms of study, kinematics and kinetics. Kinematics is the motion of the body, such as speed and acceleration, while kinetics refers to the forces applied to the body [15].

Angular kinematics as applied to the human body is an important application and element of comprehension because this concept is rooted in the study of joint movements and center of gravity calculations. Torque is presented as the twisting force applied to the joint, where counterclockwise is deemed as positive and clockwise is negative for torque vectors. The formula is as demonstrated in Eq. 1:

$$
\boldsymbol{T}=\boldsymbol{F} \cdot \boldsymbol{d}_{\perp}
$$

where $\boldsymbol{d}_{\perp}=$ the moment arm vector which is the shortest perpendicular displacement between the force line of action and the axis of rotation

$$
\boldsymbol{F}=\text { force applied vector }
$$

In torque, the moment arm and force are equally important, for understanding the weight and role of each variable within the equation as applied to the body and can assist with maximizing human performance or creating precision in human movements. For example, to create more torque, the patient can increase the moment arm or increase the 
applied force. A good variable to measure muscle strength is torque since it is independent of the force's point of application on the limb.

Moment of inertia is the resistance of the body to rotation about an axis and is defined with Eq. 2 as demonstrated below:

$$
I_{A}=\sum m r^{2}
$$

where $I_{A}=$ moment of inertia about an axis

$m=$ mass of the object

$r=$ radial distance from the axis

The joints present in the body allows the form to transform into a variety of shapes, thus giving an infinite number of moments of inertia variations. The concept of manipulating the shapes the body creates to influence the moment of inertia can be applicable to increase body rotations, such as in sports like figure skating and ballet. Inverse dynamics is the use of visual studies to determine the physics applications and equations on the body segment in question. Similar to the general applications of physics in dynamics, biomechanists also implement rigid body diagrams and inverse dynamics to comprehend the effects of Newton's Laws to calculate the forces acting on the human body. These concepts, such as moment of inertia and torque, can be combined to articulate the joint rotation, strength, and power.

Equilibrium is when the sum of forces and/or torques equal zero. This concept is split into static equilibrium, as shown with Eq. 3 and Eq. 4, and dynamic equilibrium, as 
demonstrated with Eq. 5 and Eq. 6. Static equilibrium is when the object is experiencing no movement while dynamic equilibrium refers to when the object exhibits acceleration.

$$
\begin{gathered}
\sum \boldsymbol{F}=0 \\
\sum \boldsymbol{T}=0 \\
\sum \boldsymbol{F}-m \cdot \boldsymbol{a}=0 \\
\sum \boldsymbol{T}-I \cdot \boldsymbol{\alpha}=0
\end{gathered}
$$

Static equilibrium can be used to calculate the center of gravity of the human body in the anatomical position. In the anatomical position, the general location of the center of gravity is $57 \%$ of the male height and $55 \%$ of the female height [11]. The center of gravity within the human body can change locations as the body changes shapes in accordance to the joint combinations created. Traditionally, within the clinical setting, center of gravity is determined with two techniques: the reaction board method and the segmental method. The reaction board method uses a rigid board with a scale to measure the reaction force at the feet. The segmental method uses mathematics to break up the body into segments to achieve the calculations, such as utilizing Eq. 4 to determine the overall center of gravity of the body by understanding the sum of torques on body sections.

Equilibrium can also be used to understand the concept of balance, a tradeoff between stability and mobility, by using the sums of forces and/or torques. In kinesiology, balance is deemed as the relationship between controlled body position and relative base of support in dynamic and static movements. To improve balance, based on mechanical principles, there should be an adjustment of posture and body placement. In 
the concept of balance, it is important to acknowledge that stability and mobility are inversely proportional. Balance is closely related to posture and in turn proves a dependency on the body's center of gravity. The determination of the center of gravity, vertically and horizontally, relative to the base of support will allow for the identification of mobility verses stability in the presented pose. The base of support is defined as the area created by the supporting elements of the body, such as the distance between the feet as well as the feet themselves. For example, in martial arts, a middle stance (a wider set stance) creates ample stability with the lowering of the center of gravity, but it is more difficult to move quickly out of this portion. Alternatively, a fighting stance (shoulder with apart, constant movement on the ball of the feet kind of stance) allows for ease of travel or mobility across the floor and quicker executions of defensive and offensive movements such as kicks and blocks, but this position proves to be less stable and makes one more susceptible to sweeps and impromptu takedowns. Good balance is dependent on good posture as determined with the mechanical principles, such as with force and pressure concepts. With the combination of the angular kinetics in biomechanics and balance principles, it becomes possible to determine the sides of the body that require more support, that are weaker, or unsteady and provide the information to reestablish overall stability [11].

Joint movements and rotation all differ depending on the type of joint located at that particular site, such as hinge, ball and socket, pivot, saddle, plane, and gliding joints. The main joints necessary for this study include the hinge, ball and socket, and gliding joints. The gliding joints are located in the ankles, the ball and socket joints are in the hips, and the hinge joints are in the knees [16]. Each joint contains the potential of 
experiencing three rotational movements and six degrees of freedom, as shown in Figure 1, where the rotation occurs around the rotational axis of each joint [12].

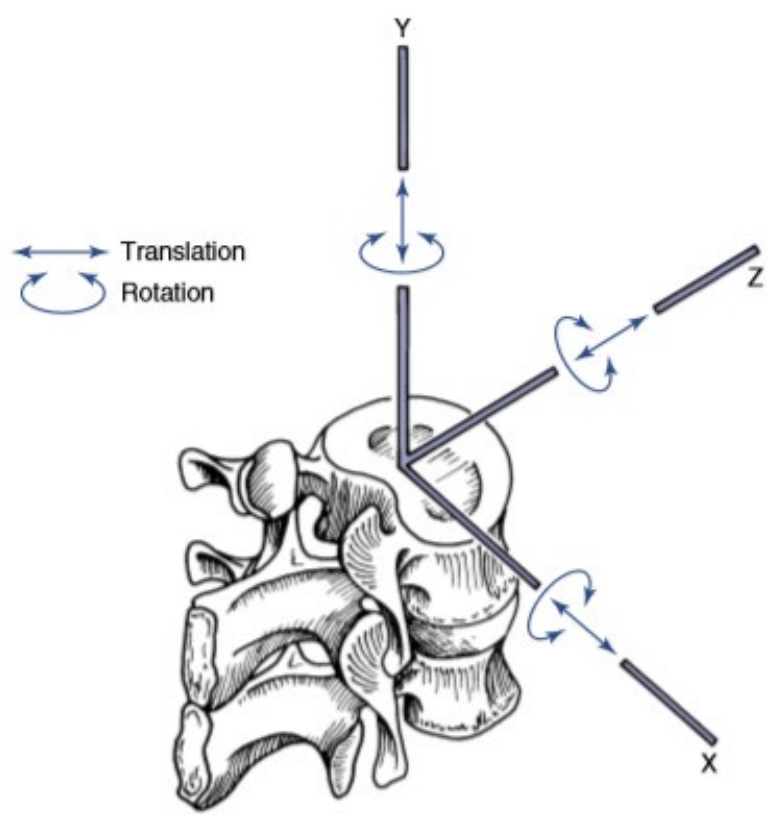

Figure 1: The identification of the translational and rotational movements on three axes with six degrees of freedom for joint functions as shown on this joint located in the spine [12].

Hip joints move from lateral to medial and vice versa, as well as from anterior to posterior and vice versa. So, the hip movement is from front to back (posterior to anterior) and outside to center (lateral to medial) [17]. The hip joint has a maximum, healthy hip rotation between 110 and 125 degrees [31-32, 34]. The knee joint's movement if from anterior to posterior, with a full range of motion between 135 and 141 degrees [17, 33-34]. The ankle functions in any direction along the surface of the joint interaction, with a range of motion between 48 and 55 degrees [17, 34]. The comprehension of the hips, knee, and ankles joint movement capabilities will enhance and contribute to the understanding of human movements during gait. 


\section{Transfemoral Amputations, Prosthetics, and the Fitting Process}

A prosthetic refers to an artificial replacement to a body part for the sake of functionality capabilities and/or cosmetic purposes. Typically, prostheses for the joints, such as knee, hip elbow, are implants as part of the joint. A removeable prosthesis, such as for the legs and arms, may have various extensions, such as the feet and hands, for different functions. Given the continual growth of technology and the comprehension of biomedical developments, the line between removeable and implanted prosthesis has blurred with the rise of devices that are capable of responding to neural firings and signals, like cochlear implants and hearing aids [8].

A transfemoral amputation is the subtraction of the leg above the knee. An amputation above the knee requires the removal of thigh tissue and part of the femoral bone, thus creating the stump. The cause of a transfemoral amputation vary from infection, trauma, vascular compromise, tumors and congenital impairments. As with any surgery, transfemoral amputations also experience complications, like muscle atrophy, surgical site infections, dehiscence (the splitting or bursting of the wound), and wounds from the stump and prosthetic interaction. Psychological complications may also occur where patients may experience a range of emotions, such as post-traumatic stress disorder (PTSD) and depression, due the sudden loss of the limb or a traumatic amputation experience [9-10].

Transfemoral prosthetics allow for the reestablished mobility for the amputee. A transfemoral prosthetic is broken down into four main parts: (1) socket, (2) knee joint, (3) 
shin/pylon tube, and (4) foot and ankle apparatus, as shown in Figure 2. The knee joint is split into two types, microprocessor or non-microprocessor. The microprocessor knee joint is a more advanced version of the non-microprocessor because it utilizes hydraulic and pneumatic systems to create a smoother bend on the knee and requires less effort from the wearer [18-20]. The microprocessor knee joint tends to be heavier and bulkier than the non-microprocessor knee joint due to the mechanisms involved in the apparatus and they have a load baring weight limit [19-20]. The non-microprocessor knee joint is a mechanical hinge joint that relies on the movement the wearer provides through body actions [18-20].

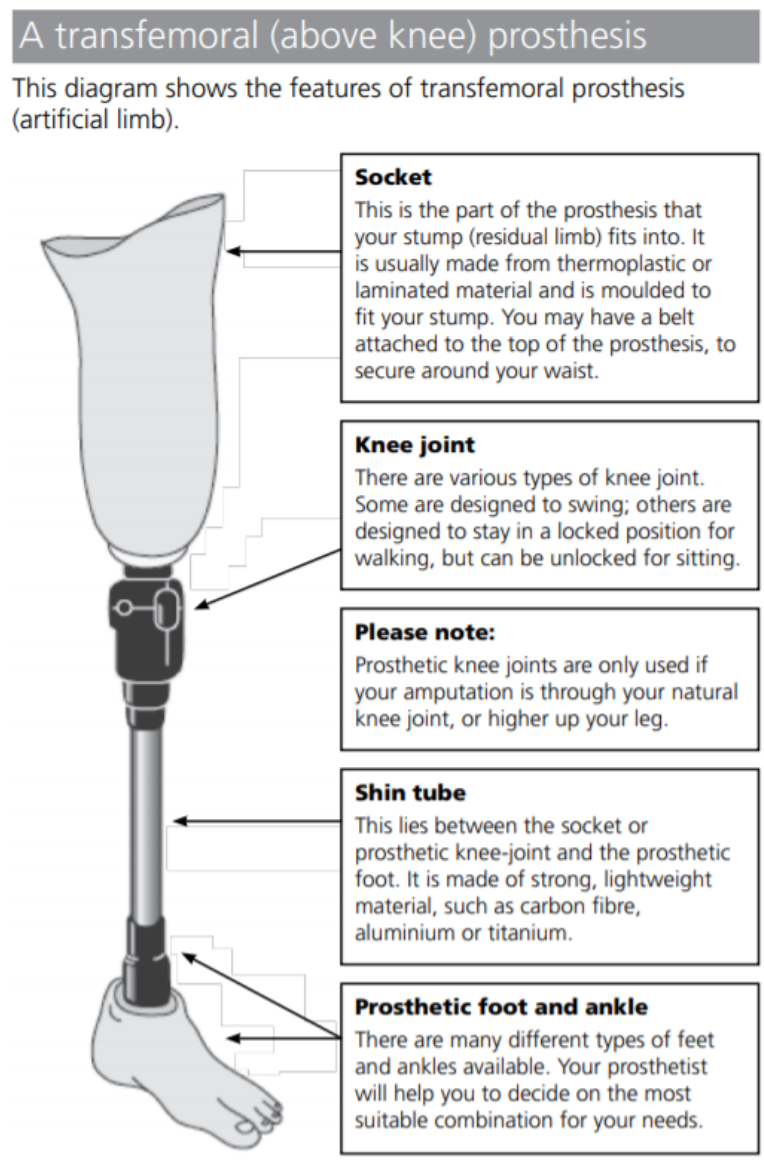

Figure 2: A transfemoral prosthetic breakdown of parts, information for patients [10]. 
Patient comfort is determined by the stump and socket interaction, thus deeming the socket as one of the most important fits to establish during the process [7]. The size and type of the prosthesis elements presented in Figure 2 are determined by insurance allowance and clinical fitting charts used during the fitting process, similar to that shown in Figure 3.

\begin{tabular}{|c|c|c|c|c|c|c|c|c|}
\hline Reference number $=$ & Side & \multicolumn{7}{|l|}{ Size } \\
\hline 1K30 & $\mathrm{L}$ & \multicolumn{7}{|l|}{16} \\
\hline Reference number & \multicolumn{8}{|l|}{$1 \mathrm{~K} 30$} \\
\hline Heel height & \multicolumn{8}{|c|}{$5+/ .5 \mathrm{~mm}$} \\
\hline Side & \multicolumn{8}{|c|}{ links $(L)$, rechts $(R)$} \\
\hline Size & $14 \mathrm{~cm}$ & $15 \mathrm{~cm}$ & $16 \mathrm{~cm}$ & $17 \mathrm{~cm}$ & $18 \mathrm{~cm}$ & $19 \mathrm{~cm}$ & $20 \mathrm{~cm}$ & $21 \mathrm{~cm}$ \\
\hline $\begin{array}{l}\text { System height with } \\
\text { 2R40 }\end{array}$ & $40 \mathrm{~mm}$ & $42 \mathrm{~mm}$ & $44 \mathrm{~mm}$ & $46 \mathrm{~mm}$ & $48 \mathrm{~mm}$ & $50 \mathrm{~mm}$ & $52 \mathrm{~mm}$ & $54 \mathrm{~mm}$ \\
\hline $\begin{array}{l}\text { Weight (without } \\
\text { adapter) }\end{array}$ & $\sim 95 \mathrm{~g}$ & $-115 \mathrm{~g}$ & $-125 \mathrm{~g}$ & $-145 \mathrm{~g}$ & $-175 \mathrm{~g}$ & $-180 \mathrm{~g}$ & $\sim 200 \mathrm{~g}$ & $-220 \mathrm{~g}$ \\
\hline Colour & \multicolumn{8}{|l|}{ beige } \\
\hline Max. body weight & $35 \mathrm{~kg}$ & & & & $45 \mathrm{~kg}$ & & & \\
\hline
\end{tabular}

Figure 3: Ottobock catalog order example based on the given patient measurements [13]. The prosthetics fitting process for transfemoral amputations consists of a range of steps called the Benchmarks, along with the additional fitter modifications to adjust the fit per patient. In the clinical environment of prosthetics and orthopedics, there are specified standards used to fit prosthetic legs on a patient: (1) product standards, (2) comfort of the user or patients' feedback, and (3) fitter's, a certified prostheses and orthotics technician, experience, and (4) trial and error, also categorized as observational gait analysis [3]. The standards are broken down into the following steps [3-5]: 
1. Stump position $\rightarrow$ the drawing of reference lines, anterior and lateral, on the stump while it is in rest position and experiencing loads.

2. Bench alignment $\rightarrow$ the manufacturing recommendations for alignment and reference lines placement that accompany each part used to assemble the prosthetic limb.

3. Static alignment $\rightarrow$ the standing and balance capabilities of the user in the prosthetic with the gathered alignments from the stump position and bench alignment. (NOTE: The user should be able to maintain balance as well as move the leg with relative ease, and ideally the knee joint and foot should be aligned with the hips.)

4. Dynamic alignment $\rightarrow$ testing and analyzing the leg during walking and making further adjustments accordingly

Through the successful alignment, a process that will be achieved by following the above-mentioned steps, and with rehabilitation, the patient should be able to achieve minimal asymmetry in walking and standing while wearing the prostheses [3]. Clinically, the alignment process is not an individualized process, but rather a generalized system of steps created by the manufacturer to provide guidance for fitting measurements that is accompanied with an element of error [5]. Since every individual's amputation and "stump" is different, the final individualized "adjustments" must be done during the dynamic alignment step. It is vital that the patient be completely comfortable when standing and walking with their prostheses. The additional adjustments are subjective and excessively dependent on the skills the technician achieves over time and with their own 
progressive experience. Due to the subjective nature of the method, the patient's prostheses fitting process is subjected to a wide range trial and error [3].

\section{Gait analysis - Natural Bipedal vs Amputee Locomotion}

Natural bipedal human locomotion is the organic walking pattern of a human being. The studies of human gait revealed that the hip-leg relationship is similar to the motion and physics of a double pendulum, as shown in Figure 4.

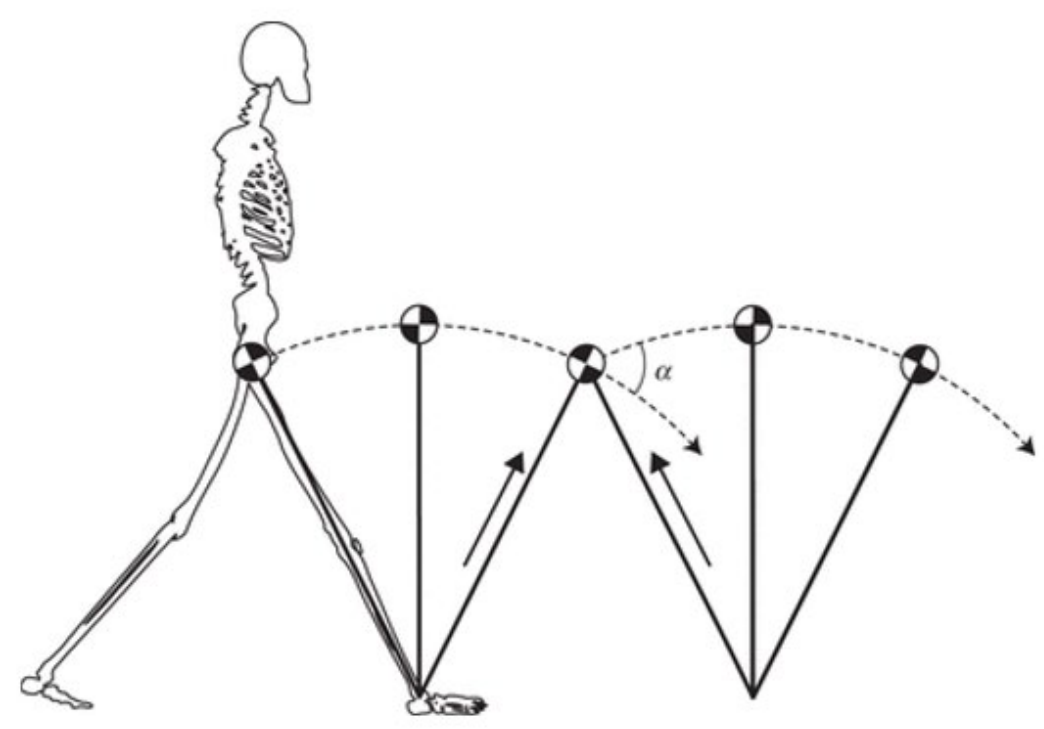

Figure 4: Double pendulum created by the hip-leg relationship during the gait cycle [2].

A gait cycle is when one heel rolls off the ground and swings before reestablishing contact with the ground. This cycle is broken up into the swing and support phases, where the support phase is theorized to occupy sixty percent of the gait cycle and the swing phase takes up forty percent. The support phase is when the foot touches the ground and the swing phase directly follows, where the foot is making no contact with 
the ground. The support limb shifts the weight from one side of the pelvis to the other, thrusting the upper body forward for momentum and to reestablish balance. The movement of the hips during the walking cycle creates a figure eight motion that demonstrates the redistribution of weight. The gait cycle is divided into seven main parts, as shown in Figure 5:

1. Initial contact $\rightarrow$ lead leg's heel strikes the ground and hips rotate forward and adjust weight to lead leg to prepare for back leg's take off, while the back leg's toes maintain ground contact.

2. Loading response $\rightarrow$ lead leg's foot fully plants on the ground and hip is fully rotated to transfer full body weight onto this leg, while the back leg begins to leave the ground.

3. Midstance $\rightarrow$ lead leg takes on all of the body weight thus making it the support limb, while the back leg is making its way from the back to the front of the body.

4. Terminal stance $\rightarrow$ lead leg's heel begins to roll off the ground, while the back leg's heel begins to touch the ground in front of the body and the hips shift downwards to begin shifting weight.

5. Pre-swing $\rightarrow$ the back leg is now becoming the support limb, while the lead limb is entering the swing phase thus continuing the transfer of weight from this leg to the new support limb.

6. Mid-swing $\rightarrow$ the back leg takes on all of the body weight, while the lead leg swings to regain its position in front of the body.

7. Terminal swing $\rightarrow$ the lead leg reestablishes contact with the ground. 


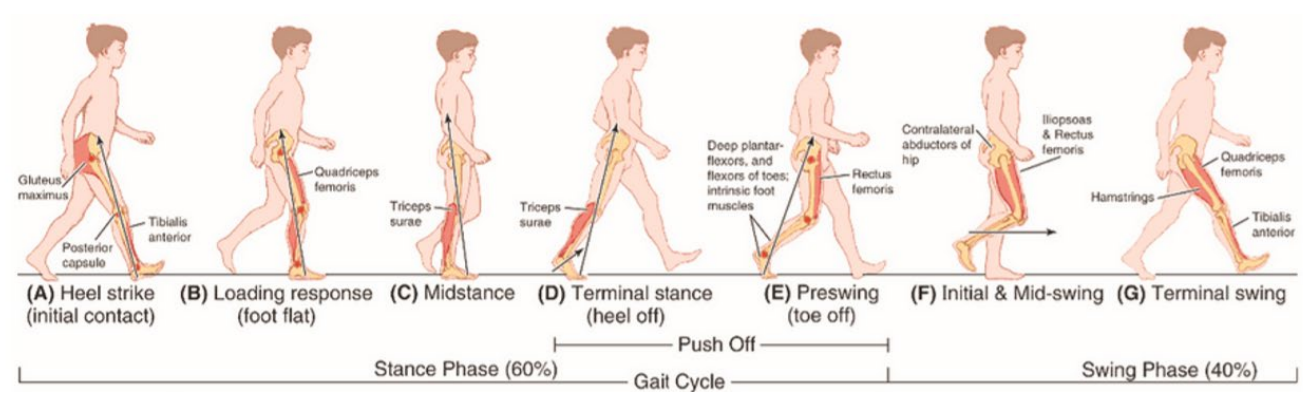

Figure 5: Natural Bipedal locomotion: seven main motion phases [2].

Ideally, a patient with both natural legs present distributes their weight $50 / 50$ on both sides to maintain symmetry and promote the most optimal transition of weight and balance maintenance for an idealized gait cycle. For amputees, the transfer of load is unsuitable due to the reidentified center of gravity that accompanies a missing limb. The natural leg typically adopts more than fifty percent of the body weight to compensate for the missing limb and maintain some balance and stability [2]. As shown in Figure 6, the prosthetics gait visibly differs from that of a natural bipedal locomotion, because the center of gravity alterations have contributed to an over-compensation in walking and standing. With a transfemoral unilateral amputation, the prosthetic greatly affects that of the wearer. Studies show that they tend to self-adopt an 8.6 percent slower gait speed with an approximately 65 percent more energy exertion and an increase to 49 percent more oxygen consumption when compared to a patient with both natural legs [9].
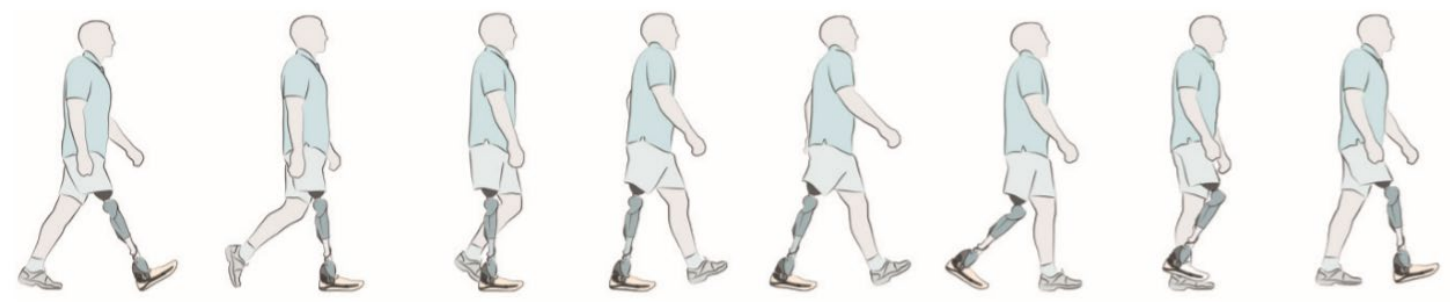

Figure 6: Leg amputee walking cycle, with a visual representation of how a leg prosthesis impacts the gait cycle. 
The goal of any leg prothesis is to have the gait on an amputee closely resemble that of natural bipedal locomotion, while achieving as close to symmetrical motions and stances. The mirroring of natural bipedal gait in a leg amputee's walking cycle should be possible with rehabilitation and adequate prosthesis fitting and alignment [3]. 


\section{CHAPTER 3 - METHODOLOGY}

The comprehensive analysis of gait through symmetry, center of mass, and balance was achieved with the use of three software applications, Maya, Solidworks, and MatLab. The calculations of the natural bipedal structure and the transfemoral amputee structure were accomplished with the assistance of all of the previously mentioned softwares working in conjunction with each other. This section breaks down the test preparation required for each application and the important equations and data needed to achieve the analysis.

\section{Test Preparation}

\section{Maya Models}

Maya is an Autodesk 3D animation software typically used to create movies and short films, but this software has been utilized for engineering applications and anatomy analysis. Maya is simply a stepping stone to reach the path of engineering calculations and analysis. In Maya it is far easier to create close to real models to represent the organic form of human life and anatomy, because Maya creates that platform to not only model but also control and animate the models created. This software was built for mesh manipulation to create entertainment, but in this instance, Maya was implemented to create the basis for the engineering applications.

As mentioned above, the goal of a leg prosthesis is to provide the wearer with a gait as closely related to normal natural bipedal gait as possible. To establish basic human gait calculations and a baseline for future comparisons, such as center of gravity, equilibrium and torque, it was first important to model the seven steps of natural bipedal 
locomotion, as shown in Figure 5, in the Maya 3D animation software. The natural bipedal model created an even platform for comparison once placed next to the Maya 3D modeled figure of a transfemoral amputee. The steps listed in Table 1 provide a further breakdown of the Maya modeling, rigging, and animating process.

Table 1: Maya Process - Modeling, Rigging, and Animating.

\begin{tabular}{|l|l|}
\hline Steps & Actions \\
\hline 1 & $\begin{array}{l}\text { Obtain reference images for the front and side views of the human body } \\
\text { (silhouetted images were easier to use in this case) }\end{array}$ \\
\hline 2 & $\begin{array}{l}\text { Bring in those images as reference planes in Maya (select window, click } \\
\text { View }>\text { Image Reference) }\end{array}$ \\
\hline 3 & $\begin{array}{l}\text { Model the figure with the lowest resolution manageable, but with enough } \\
\text { resolution that the model is still able to convey the concept of a figure } \\
\text { (resolution }=\text { number of faces on the mesh polygon) }\end{array}$ \\
\hline 5 & $\begin{array}{l}\text { Rig the model: change the drop down on the left from Modeling to Rigging } \\
\text { Click the Skeleton tab }>\text { Create Joint }\end{array}$ \\
\hline 6 & $\begin{array}{l}\text { Place the rig on the model as shown in Figure 7 } \\
\text { Click the rig then shift select click the mesh model, click the Skin tab > } \\
\text { Bind Skin }\end{array}$ \\
\hline 7 & $\begin{array}{l}\text { Check the paint weight of the skeleton by first clicking the mesh then } \\
\text { clicking the Skeleton tab }>\text { Paint Weights (white, when the joint is selected }\end{array}$ \\
\hline 8 &
\end{tabular}




\begin{tabular}{|c|c|}
\hline & $\begin{array}{l}\text { in the paint weights window, means complete influence, while black means } \\
\text { no influence) }\end{array}$ \\
\hline 9 & $\begin{array}{l}\text { Create IK handles for the legs by clicking the Skeleton tab }>\text { Create IK } \\
\text { Handles } \\
\text { (click from the top leg joint to the ankle = IK 1, from the ankle to the } \\
\text { midtoe = IK 2, and from the midtoe to the toe = IK 3). }\end{array}$ \\
\hline 10 & $\begin{array}{l}\text { Finally, create the controls by creating spline circles. Click the } \\
\text { Curves/Splines tab }>\text { click the circle }\end{array}$ \\
\hline 11 & $\begin{array}{l}\text { Move and size the circle as fit, then click the Modify tab }>\text { Freeze } \\
\text { Transformations }\end{array}$ \\
\hline 12 & $\begin{array}{l}\text { Click the spline then shift select the joint. In the rigging drop down, click } \\
\text { the Constraints tab > Parent }\end{array}$ \\
\hline 13 & $\begin{array}{l}\text { Continue steps } 10 \text { - } 12 \text { until your model looks like Figure } 8 \text { and your } \\
\text { outliner looks like Figure } 9 \text { for controls (CTRLS) }\end{array}$ \\
\hline 14 & $\begin{array}{l}\text { Select the controls and use } \mathrm{QWER} \text { to move and manipulate your model and } \\
\text { move the model into the correct positions ( } \mathrm{Q}=\text { select, } \mathrm{W}=\text { translate, } \mathrm{E}=\text { rotate, } \\
\mathrm{R}=\text { scale) and press ' } \mathrm{S} \text { ' to key the position. }\end{array}$ \\
\hline 15 & $\begin{array}{l}\text { For the amputee model, click the model, hold down right click and move } \\
\text { the mouse to faces. Select the necessary faces, and simply delete a leg from } \\
\text { the from the knee down. Select the edges and fill the hole with the Bridge } \\
\text { tool }\end{array}$ \\
\hline
\end{tabular}




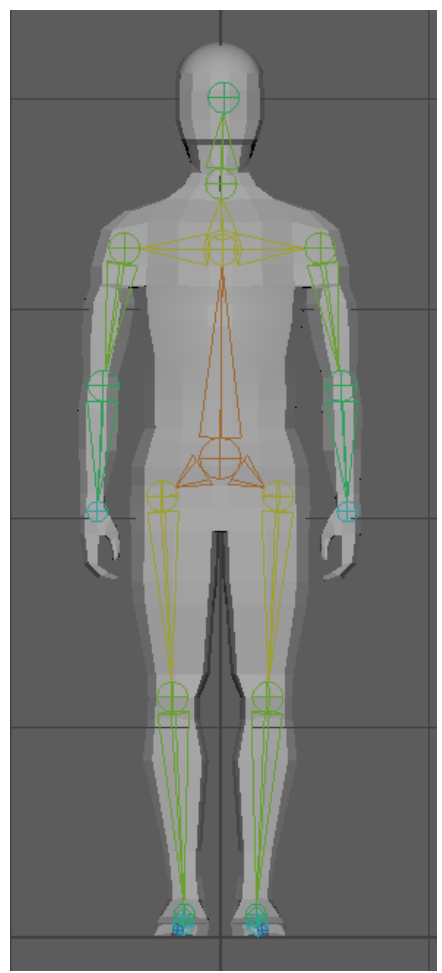

Figure 7: Maya mesh model with skeleton (the colorful system within the gray body).

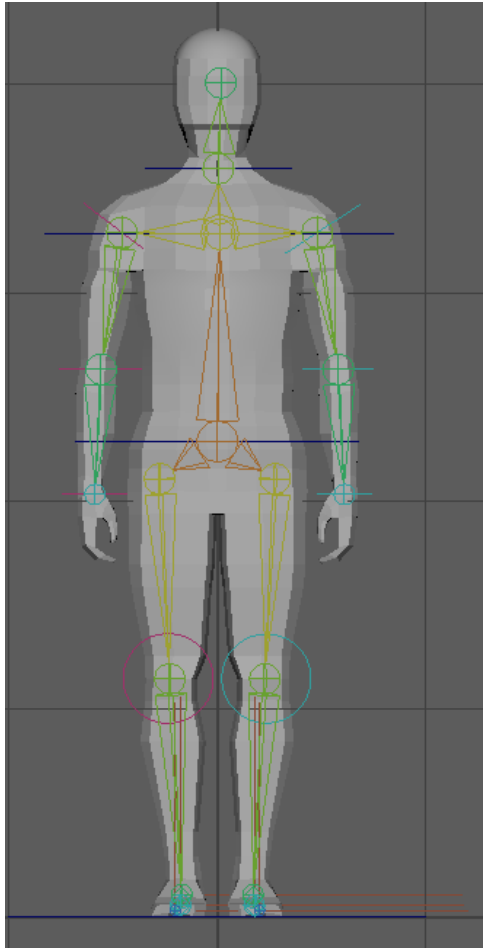

Figure 8: Maya bound mesh model with control splines (the blue, green and pink lines). 


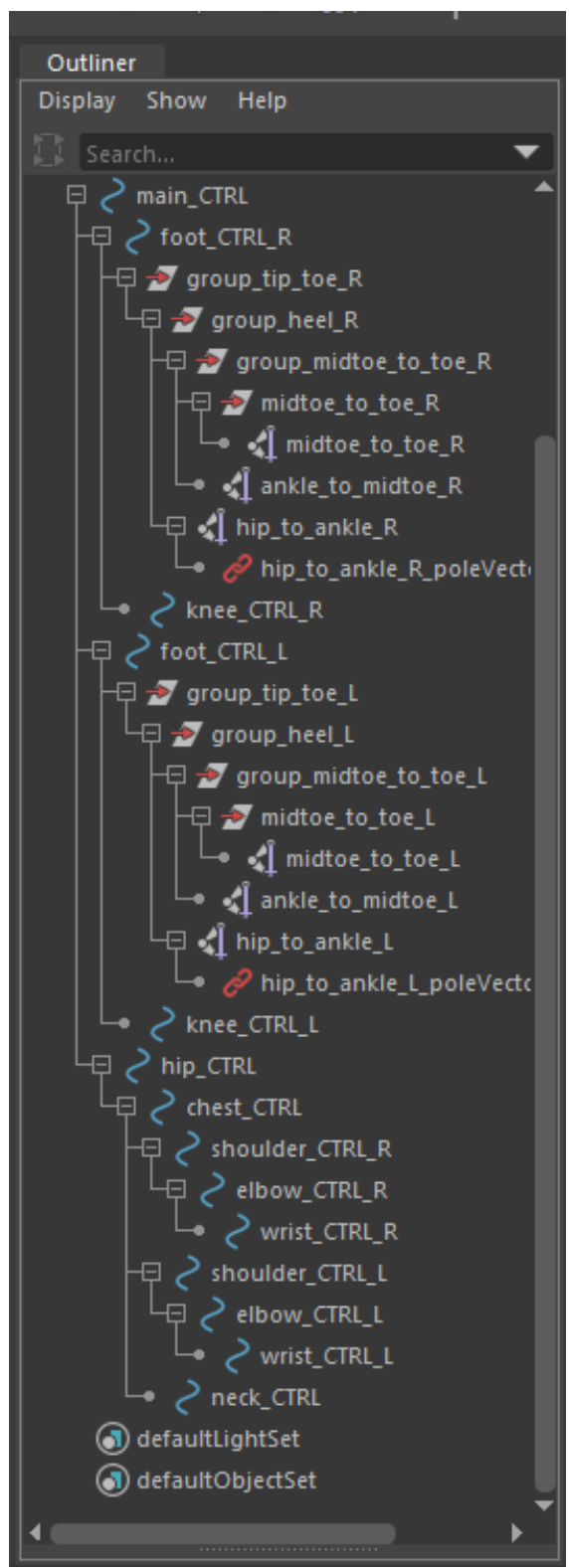

Figure 9: The outliner of the control system (spline curves and IK handles).

Repeat steps $1-3$ with prosthetic reference images in place of the human body references to model the prosthetic limb for future use and analysis. 


\section{Maya to Solidworks conversions}

Now that the models have been created, it is time to transition between the art and engineering worlds. To bridge the gap between engineering and modeling, or in this case, Maya and Solidworks, first the Maya files must be converted to something that is recognizable to Solidworks. Maya saves its files as either .ma or .mb, neither of which can be read by Solidworks, let alone allow for further analysis or manipulation. With the Maya file, follow the steps listed in Table 2 to obtain a stp file, a Solidworks friendly file that can not only be recognized but also allow for further manipulation and analysis.

Table 2: Converts a .ma file to a .stp file in Maya.

\begin{tabular}{|l|l|}
\hline Steps & Actions \\
\hline 1 & $\begin{array}{l}\text { Picking up from the last step in Table 1, click the Display tab }>\text { Heads up } \\
\text { Display }>\text { Poly Count }\end{array}$ \\
\hline 2 & $\begin{array}{l}\text { Select the mesh model, click the Modify tab }>\text { Convert }>\text { Polygons to } \\
\text { Subdivs } \square\end{array}$ \\
\hline 3 & $\begin{array}{l}\text { In this window, make sure the Convert Faces count is higher than that of } \\
\text { the polygon that is being converted (Ex: } 100 \text { faces on polygon, then make } \\
\text { the convert polygon number 101), then click apply. }\end{array}$ \\
\hline 4 & $\begin{array}{l}\text { Select the mesh model again, click the Modify tab }>\text { Convert }>\text { Subdivs to } \\
\text { NURBS. }\end{array}$ \\
\hline
\end{tabular}




\begin{tabular}{|l|l|}
\hline 5 & $\begin{array}{l}\text { Save the file. Then click the File tab > Export All. Change the drop down } \\
\text { to STEP file (.stp), name the file and choose a location before clicking } \\
\text { export. }\end{array}$ \\
\hline
\end{tabular}

The .stp file saved from this process will only save the last "position" of the model in Maya, so be sure to export all the parts necessary using the above steps. In this instance, the first four steps of the walking process, as shown in Figure 5, were exported as separate .stp files. The body in segments, such as the arm, leg, torso, and head with neck, the prosthetic leg modelled (as a whole and parts), and the amputee model with a variation of stump lengths were also be exported as individual .stp files for further analysis.

\section{Maya MEL code}

In this section, the animation created using Table 1 was utilized to gain rotational joint data from the keyed frames and joint movements. To do this, the study of MEL code (Maya embedded language) was initiated to obtain an understanding of the actions and results that were desired from this code. The primary actions of the code were as follows:
a. Locate the joints within the model
b. Identify the joint orientation of specified joints
c. Isolate joint orientation (specifically $\mathrm{z}$ rotation) for primary key frames
d. Store isolated values in a matrix
e. Display isolated values 
In this instance, the stored values from point $d$ were manually inputted into an excel file and saved in the same folder as the future MatLab code in preparation for the MatLab interface interaction and manipulation.

\section{Solidworks Analysis}

Solidworks, an engineering, technical analysis and modeling application, assisted in giving the center of mass information that is necessary to further the research. Follow the listed steps presented in Table 3 to accomplish this for human body center of mass results.

Table 3: Human body center of mass analysis - natural bipedal and amputee male anatomy.

\begin{tabular}{|l|l|}
\hline Steps & Actions \\
\hline 1 & $\begin{array}{l}\text { Open the .stp file saved from Maya with File > Open > change drop down } \\
\text { on bottom right to STEP > choose file > click Open }\end{array}$ \\
\hline 2 & $\begin{array}{l}\text { A window will pop up that says, "Do you wish to run Import Diagnostics } \\
\text { on this part?", click Yes. } \\
\text { In Run Diagnostic options window, click the "Attempt to heal all" option. }\end{array}$ \\
\hline 3 & $\begin{array}{l}\text { If there is a Faces error, click the "Attempt to heal all Faces" option. } \\
\text { Once everything has been successfully healed with no errors left, click the }\end{array}$ \\
\hline 5 & $\begin{array}{l}\text { When the window pops up stating "Do you want to proceed with feature } \\
\text { recognition?", click yes }\end{array}$ \\
\hline 6
\end{tabular}




\begin{tabular}{|c|c|}
\hline 7 & Click then right click the Materials tab in the tree on the left side \\
\hline 8 & Click the "Edit Material" option \\
\hline 9 & Choose a material and click Apply and Close (in that order) \\
\hline 10 & Click the Imported\# tab in the tree on the left side \\
\hline 11 & Click the Evaluation tab in the bar present at the top \\
\hline 12 & Click Mass Properties button \\
\hline 13 & Alternatively, Features tab $>$ Reference Geometry $>$ Center of Mass \\
\hline 14 & $\begin{array}{l}\text { Click the arrow at the top left to reveal the file and other options, click } \\
\text { View }>\text { Hide/Show }>\text { Center of Mass }\end{array}$ \\
\hline 15 & Save the stp file as Part and name the file with File $>$ Save As \\
\hline 16 & File $>$ New $>$ Drawing \\
\hline 17 & $\begin{array}{l}\text { Select or browse for the newly saved item WITH the center of mass icon } \\
\text { drop }\end{array}$ \\
\hline 18 & $\begin{array}{l}\text { Place the front and side views of the model in the desired locations and } \\
\text { then click the green check mark to apply }\end{array}$ \\
\hline 19 & $\begin{array}{l}\text { Click the Insert }>\text { Model Items }>\text { select one of the views and change the } \\
\text { drop down to "Entire model" }\end{array}$ \\
\hline 20 & $\begin{array}{l}\text { In the reference geometry section, select the center of mass symbol and } \\
\text { click the green check mark to apply }\end{array}$ \\
\hline 21 & Repeat step 14 to display the marker \\
\hline
\end{tabular}




\begin{tabular}{|l|l|}
\hline 22 & $\begin{array}{l}\text { Click the Annotate tab }>\text { Smart Dimensions, to create dimensions from the } \\
\text { center of mass icon to the }(0,0,0) \text { location of the model to get xyz values } \\
\text { of the marker's location }\end{array}$ \\
\hline
\end{tabular}

Follow Table 4 to gain the center of mass for the prosthetic limb. These steps differ from the ones presented in Table 3, because different materials and part assemblies are involved in the overall analysis of this prosthesis. The materials for each part of the prosthetic, as shown in Figure 2, are as follows:

a. Socket - plastics, such as polypropylene, or light metals, such as aluminum or titanium [21]

b. Knee Microprocessor - hydraulic or pneumatic systems made of PTFEs with a hard plastic or metal components casing [25]

c. Knee non-microprocessor - hard plastic or metal components [26]

d. Pylon tube - stainless steel, aluminum, or titanium [22-23]

e. Ankle - stainless steel or titanium [27]

f. Foot - wood or plastic covered with a foam or rubber outside [21,24]

A combination of these materials were assigned to the prosthetic parts and assembled in Solidworks to study how different materials may alter the center of mass to height ratios. 
Table 4: Prosthetic leg material assignment, parts assembly, and center of mass analysis

\begin{tabular}{|l|l|}
\hline Steps & Actions \\
\hline 1 & $\begin{array}{l}\text { Follow the steps } 1-9 \text { presented in Table } 3 \text { to Open, assign materials listed } \\
\text { above to the appropriate .stp file part, and save (be sure to save the part } \\
\text { files in the same folder as the original .stp file for assembly to be } \\
\text { successful) }\end{array}$ \\
\hline 2 & $\begin{array}{l}\text { Create an assembly with File }>\text { New }>\text { Assembly }>\text { choose a part of the } \\
\text { prosthetic apparatus to begin with (starting with the extremities, such as the } \\
\text { socket or foot, is recommended) }\end{array}$ \\
\hline 3 & $\begin{array}{l}\text { Click the green check mark at the top left corner to apply } \\
\text { next part file (recommended: choose the next prosthetic part in the } \\
\text { hierarchy, such as the knee processor if starting with the socket or the ankle } \\
\text { if starting with the foot) }\end{array}$ \\
\hline 4 & $\begin{array}{l}\text { Hover the mouse next to the existing part and click to place the new part } \\
\text { down }\end{array}$ \\
\hline 5 & $\begin{array}{l}\text { To add constraints to the parts, go to the Assembly tab }>\text { Mate } \\
\text { apply }\end{array}$ \\
\hline 5 & \begin{tabular}{l} 
Repeat steps $2-8$ until the assembly resembles Figure 10 \\
\hline 5
\end{tabular}
\end{tabular}




\begin{tabular}{|l|l|}
\hline 10 & $\begin{array}{l}\text { Repeat steps } 11-12 \text { and/or steps } 13-22 \text { in Table } 3 \text { to get the Mass } \\
\text { Properties of the Assembly }\end{array}$ \\
\hline 11 & $\begin{array}{l}\text { After repeating step 22 in Table 3, add annotation balloons by clicking the } \\
\text { Annotation tab }>\text { Click the drawing view }>\text { click Auto Balloons }\end{array}$ \\
\hline 12 & $\begin{array}{l}\text { Add a bill of materials to show the materials used for each prosthesis } \\
\text { element by clicking the arrow in the top left to reveal File and other tabs. } \\
\text { Click Insert }>\text { Table }>\text { Bill of Materials }>\text { select the view with the balloons }> \\
\text { click on the screen to drop the bill on materials on the drawing }>\text { click the } \\
\text { green check mark to apply }\end{array}$ \\
\hline
\end{tabular}

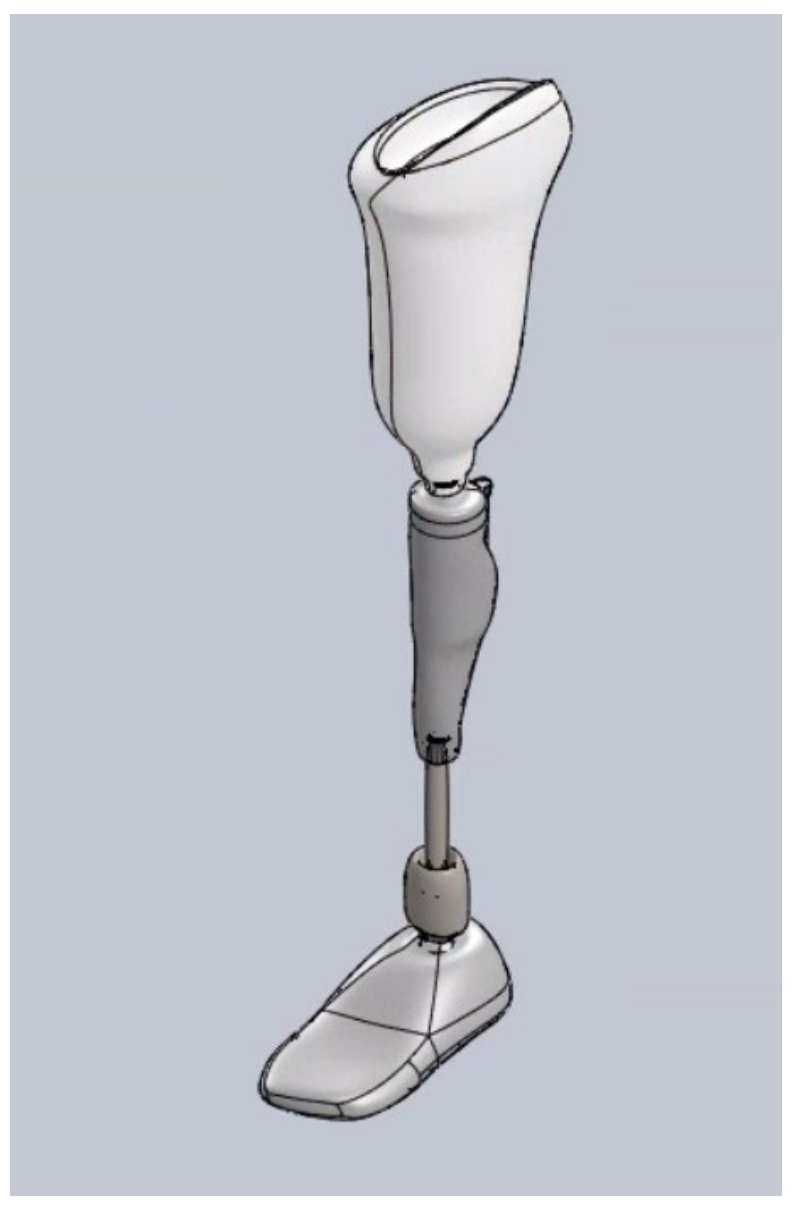

Figure 10: Solidworks assembly of prosthetic limb parts with assigned materials. 
For all of the models, it was important to establish the center of mass' location in the xyz directions as well as the size of the figure in the same directions. This collected data helped with establishing a ratio to compare the center of mass locations exhibited on the different models. The equation presented below, Eq. 7, were used to establish the ratios for comparison:

$$
\frac{x_{A}}{x_{B}}=\text { center of mass ratio }
$$

Where $x_{A}=$ center of mass position from $(0,0,0)$

$$
x_{B}=\text { total length }
$$

For further analysis, the percent change equation, Eq. 8, was used to compare the center of mass ratios to the previous study. The previous study showed that a 3.7 percent change in symmetry is insignificant, while any asymmetry percentages that are 10 percent and above involk gait hinderence and disabilities [43].

$$
\text { percent change }=\left|\frac{\text { New value }- \text { Original value }}{\text { Original value }}\right| \times 100
$$

\section{MatLab Calculations}

MatLab is a multifunctional, user friendly coding software and language that assisted in wrapping up and connecting all of the above-mentioned parts. The goal of this application was to apply the concepts mentioned in the previous chapters in mathematical and analytical processes through code. The codes created were constructed around the information one would be able to obtain from a patient, such as weight and height. Body 
percentages for limb length and weight, as shown in Tables $5-6$, were used in conjunction with the user input.

Table 5: Weight percentages of limbs based on total body weight [28].

\begin{tabular}{|c|c|c|}
\hline Segment & Male & Female \\
\hline Head & $8.26 \%$ & $8.20 \%$ \\
\hline Whole Trunk & $55.1 \%$ & 53.25 \\
\hline Thorax & $20.1 \%$ & $17.0 \%$ \\
\hline Abdomen & $13.1 \%$ & $12.2 \%$ \\
\hline Pelvis & $13.7 \%$ & $16.0 \%$ \\
\hline Total Arm & $5.70 \%$ & $4.97 \%$ \\
\hline Upper Arm & $3.25 \%$ & $2.90 \%$ \\
\hline Forearm & $1.87 \%$ & $1.57 \%$ \\
\hline Hand & $0.65 \%$ & $0.50 \%$ \\
\hline Forearm \& Hand & $2.52 \%$ & $2.07 \%$ \\
\hline Total Leg & $16.7 \%$ & $18.4 \%$ \\
\hline Thigh & $10.5 \%$ & $11.8 \%$ \\
\hline Leg (Shank) & $4.75 \%$ & $5.35 \%$ \\
\hline Foot & $1.43 \%$ & $1.33 \%$ \\
\hline Leg (Shank) \& Foot & $6.18 \%$ & $6.68 \%$ \\
\hline
\end{tabular}


Table 6: Length percentages of limbs based on total body height [29].

\begin{tabular}{|c|c|}
\hline Segment & Length \\
\hline Head \& Neck & $10.75 \%$ \\
\hline Torso & $30.00 \%$ \\
\hline Upper Arm & $17.20 \%$ \\
\hline Lower Arm & $15.70 \%$ \\
\hline Hand & $5.75 \%$ \\
\hline Thigh & $23.20 \%$ \\
\hline Calf (Shank) & $24.70 \%$ \\
\hline Foot & $14.84 \%$ \\
\hline
\end{tabular}

In Table 6, the Foot length percentage is the length of the sole. To find the height of the foot from the ankle to the ground, simply add up all of the percentages (not including the foot) and subtract that value from $100 \%$.

The MatLab Calculations section was broken down into the following sections for ease of comprehension and analysis using the percentage data presented in Tables $5-6$ :

\section{a. Center of Mass Percentages}

This section used the data provided by the Solidworks Mass Properties analysis of the male body in anatomical position. The main purpose is to obtain ratio using Eq. 7 . In this instance, $x_{A}$ is the center of mass $x y z$ coordinate and $x_{B}$ is the total length, width, height of the model. 


\section{a. Equilibrium and Rotational Torque}

This code used a modified version of Eq. 1, and calculate rotational torque based on the legs angled positions with respect to the ground $\left(T_{r}\right)$ the limb may take during the gate cycle using Eq. 9 - Eq. 11, as shown below. Equilibrium was tested using Eq. 4, the sum of torques, setting the left and right sides of the body equal to each other.

$$
\begin{gathered}
T_{r}=\sin (\theta) * l * W \\
T_{r}=\cos (\theta) * l * W \\
T_{r}=\tan (\theta) * l * W
\end{gathered}
$$

Where $1=$ length of the leg

$\theta=$ angle of rotation at the joint in the $\mathrm{z}$ - direction

$$
\mathrm{W}=\text { weight of the limb }
$$

The equation usage was dependent on the leg's position and weight, as well as the three joints' (hip, knee, and ankle) relationship to each other during the main phases of gait. The implication of loops, mainly iflelse statements and for loops, assisted in achieving a self-sufficient analysis code. 


\section{CHAPTER 4 - DATA AND ANALYSIS}

This chapter discusses the results of the individual sections and provide a discussion for the respective parts. The analysis began with the Maya applications and results of the modeled and animated walk cycle for both bipedal natural male anatomy, as well as an amputee with and without a prosthetic limb for comparisons. The coding software in Maya MEL code, was addressed and manipulated to provide sample data and results from the animated segment. Solidworks analysis acted as the transition between art and engineering by providing analytical center of mass data on the Maya models. This discussion continued with the MatLab code calculations and algorithms that evaluated the collected and given data.

Maya Models

A male figure was used to create the models for the bipedal and amputee anatomy for this portion of the study. The walking cycle presented in Figure 5 was replicated with Maya modeling and animating to demonstrate the software capabilities of motion and shape likeness to human movements, as presented in Figures $11-17$. 


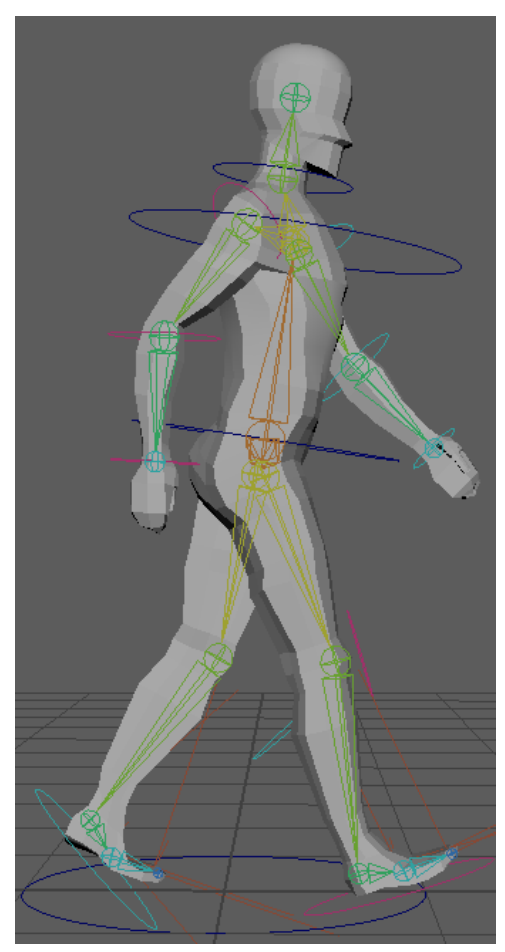

Figure 11: Maya rendition of walking cycle step 1, heel strike (initial contact), as presented in Figure 5.

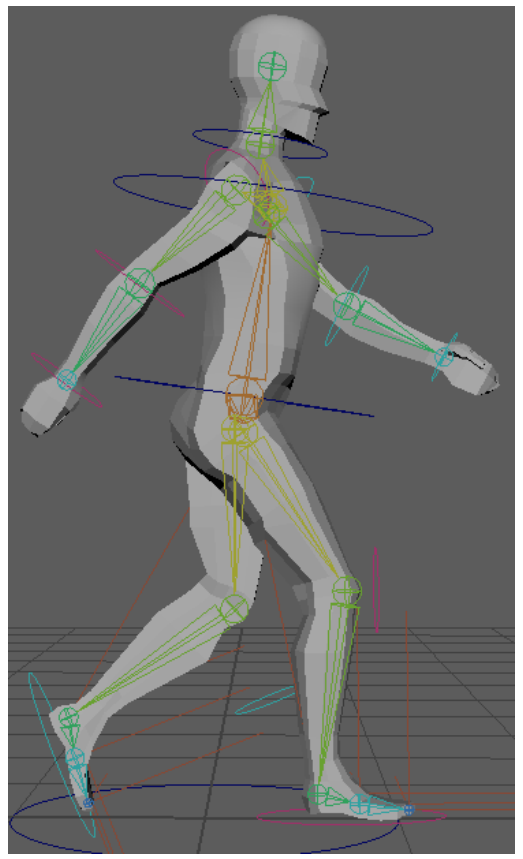

Figure 12: Maya rendition of walking cycle step 2, loading response (foot flat), as presented in Figure 5. 


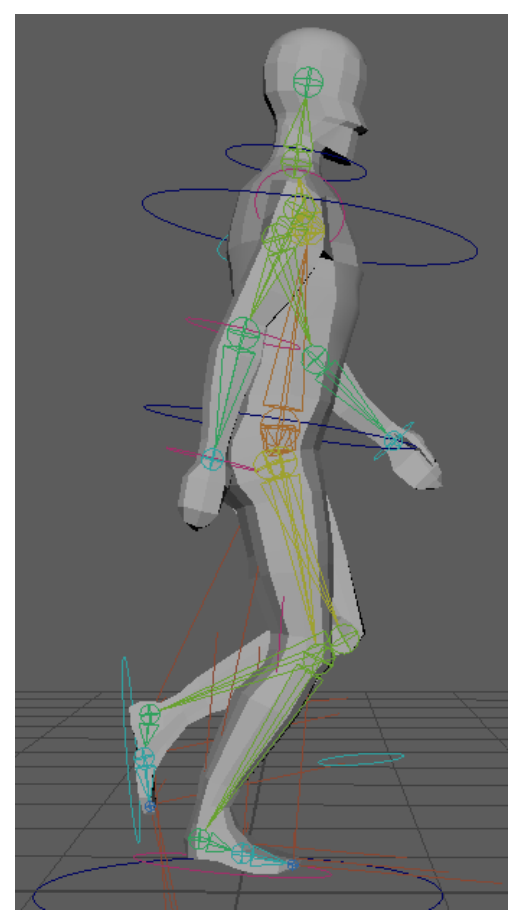

Figure 13: Maya rendition of walking cycle step 3, midstance, as presented in Figure 5.

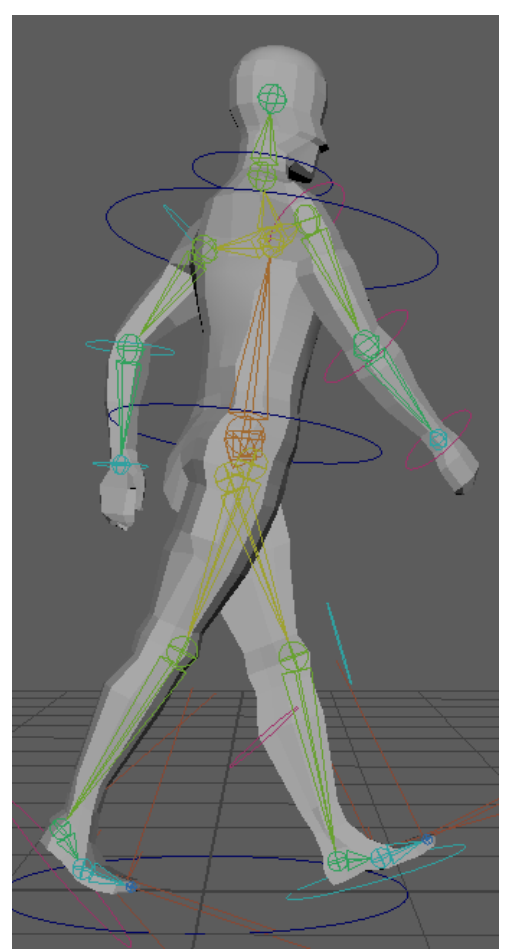

Figure 14: Maya rendition of walking cycle step 4, terminal stance (heel off), as presented in Figure 5. 


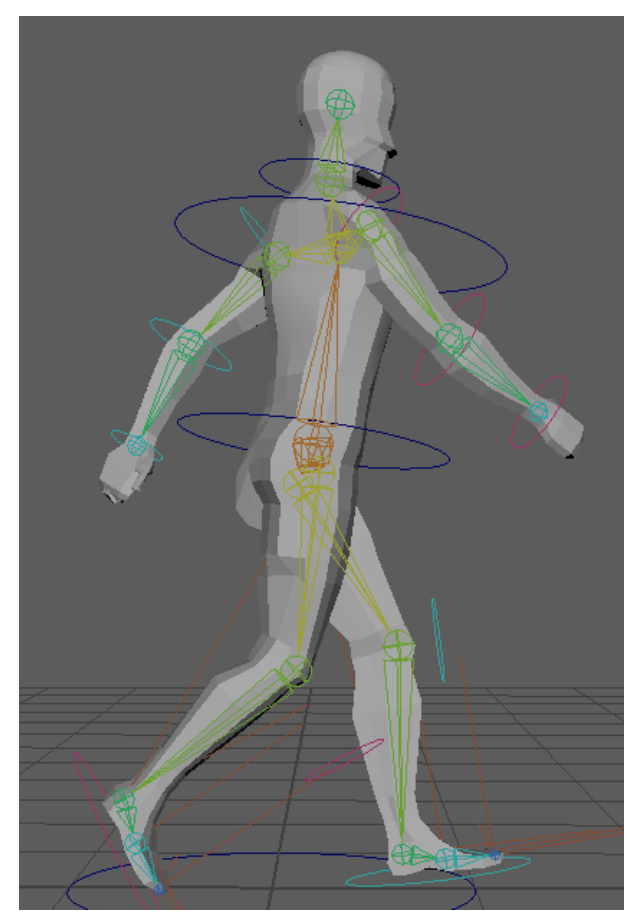

Figure 15: Maya rendition of walking cycle step 5, pre-swing (toe off), as presented in Figure 5.

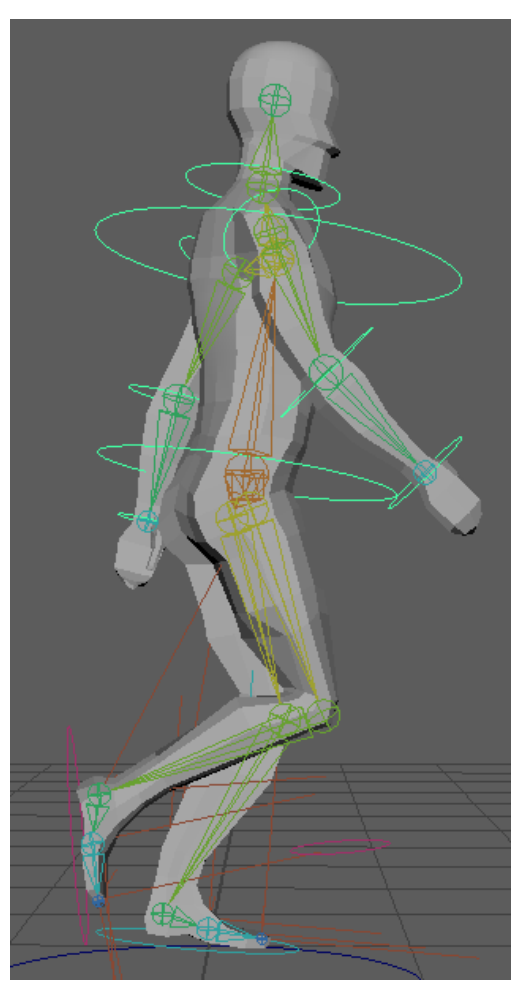

Figure 16: Maya rendition of walking cycle step 6, initial and mid-swing, as presented in Figure 5. 


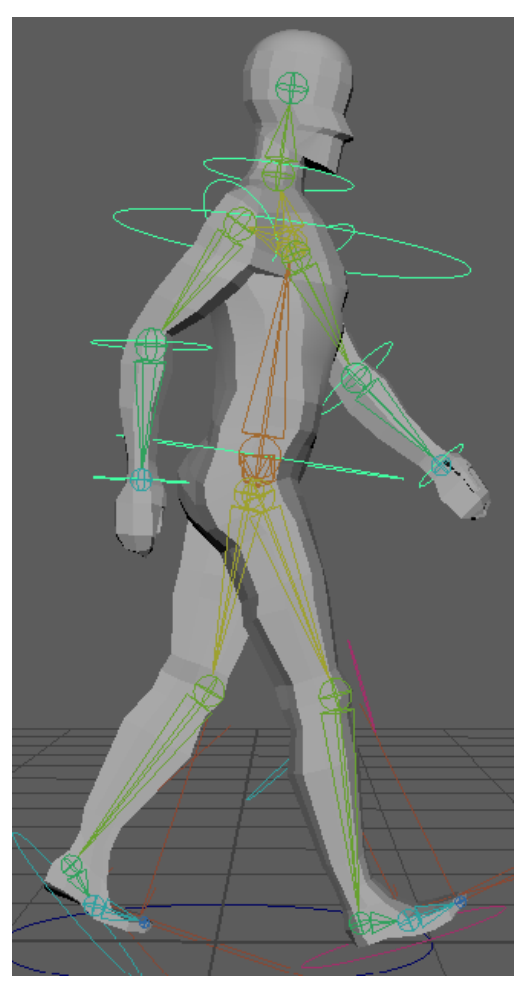

Figure 17: Maya rendition of walking cycle step 7, terminal swing, as presented in Figure 5.

When finished and compiled in post-production (video editing software), it would be easy to see the bipedal locomotion in action with the presented model and the steps mentioned above working in unison to propel the body into a forward moving path.

With this model set in place, it facilitated the development of the amputee with a prosthetic for gait cycle animation. It was evident that this cycle presented some differences when compared to that of the locomotion presented above, as shown in Figures $18-24$. 


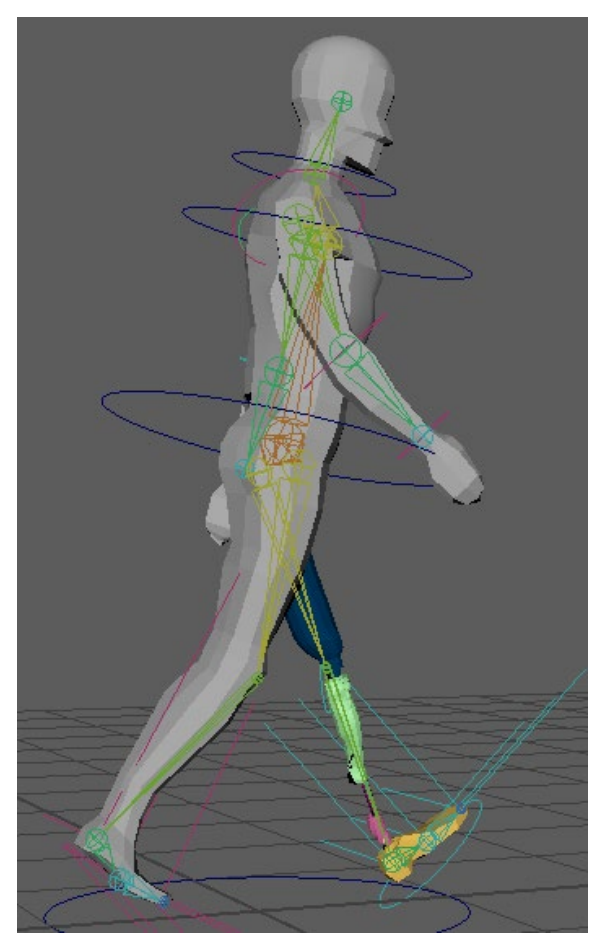

Figure 18: Maya rendition of walking cycle step 1, heel strike (initial contact), as presented in Figure 6.

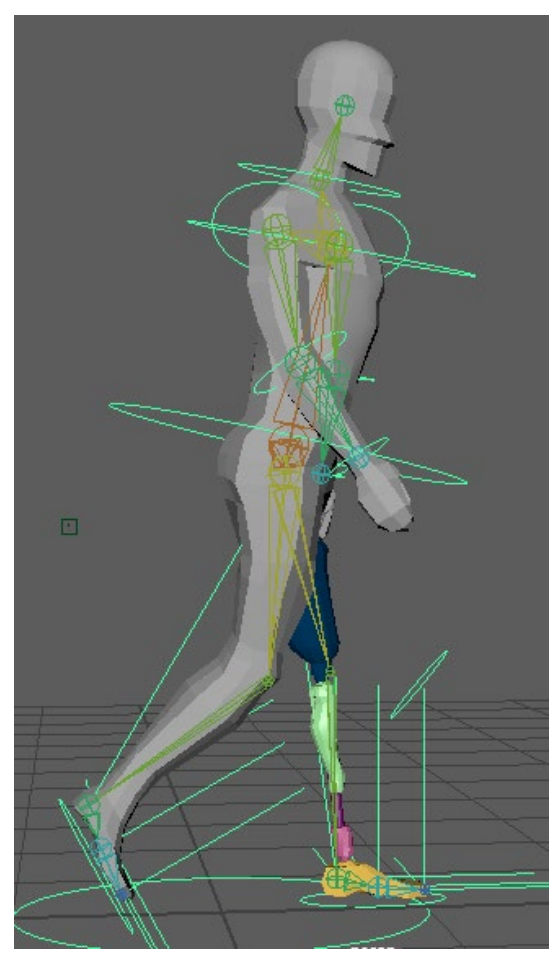

Figure 19: Maya rendition of walking cycle step 2, loading response (foot flat), as presented in Figure 6. 


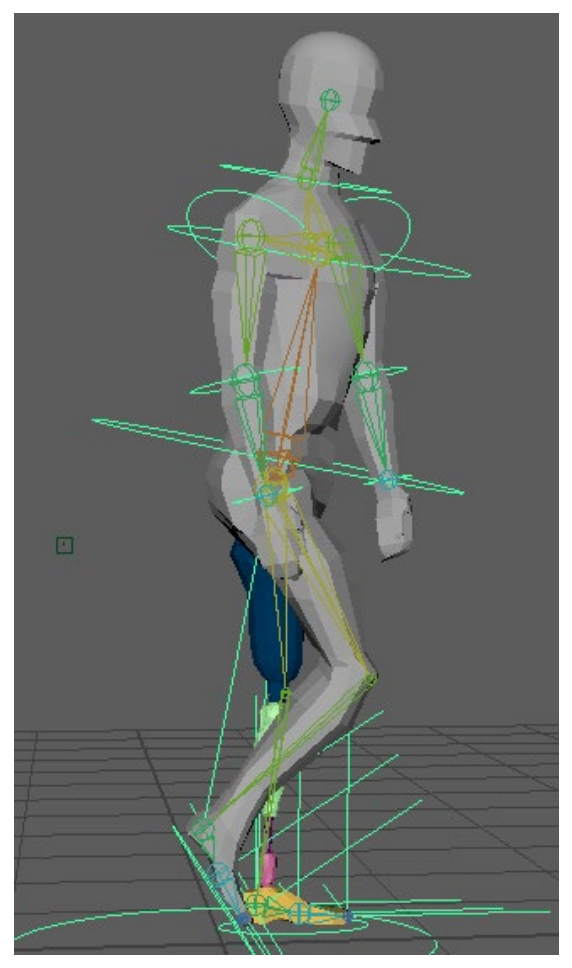

Figure 20: Maya rendition of walking cycle step 3, midstance, as presented in Figure 6.

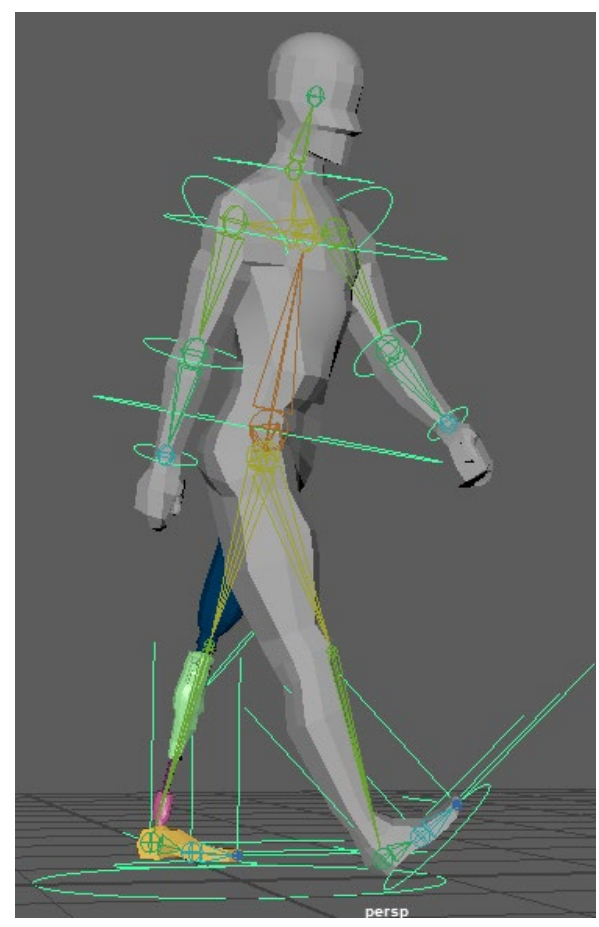

Figure 21: Maya rendition of walking cycle step 4, terminal stance (heel off), as presented in Figure 6. 


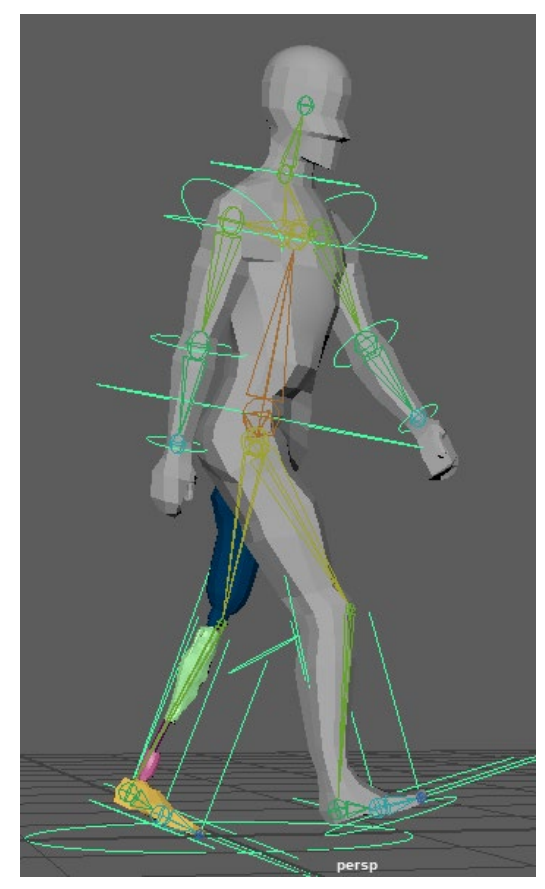

Figure 22: Maya rendition of walking cycle step 5, pre-swing (toe off), as presented in Figure 6.

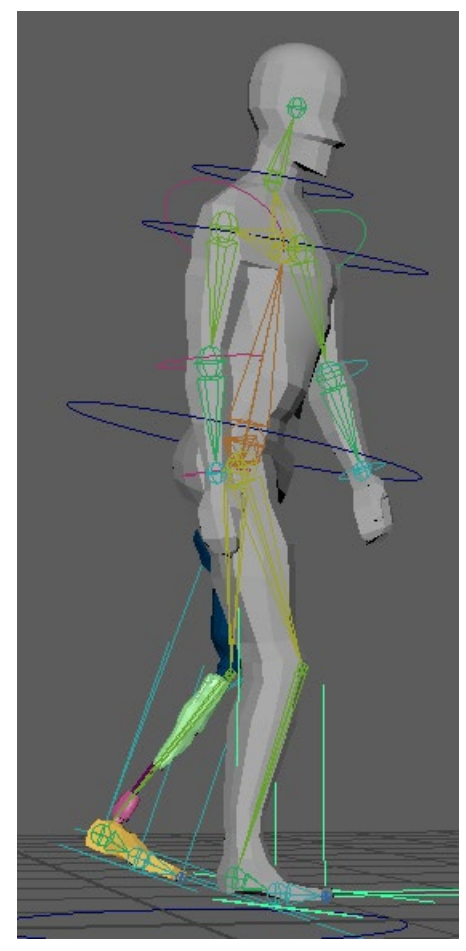

Figure 23: Maya rendition of walking cycle step 6, initial and mid-swing, as presented in Figure 6. 


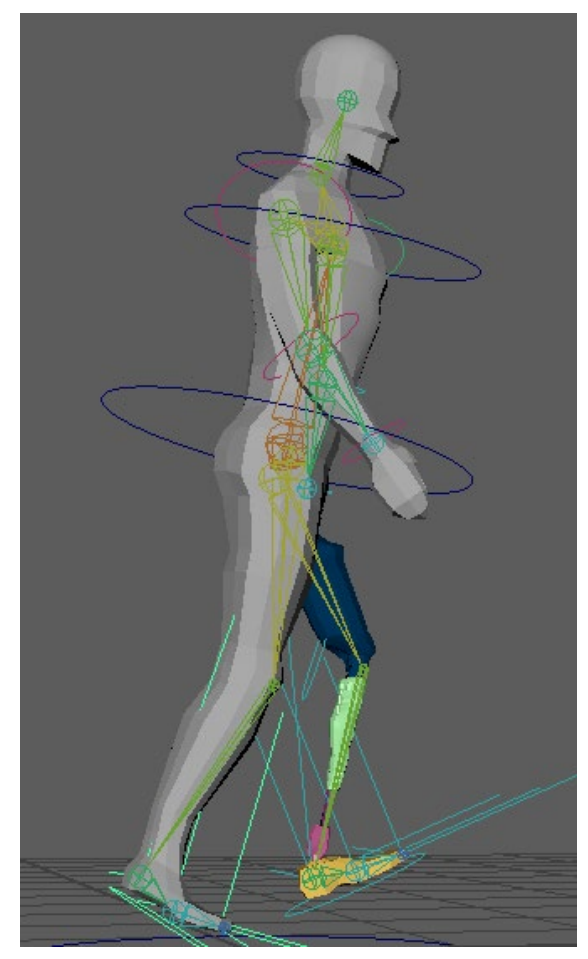

Figure 24: Maya rendition of walking cycle step 7, terminal swing, as presented in Figure 6.

When the prosthesis gait phases were compared to the natural bipedal locomotion, it was evident that the shift of weight between the legs differs. In the prosthesis gait representation, the hip dips more to the natural leg when the natural leg is switching to the role of the support leg. This occurs because the prosthetic does not present the same range of motion capabilities that the natural leg demonstrates. Oftentimes, the muscle atrophy and the weight of the prosthetic limb can cause a dramatic alteration in gait cycles. These changes are often exhibited in the over-compensation of the natural leg baring more weight and an over rotation of the hips to lift and carry the prosthetic limb forward. 


\section{Maya MEL Code Output}

The ideas and concepts of coding language translate between softwares, so the use of the knowledge gained from previous MatLab coding experience bridged the gap between the unknown of MEL code with the comfortable syntax of MatLab. For the results presented in Table 7 below, the concept of a for loop was applied to establish, write, and collect the data created by the IK handle bound joint rotations in the natural gait animation. The significant figures presented in Table 7's data hold importance to replicate the joint locations within the animation for further testings in the future.

Table 7: MEL code output of the joint rotations in the $\mathrm{z}$ directions of the lower limb joints in degrees.

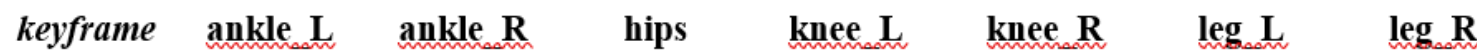

\begin{tabular}{|c|c|c|c|c|c|c|c|}
\hline 1 & -0.040615 & 0.024594 & 3.401869 & 1.080216 & -2.543299 & -4.46926 & -3.323824 \\
\hline 4 & -0.521255 & 0.633937 & 3.401869 & 4.293844 & -6.193585 & -5.190691 & -3.30471 \\
\hline 7 & -0.672397 & -0.52588 & 1.051624 & 4.635675 & -10.55321 & -0.923577 & -3.073526 \\
\hline 10 & -0.046487 & -0.32123 & -2.66328 & -0.713191 & -7.210301 & 5.982914 & 5.636809 \\
\hline 13 & -0.371963 & -0.753671 & -4.786082 & 0.977643 & -0.0193317 & 7.981991 & 8.413951 \\
\hline 16 & -0.865706 & 0.158274 & -3.50672 & 5.654968 & -3.953246 & 5.602036 & 8.127748 \\
\hline 19 & 0.263832 & 0.546215 & -1.80388 & 10.230849 & -4.982331 & 6.278303 & 4.821037 \\
\hline 22 & -0.068327 & -0.10415 & 0.216613 & 7.157936 & -0.557554 & 0.212984 & 0.474415 \\
\hline 25 & -0.040615 & 0.024694 & 3.401869 & 1.080216 & -2.543299 & -4.46926 & -3.323824 \\
\hline
\end{tabular}

In the Maya model, rigging, and animation, the chosen naming conventions are as shown above in Table 7, where L and R represents left and right, respectively, and LEG and 
HIPS stands for the hip ball and socket joint and pelvis bone, respectively. The $\mathrm{z}$ rotation values vary between positive (anterior rotation) and negative (posterior rotation) depending on the direction of rotation and the IK handle control movements. An IK handle is an inverse kinematics constraint that allows for ease of joint movements for the animation. The chosen time points, as presented in the KEYFRAME TIME column, of observation are based on the conventional walk cycle animation method, as shown in Figure 25. These time periods indicate the vital poses necessary to mark in order to achieve a realistic, smooth character gait. The magnitude of the values presented prove to be smaller than expected for some of the LEG_L, LEG_R, KNEE_L, and KNEE_R rotational numbers. This could be due to the constraint that the IK handles placed on the joints, their rotation, and the manipulation. IK handles are the most efficient and known way to create controls for leg movements, because it bypasses the parent joint hierarchy and moves the lower limb in the similar way that it would function naturally. Naturally, the foot movement is the primary driving force that dictates weight distribution and hip placements.

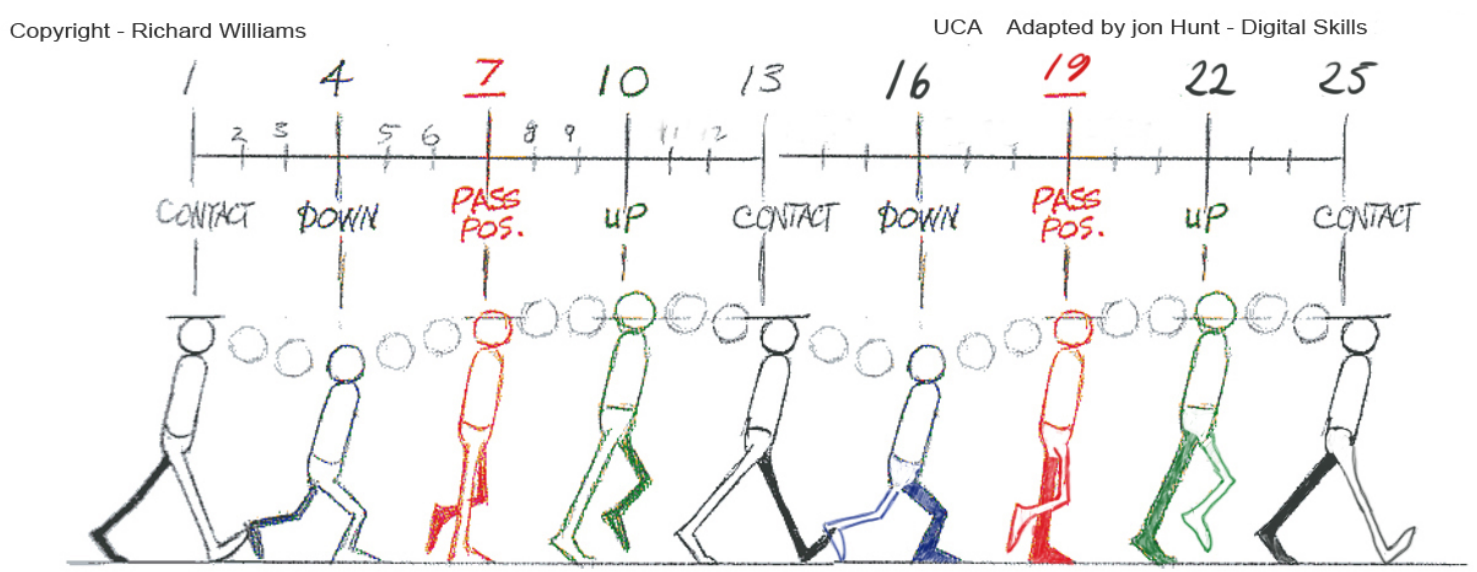

THE INBETWFNS ARE GOING TO BE ON THIRDS.

Figure 25: Traditional animation walk cycle guidelines [30]. 
Below, Figures $27-29$ show the graphed output presented in Table 7 for further comparison and visual comprehension, where the $L E G \_L$ and $L E G \_R$ values are multiplied by negative one before graphing due to an IK handle constraint property. Figures 26 and 30 demonstrate the typical hip rotation during natural gait and the hip, knee, and ankle joint rotations, respectively, completed during previous studies. In comparing Figures $29-30$, it is evident that the MEL code HIPS output data is relatively close to the presented graph, where 25 keyframe time is equivalent to 100 Percent gait. Figure 27 (lead leg) was used for comparison with Figure 26 because the previous study data in this figure is based on the lead leg of the patient. When comparing both figures, it is evident that the MEL code output data for the left leg (Figure 27) closely resembles the pattern presented in Figure 26 with minor variations of error. The error could be considered minimal since each individual exhibits slight, natural gait deviations. These similarities validate that the animation used for analysis accurately depicts the human walk cycle.

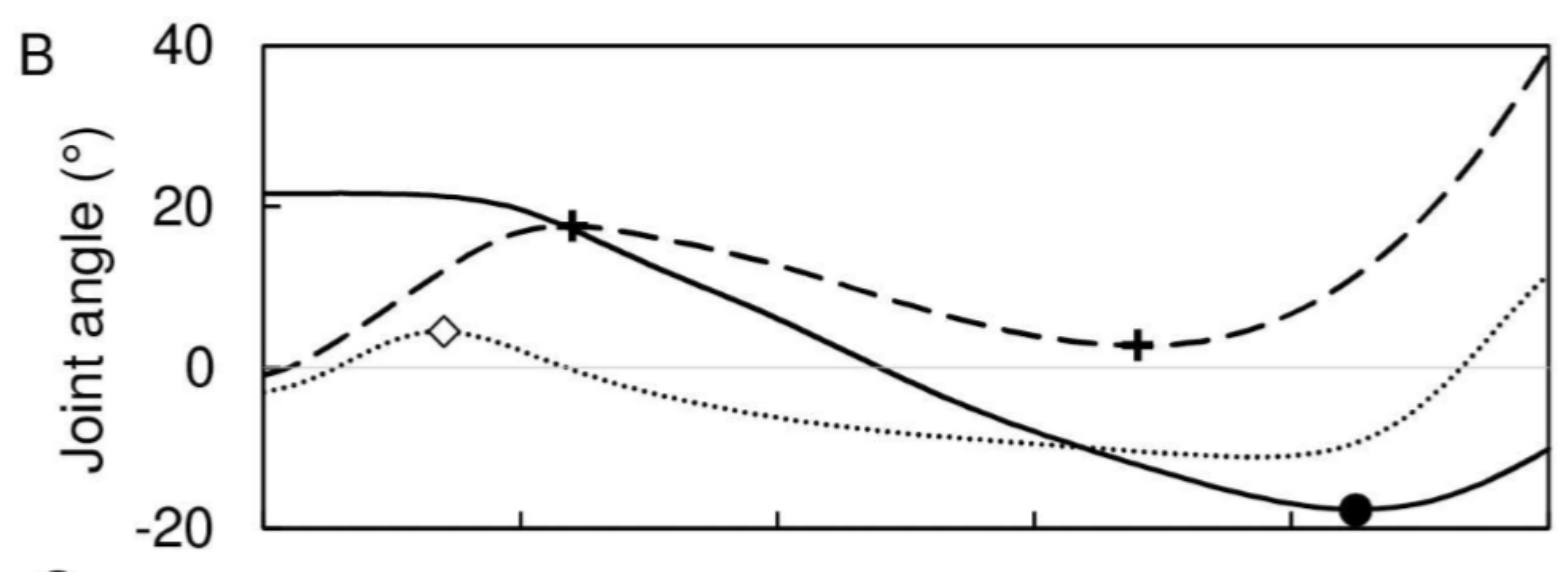

Figure 26: Joint angle data (degrees) of lead leg, where solid line $=$ hip, dashed line $=$ knee, and dotted line $=$ ankle [35]. 


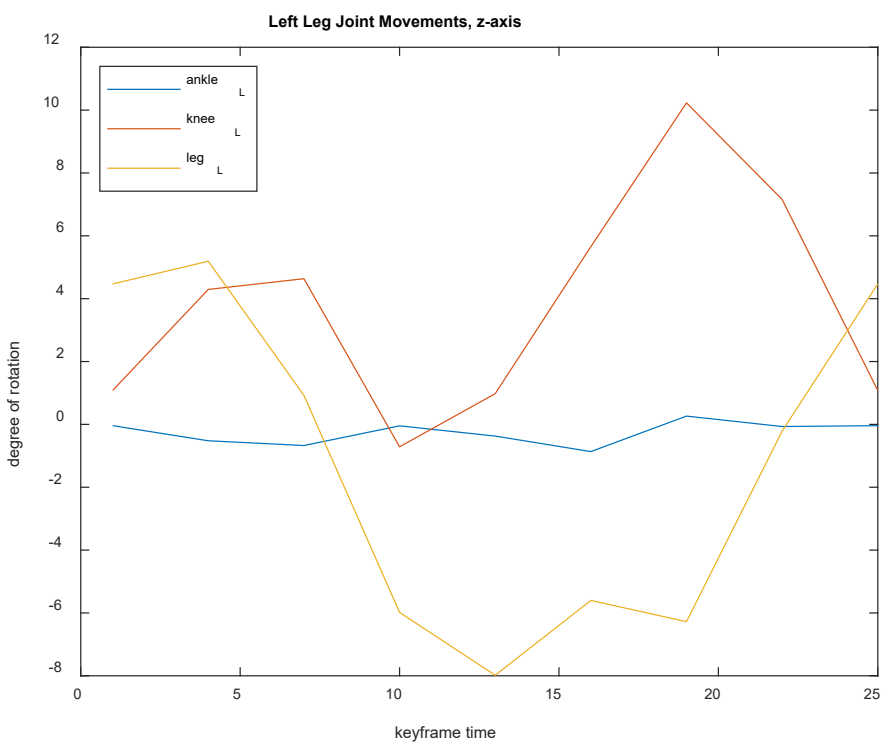

Figure 27: Left leg (lead leg) joint movements, z-axis, of Maya model using MEL code output from Table 7.

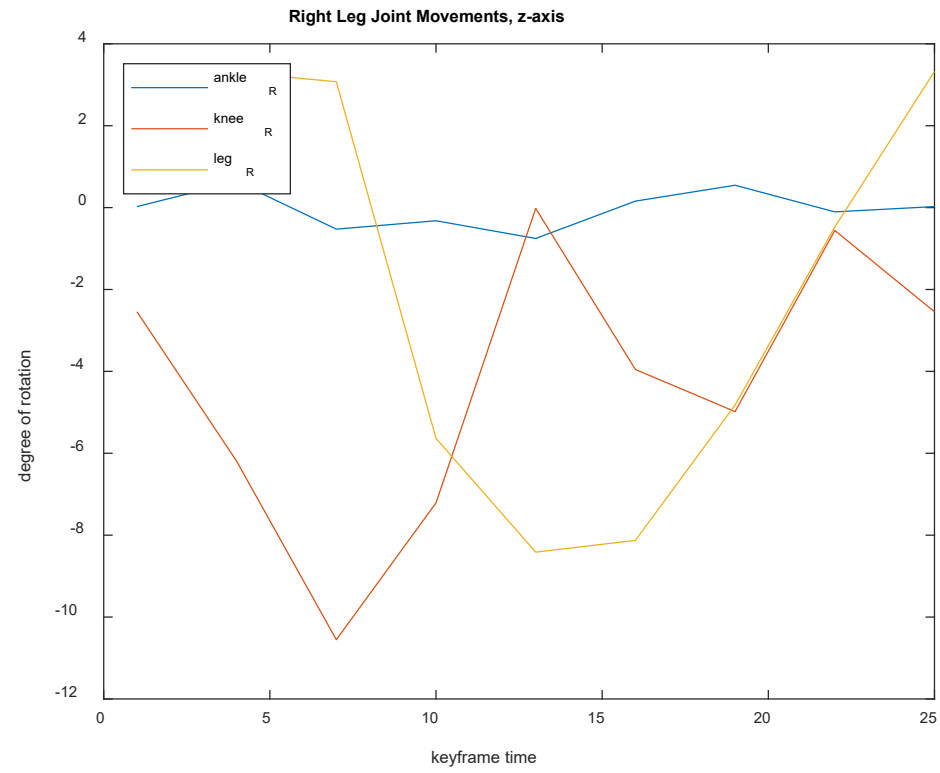

Figure 28: Right leg joint movements, z-axis, of Maya model using MEL code output from Table 7. 


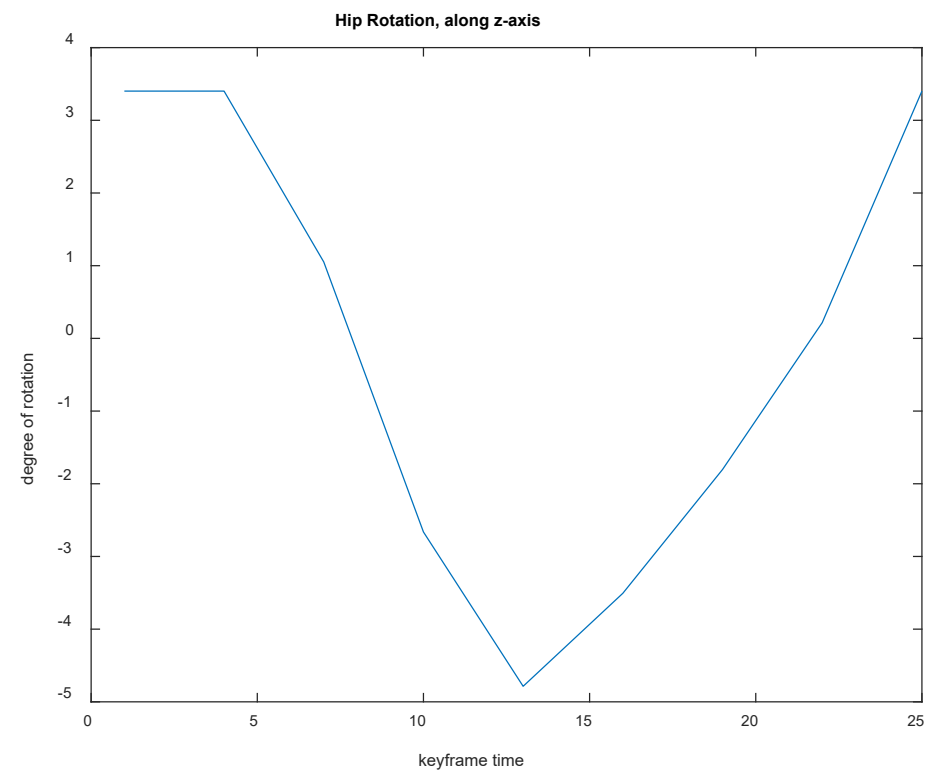

Figure 29: Hips/pelvis rotation, z-axis, of Maya model using MEL code output from Table 7.

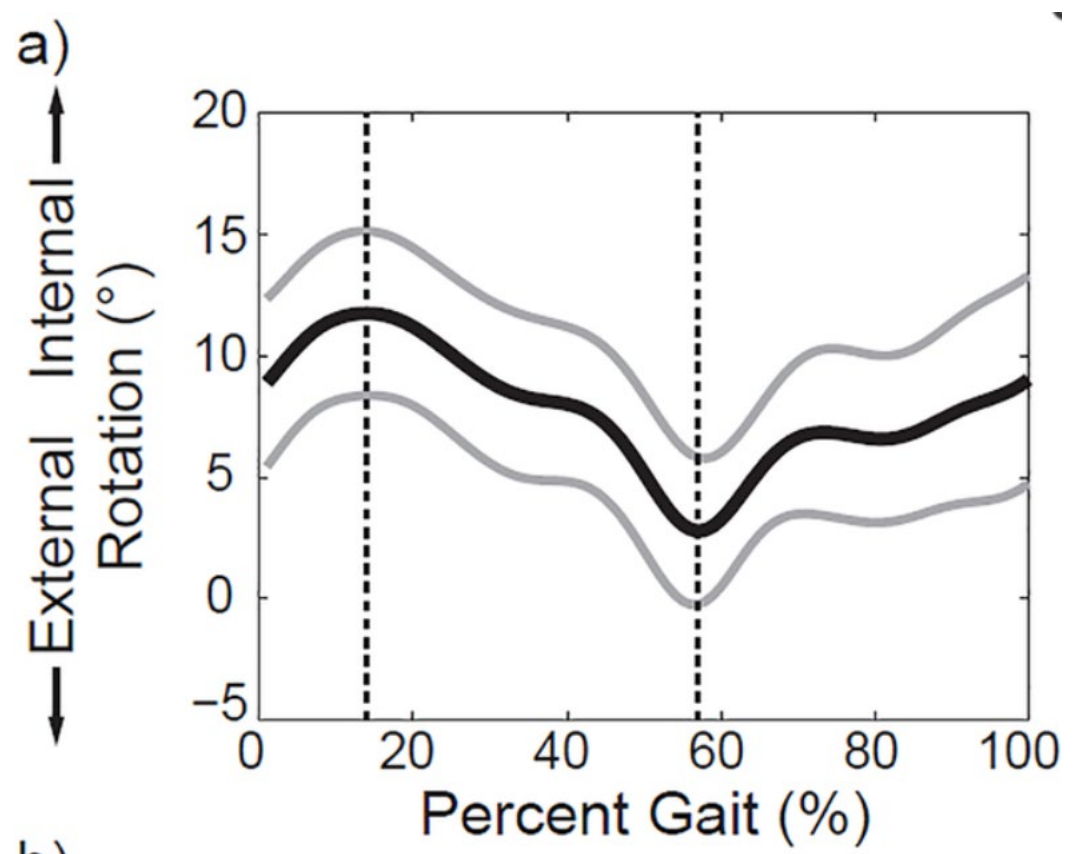

Figure 30: Hip rotation data, where solid black line = hip rotation, solid grey lines $=$ interval of rotation, and the dotted lines $=$ maximum and minimum rotation locations. [42]. 


\section{Solidworks Analysis}

In Solidworks, three primary model groups were anaylized for center of mass changes and comparisons:
a. Natural Bipdal Locomotion
b. Natural Bipedal vs Amputee Anatomies
c. Natural vs Prosthesic Legs

Natural Bipedal Locomotion

For the natural bipedal locomotion, the first 4 steps of the walk cylce (Figures 11 - 14) were translated to a readable Solidworks document for further analysis. Since the last 3 steps of the walk cylce mirror the first 3 , an analysis of only 4 out of 7 steps was necessary to gain the desired information. For these models, they were tranferred to Solidworks using the steps presented in Table 2 and the center of mass for each model was established using the steps stated in Table 3. The results are as presented in Figures $31-38$, as shown below. 


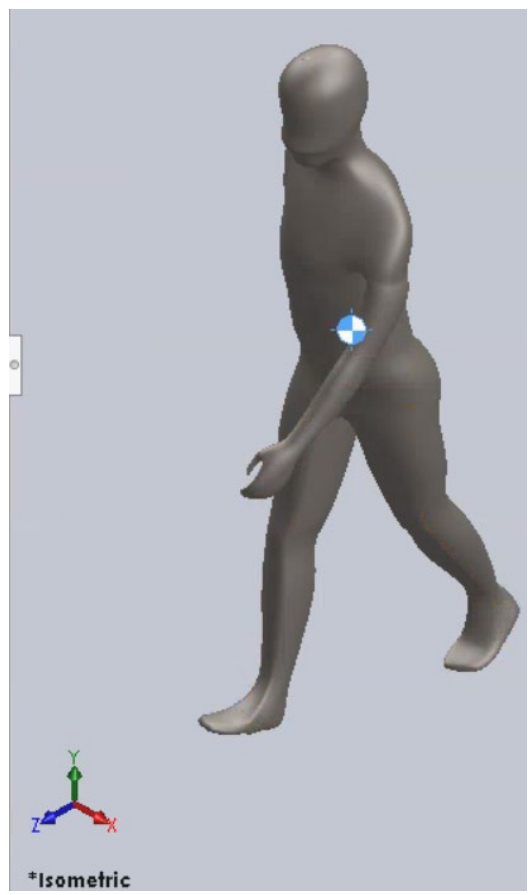

Figure 31: Solidworks 3D model of walking cycle step 1, heel strike (initial contact) with center of mass, as presented in Figure 5.
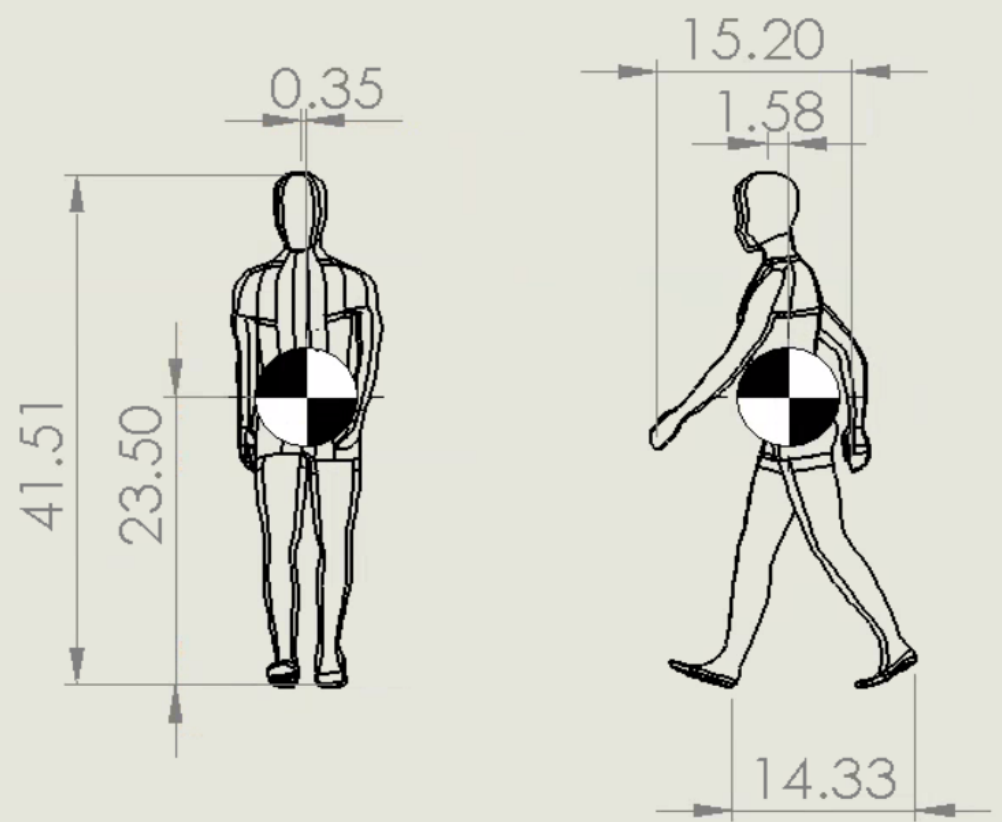

Figure 32: Solidoworks drawing of walking cycle step 1, heel strike (initial contact) with center of mass location, as presented in Figure 5. 


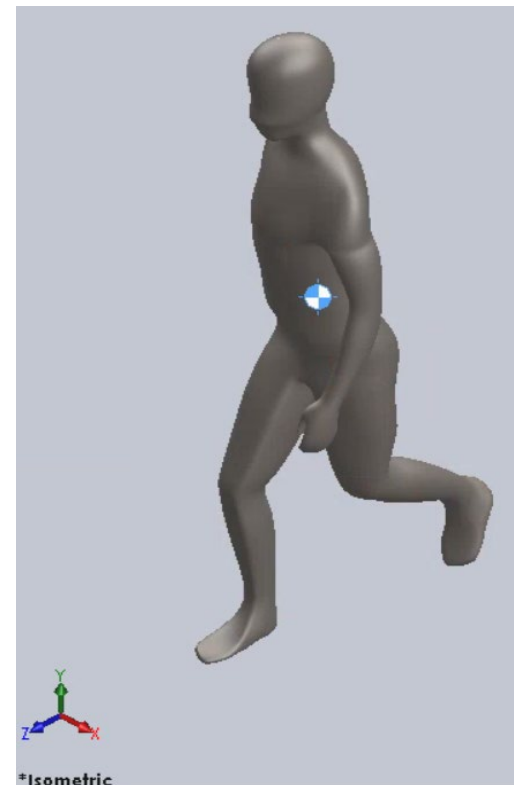

Figure 33: Solidworks 3D model of walking cycle step 2, loading response (foot flat) with center of mass, as presented in Figure 5.
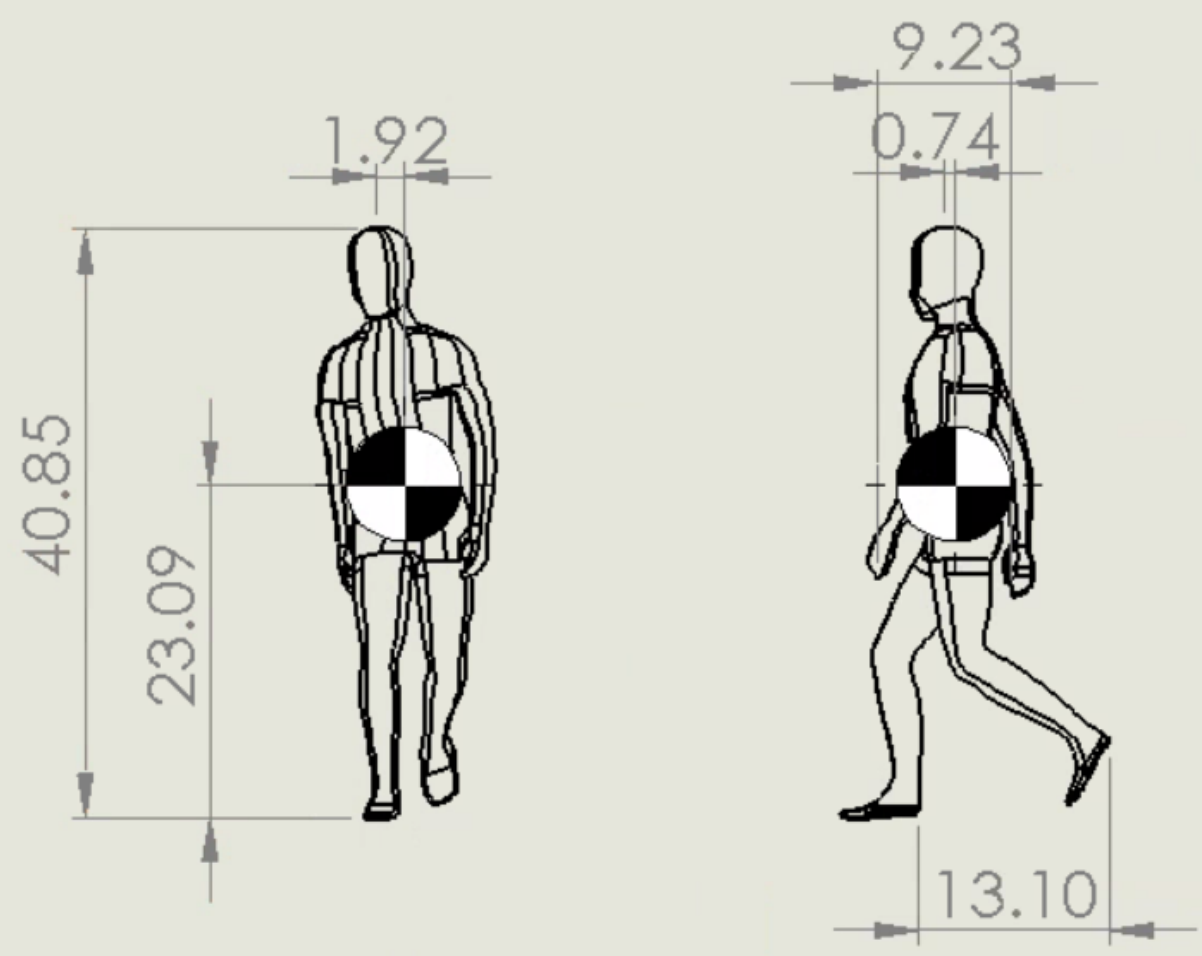

Figure 34: Solidworks drawing of walking cycle step 2, loading response (foot flat) with center of mass location, as presented in Figure 5. 


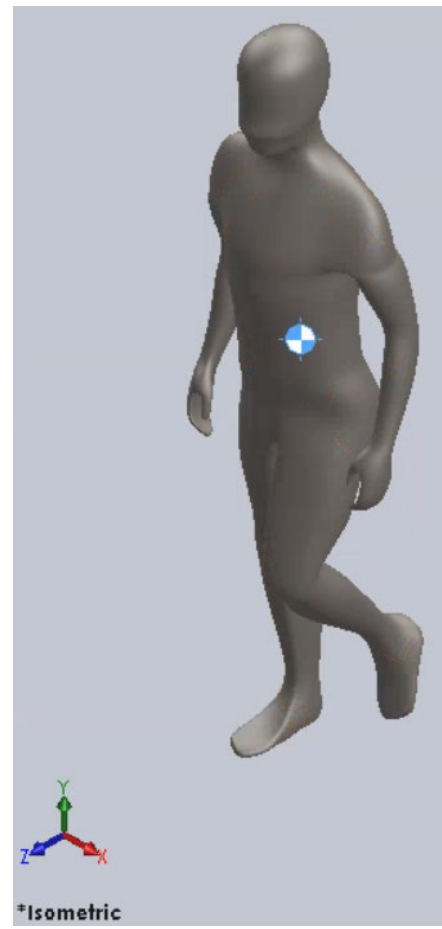

Figure 35: Solidworks 3D model of walking cycle step 3, midstance, with center of mass, as presented in Figure 5.

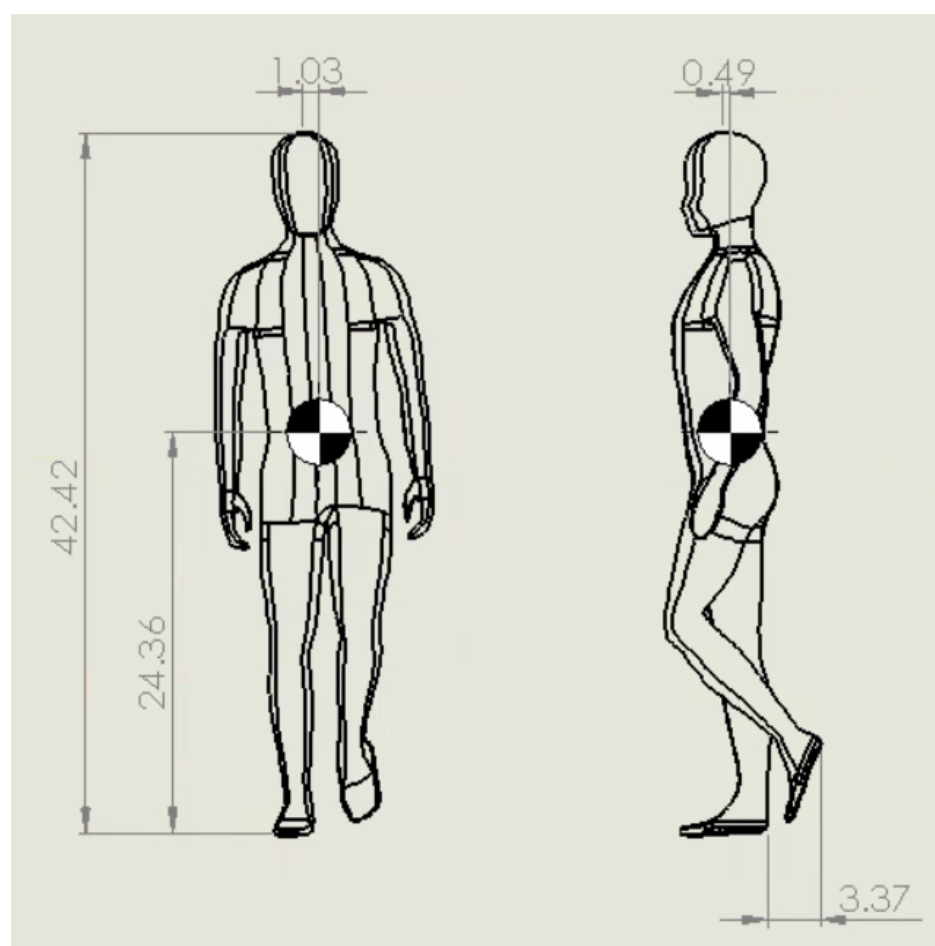

Figure 36: Solidworks drawing of walking cycle step 3, midstance, with center of mass location, as presented in Figure 5. 


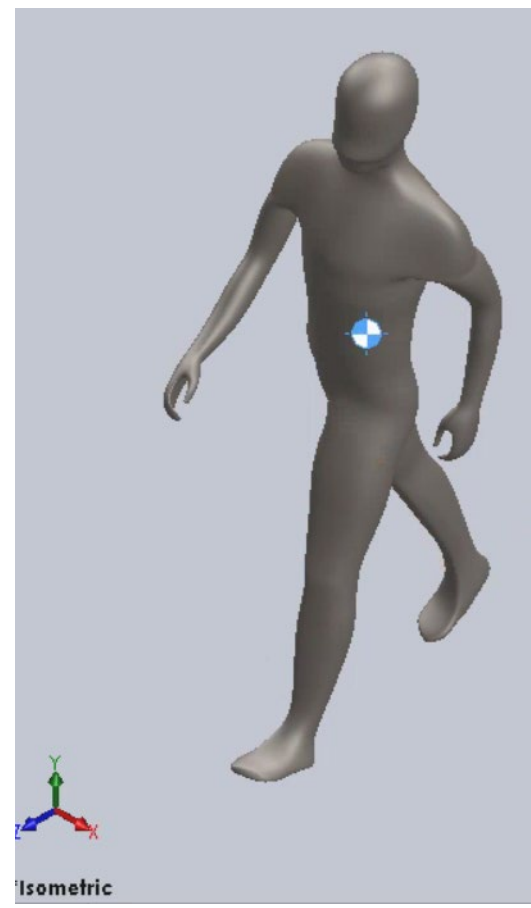

Figure 37: Solidworks 3D model of walking cycle step 4, terminal stance (heel off), with center of mass, as presented in Figure 5.

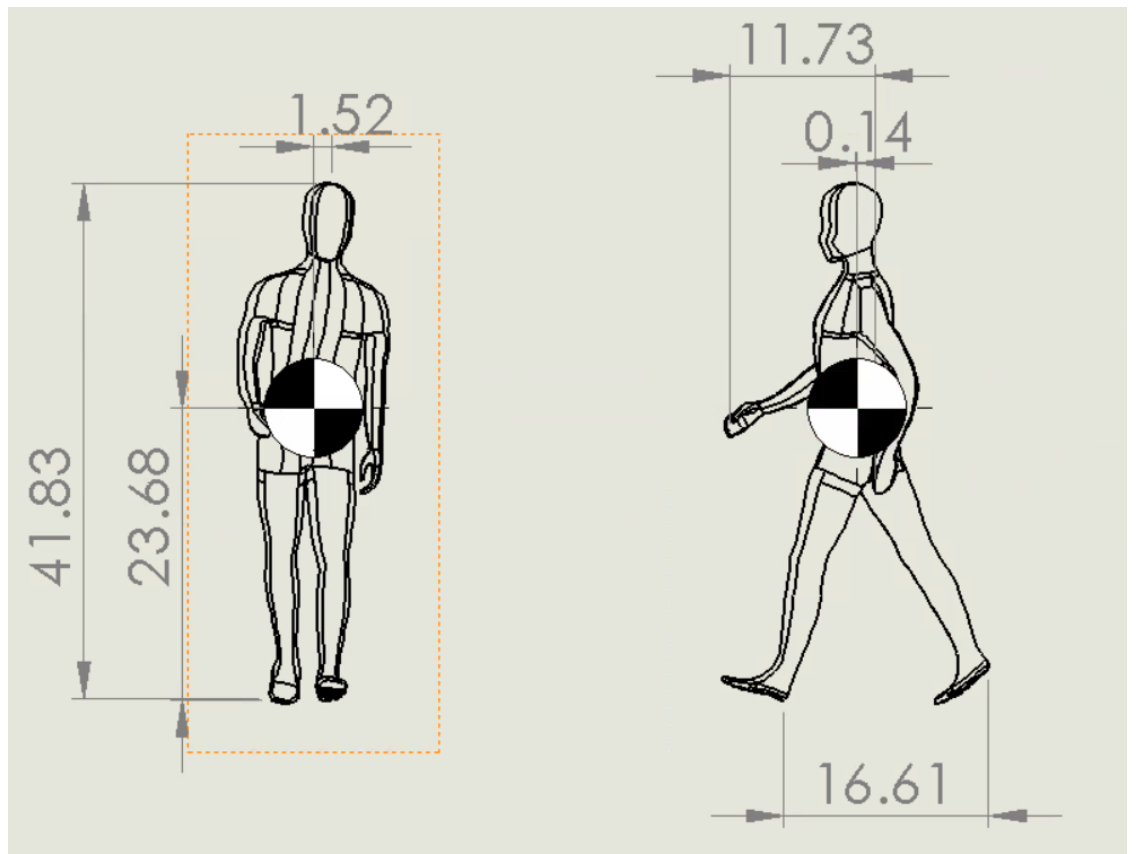

Figure 38: Solidworks drawing of walking cycle step 4, terminal stance (heel off), with center of mass location, as presented in Figure 5. 
Immediately, it is obvious that the overall height of each stage presented above are a range of values and will even differ from the height of the model in the set, anatomical position. The reason for this change in height is simple. When humans walk, each step is executed with force and momentum and most importantly, the hips sink into the stance to help with reestablishing stability during each phase. The hip's figure eight movement, as discussed in Chapter 2, is the natural motion that occurs during bipedal locomotion. Figure 34 shows the shortest overall height because in animation, this is called the "down pose", as shown in Figure 25, or the lowest point the hips go during the gait process. Constrastingly, Figure 36 demonstrates the tallest overall height because in animation this is known as the "up pose" and the highest point in the figure eight that the hips reach during a gait cycle.

For the center of mass, the main axis of concern is the z-axis alterations, since the body experiences the most anatomoical position changes in this direction. Based on the dimensions provided in Figures 32, 34, 36, and 38, it is evident that the center of mass is constantly fluctuating as the human body executes a step in natual locomotion. Of the four stages that are displayed, the biggest change was exhibited in step 1, as shown in Figure 32 , where the z-axis dimesion is 1.58 inches from the center of the body. As stated before, the base of support is the most vital element of stabilty. Concluding that the expanded base of support, when compared to the anatomically positioned body in Figure 40, as a contributing factor is not a far off assumption. In Figure 32, the heels of the feet are 14.33 inches apart in the $\mathrm{z}$ direction, while the feet are directly next to each other in Figure 34. In the instance shown in Figures $31-32$ this is the intial heel stike, the moment where the lead leg makes contact with the ground. Most importantly, in this 
moment, the torso bends forward, the hips rotate and dip towards the lead leg to gain the momentum to propel the body forward. Knowing this information, when analyzing the center of mass change in Figure 38 when compared to Figure 32, the values alter unexpectedly. In Figure 38, the base of support is much wider than that exhibited in Figure 32, but the center of mass has shifted towards the back of the body. A further analysis of the human gait cycle expresses that this moment captured in Figure 38 is the moment when the weight and "lead leg" responsibility shifts from one leg to the other. The shift in weight from one side of the body to the other also has an effect on the center of mass fluctuations. The center of mass value variations are an indication of the body constantly attempting to regain or maintain balance during normal, natural locomotion, since it is known that balance is dependent on the body's center of mass.

Natural Bipedal vs Amputee Anatomies

The focus of this analysis was to determine the center of mass location differences between the natural and amputee anatomies using Solidworks. Understanding the dynamics of the center of mass enabled a better comprehension of how the loss of a limb alters basic balance elements. Figures 39 and 41 show 3D Soliworks models of the natural and amputee anatomies, where the amputee has a medium sized stump. Figures 40 and 42 further identified the dimensions of the center of mass locations, where the $\mathrm{x}$ and z-directions were in relation to the center of the body, and the y-direction dimension was from the bottom of the foot. 


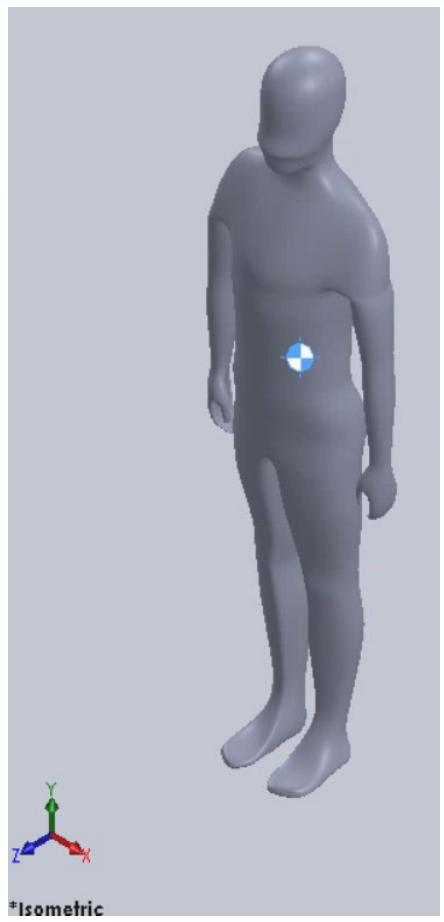

Figure 39: Solidworks 3D view of natural anatomy and center of mass location.
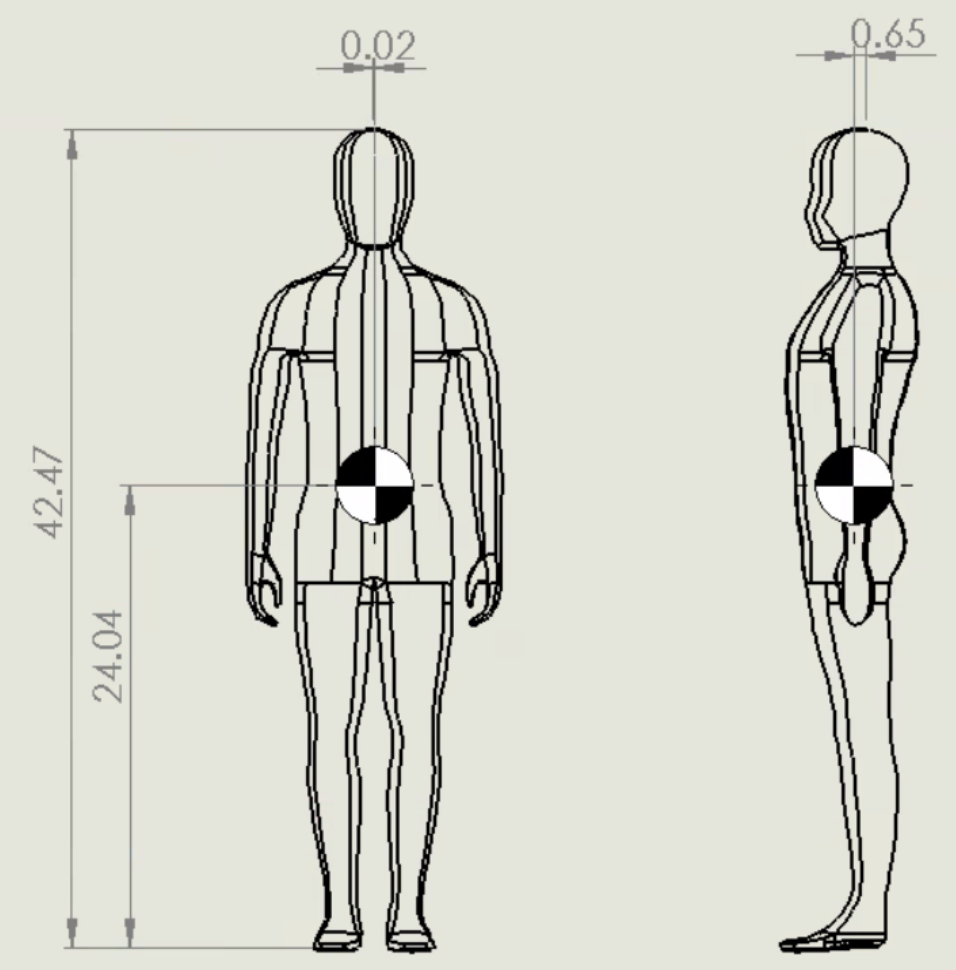

Figure 40: Solidworks drawing of natural anatomy with center of mass and the respective dimensions. 


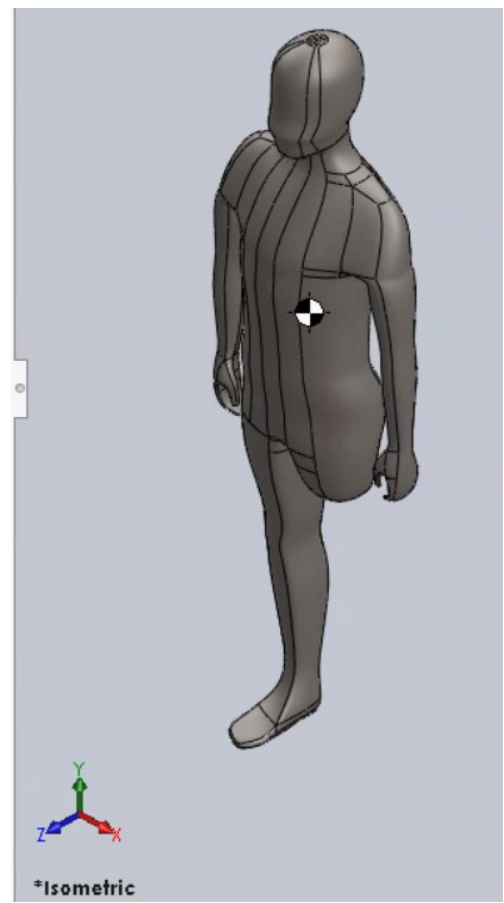

Figure 41: Solidworks 3D view of amputee anatomy with medium sized stump and center of mass location.
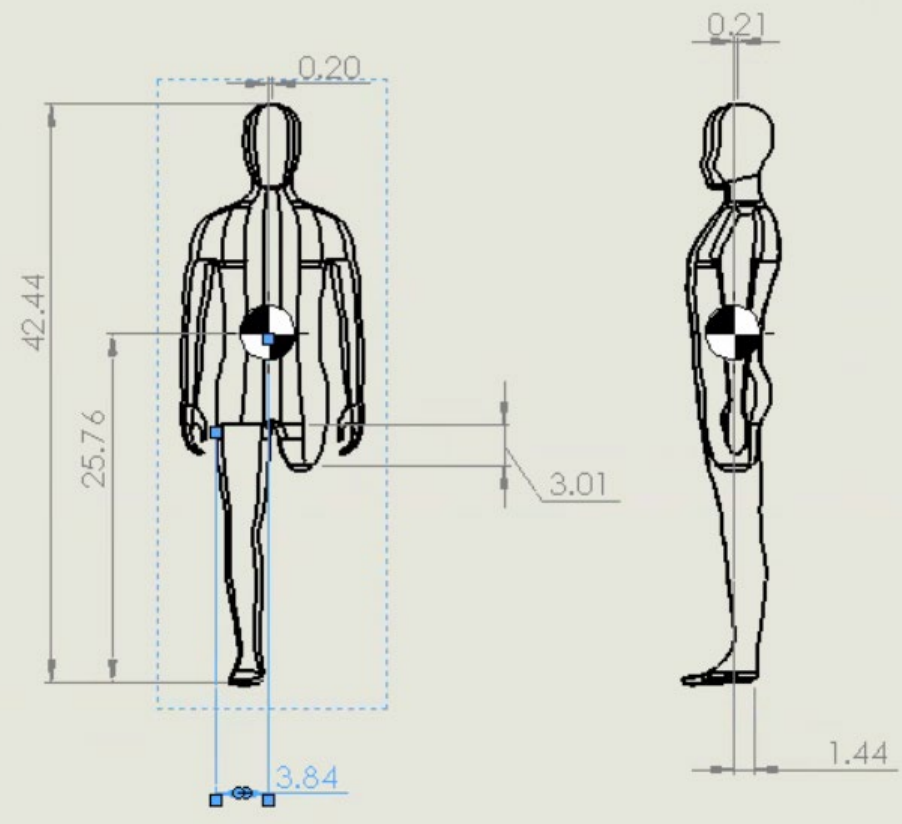

Figure 42: Solidworks drawing of amputee anatomy, medium stump, with center of mass and the respective dimensions. 
In comparing Figures 40 and 42, it is apparent that there are center of mass placement differs between the amputee and natural anatomies, as shown in Table 8 . The value changes may be minute in Figures 40 and 42, but even the slightest of changes in the human anatomy can dramatically impact the overall symmetry and balance of the patient. In this instance, the amputee's center of mass shift can be contibuted to the reestablishment of balance and compensation for the missing limb. The base of support is suddenly smaller due to the missing limb. This can be a speculated influence on the center of mass location shifts, since the base of support is the foundation of stability and mobility.

Table 8: Center of mass location data from Solidworks for natural and amputee anatomy.

\begin{tabular}{c|ccc}
\multicolumn{1}{c}{ Anatomy } & $x$-direction & $y$-direction & $z$-direction \\
\hline Natural & 0.02 in & 24.04 in & 0.65 in \\
Amputee (medium & 0.20 in & 25.76 in & 0.21 in \\
stump) & & &
\end{tabular}

To further the study, the three different stump lengths with the single amputee model were tested and the center of mass was determined, as shown in Figure $41-46$. In this instance, the purpose was to observe whether the three general stump lengths alter the center of mass or if these values are less reliant on this length change. After revisiting the definition of a transfemoral amputation (an amputation above the knee), the stump lengths were determined. A large stump length is when the amputation is right at the knee 
joint. A small stump length is when the amputation is closest to the hip joint. While a medium amputation is a length between the small and large length.

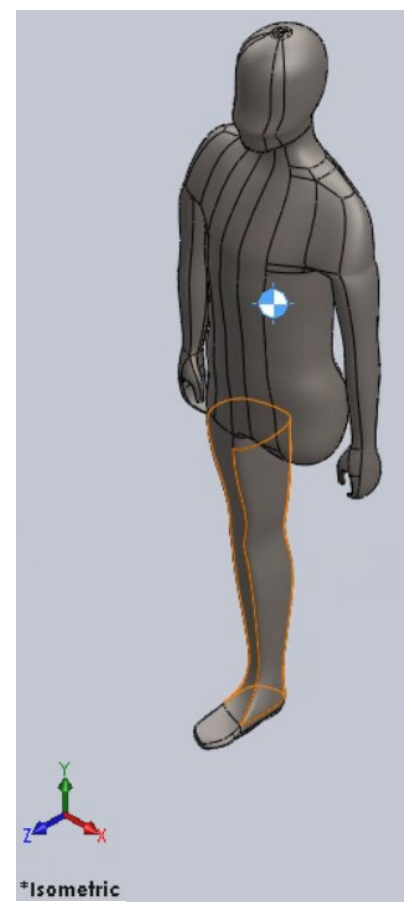

Figure 43: Solidworks 3D view of amputee anatomy with small sized stump and center of mass location.
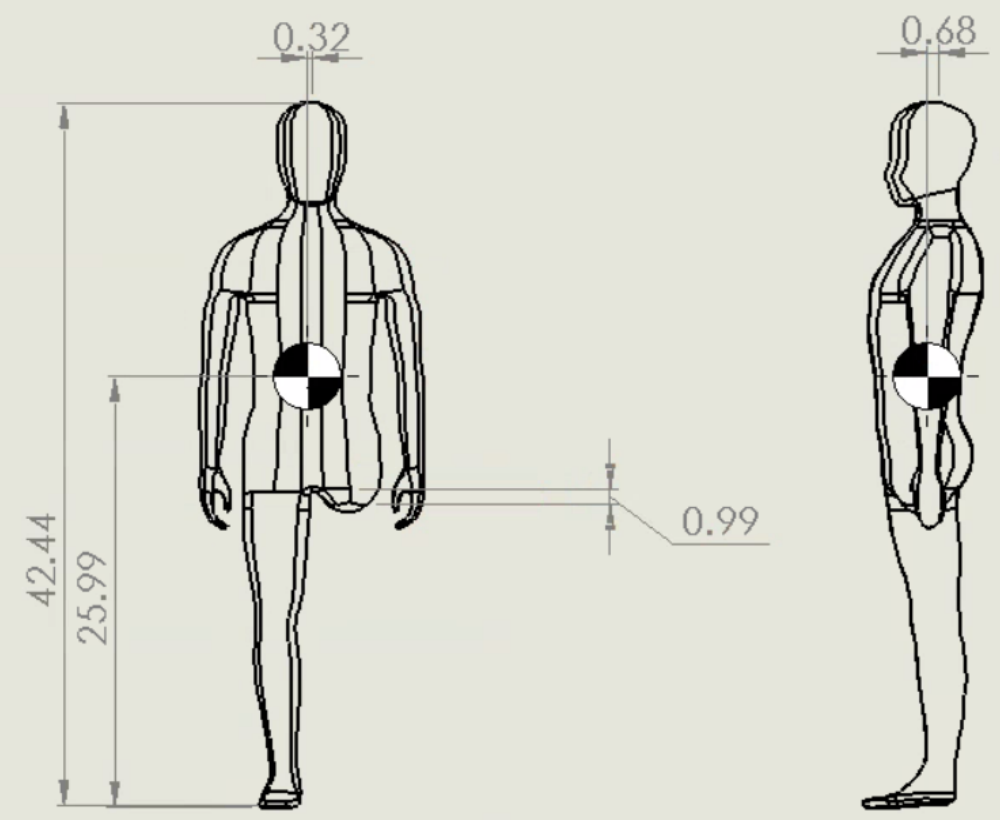

Figure 44: Solidworks drawing of amputee anatomy, small stump, with center of mass and the respective dimensions. 


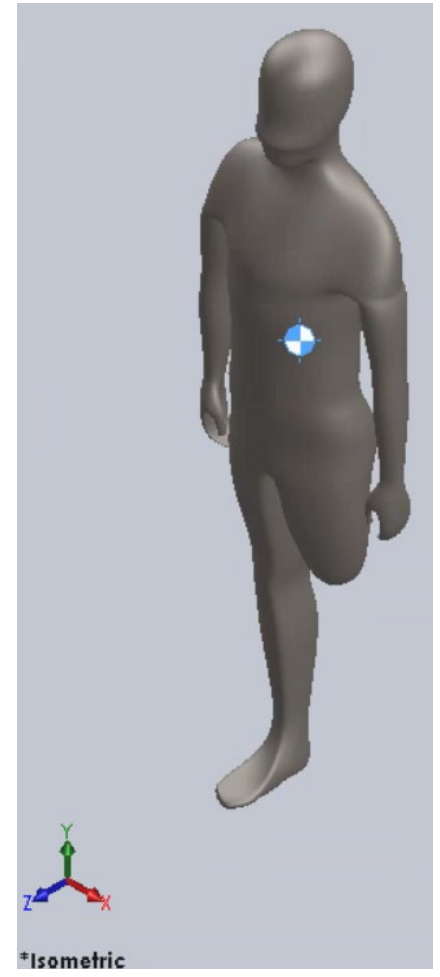

Figure 45: Solidworks 3D view of amputee anatomy with large sized stump and center of mass location.
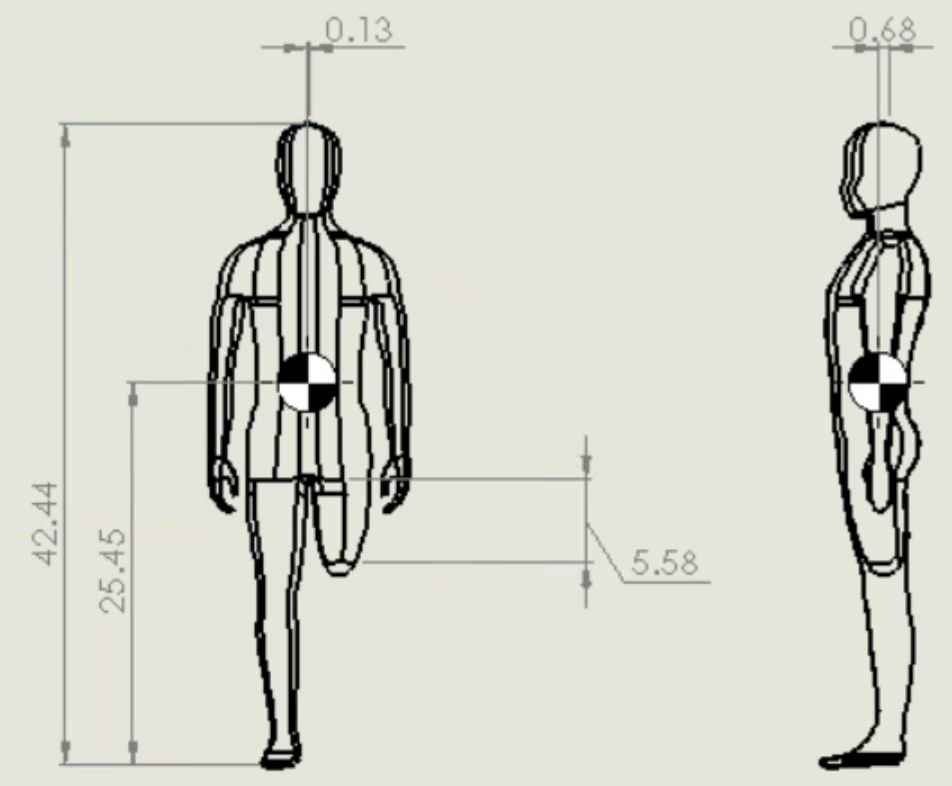

Figure 46: Solidworks drawing of amputee anatomy, large stump, with center of mass and the respective dimensions. 
Based on the data collected from Figures 41 - 46, as presented in a compilation in Table 9, the length of the stump does, in fact, influence the location of the center of mass. For example, the longer stump produces smaller y values. The $\mathrm{x}$ direction values showed that a shorter stump caused the center of mass to favor the natural leg by shifting towards it. The $\mathrm{x}$ and $\mathrm{y}$ shifts could be determined as the body's way to compensate for the missing limb and viewed as a way to shift more of the kinetic and kinematic responsbilities to the whole natural leg for movement and balance.

Table 9: Center of mass location data from Solidworks for different stump lengths.

\begin{tabular}{c|rcrc}
\multirow{2}{*}{$\begin{array}{c}\text { Stump size } \\
\text { length }\end{array}$} & \multicolumn{1}{c}{ Stump } & -direction & $y$-direction & $z$-direction \\
\hline Small & 0.99 in & 0.32 in & 25.99 in & 0.68 in \\
Medium & 3.01 in & 0.20 in & 25.76 in & 0.21 in \\
Large & 5.58 in & 0.13 in & 25.45 in & 0.68 in
\end{tabular}

\section{Natural vs Prosthetic Legs}

This analysis focused on comparing the center of mass location of a natural leg with the prosthetic leg. In doing so, the differences and similarities between the two positions revealed if the center of mass ratio that exists in a prosthetic really mimicked the ratios presented in the natural leg, as intended. Figures 47 and 49 show the center of mass marker in a 3D space on the natural and prosthetic limbs with the respective coordinate systems, while Figures 48 and 50 go more in depth with the necessary values in a $2 \mathrm{D}$ engineering drawing to calculate the ratios. 


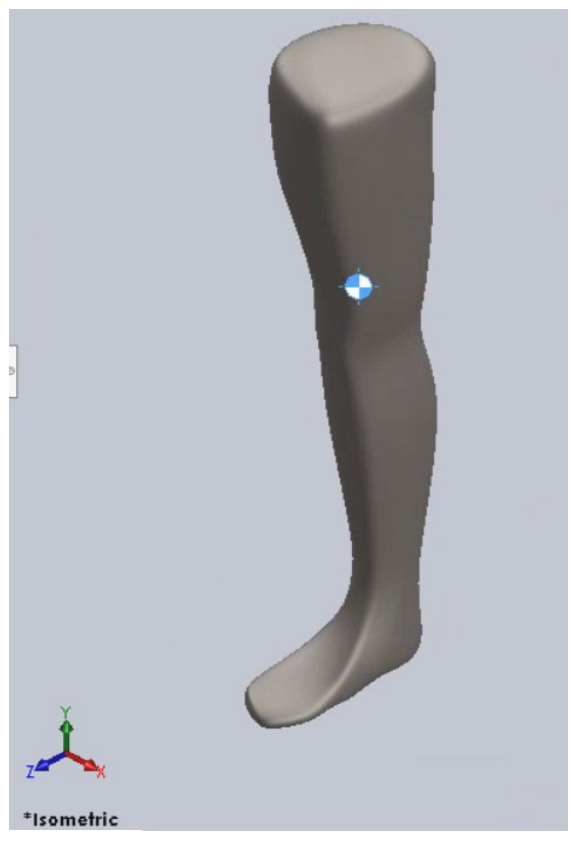

Figure 47: Solidworks 3D view of the natural leg and center of mass location.
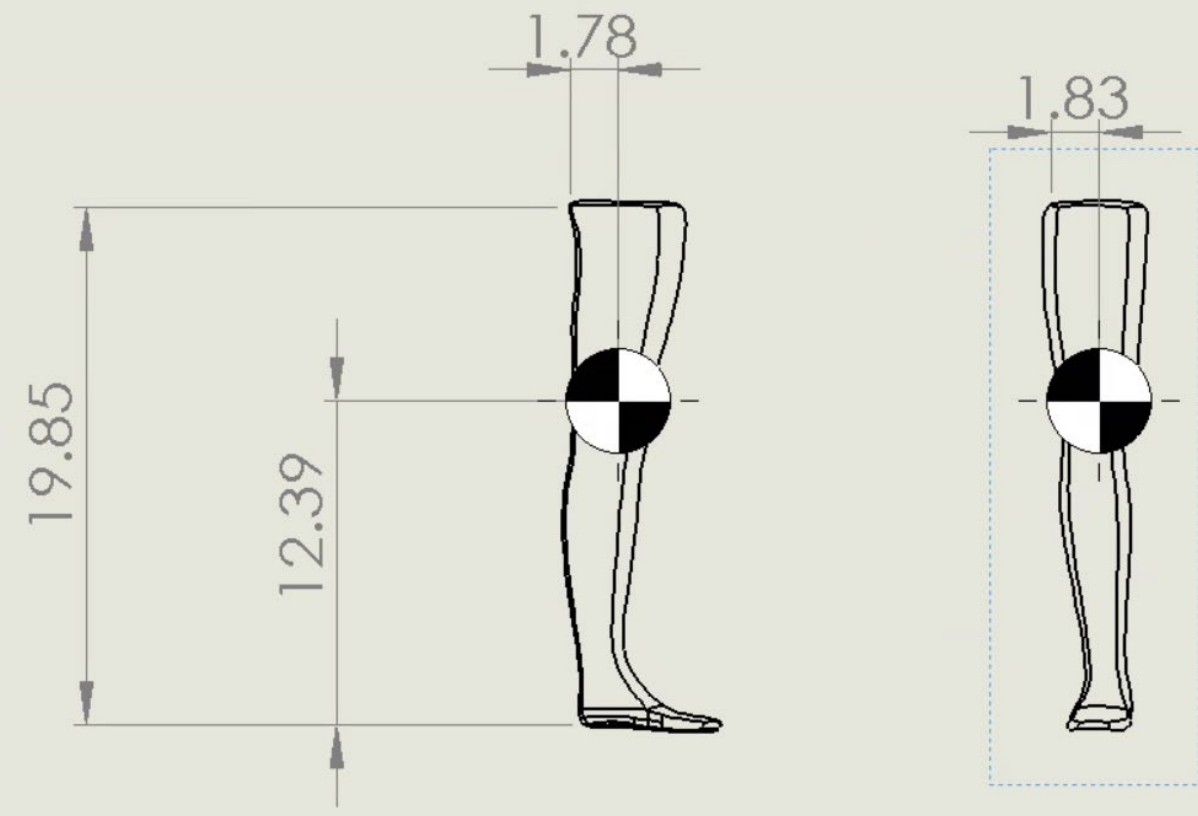

Figure 48: Solidworks drawing of natural leg with center of mass and leg dimensions. 


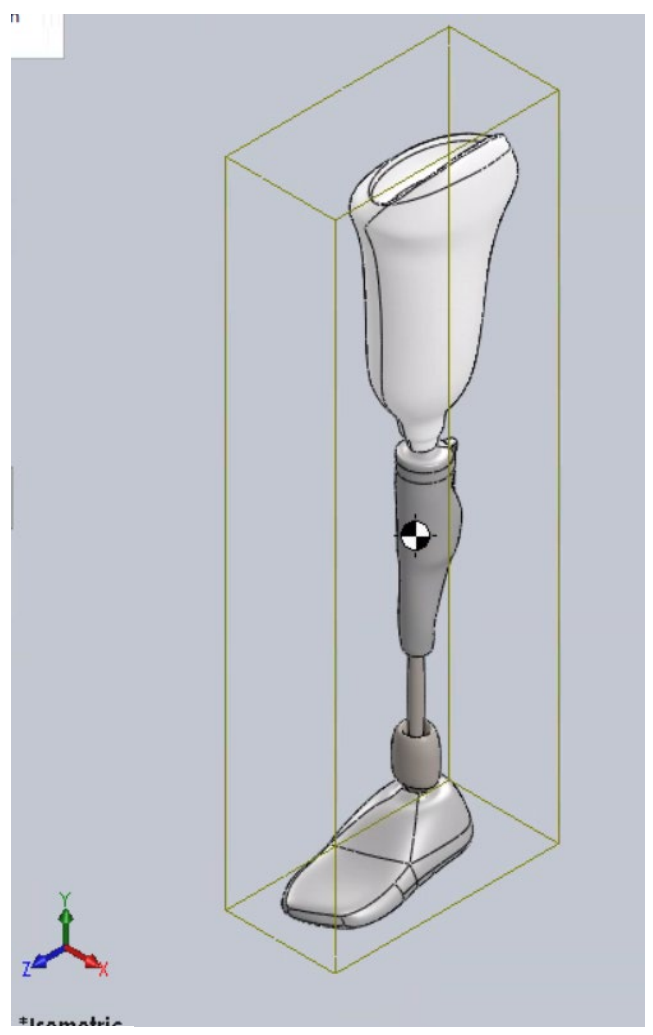

Figure 49: Solidworks 3D view of the prosthetic leg and center of mass location.

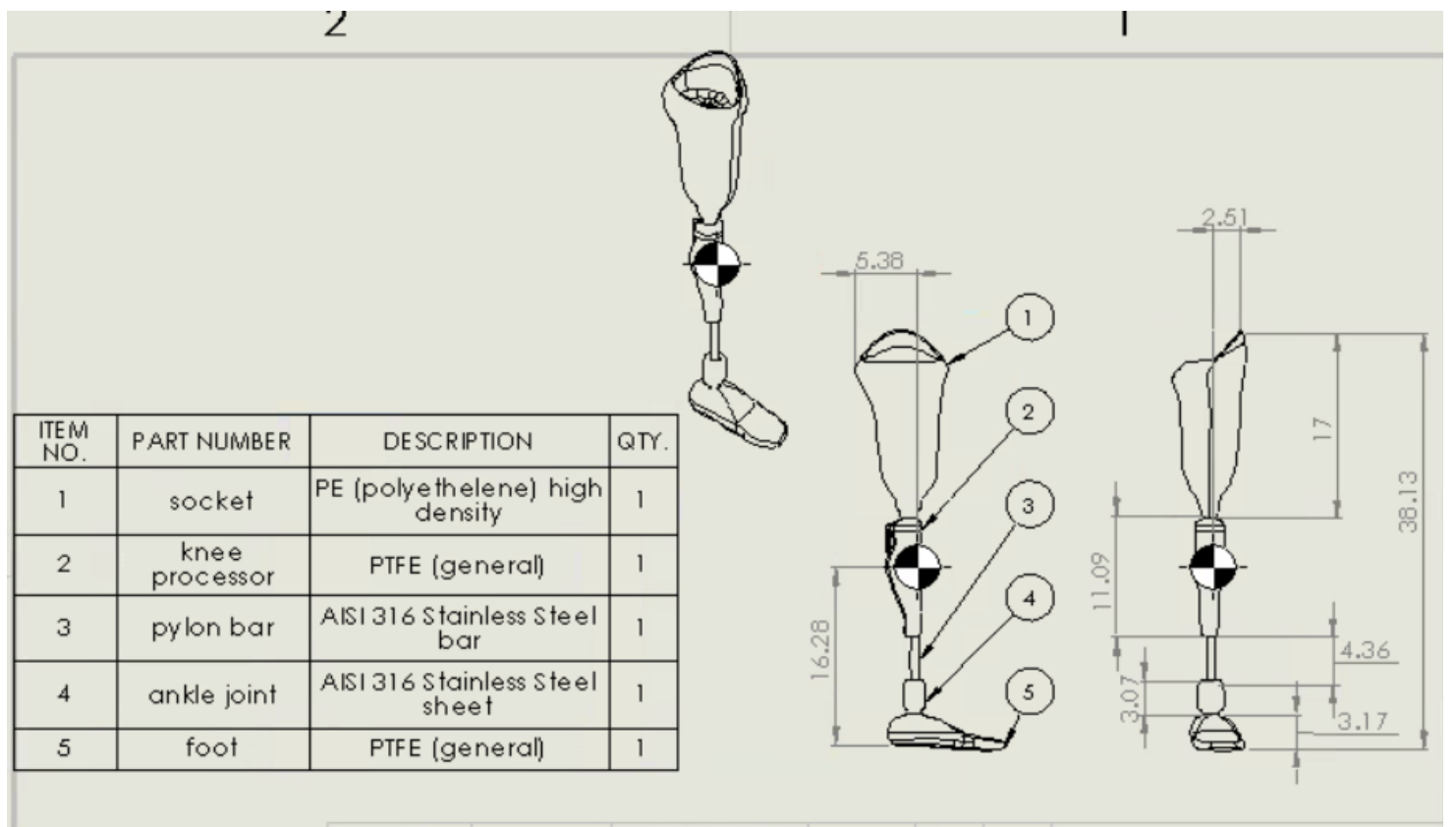

Figure 50: Solidworks drawing of prosthetic leg with center of mass and leg dimensions, and a bill of materials, combination 1 . 
In Figure 48, the overall length of the leg, $\mathrm{x}_{\mathrm{B}}$, is 19.85 in, while the center of mass location, $\mathrm{x}_{\mathrm{A}}$, is 12.39 in. When these values were substituted into Eq. 7, the ratio value for the natural leg, $\mathrm{COM}_{\mathrm{NL}}$ is 0.6241 or about $62.41 \%$ of the length of the leg. In Figure 50, following the same procedures as previously stated, $\mathrm{x}_{\mathrm{B}}$, the total length of the prosthetic in the $\mathrm{y}$ direction, is $38.13 \mathrm{in}$, while the center of mass location, $\mathrm{x}_{\mathrm{A}}$, is $16.28 \mathrm{in}$, thus giving producing a value, $\mathrm{COM}_{\mathrm{PL}}$, of 0.4264 or $42.64 \%$ of the prosthetic. Based on visual observations of Figures 47 and 49, it was evident that the center of mass on the natural leg is located right above the knee joint (the hinge joint and point of bending). In the prosthesis, the marker is indicated right below the point of intended bending. The different locations raise many questions. Does this inequality contribute to balance issues and gait asymmetries? And primarily, what can be done to fix this? Materials change? Pylon rod lengthening or shortening?

The natural placement of the center of mass marker on the organic leg is an element that cannot be changed, but can possibly be mirrored for the sake of the patient's comfort, mobility, stability, and symmetry. In order to mimic the center of mass location on the natural leg, elements of the prosthetic limb must be altered to achieve the desired results. The pylon rod length is an element of the prosthetic that is dependent on patient height and stump length and designed to provide the connection between the ankle joint and the knee joint mechanisms. So, to further the study on the prosthetic leg's center of mass sensitivity, additional studies were conducted that concentrated on the evaluation of the prosthesis with a combination of different materials. 


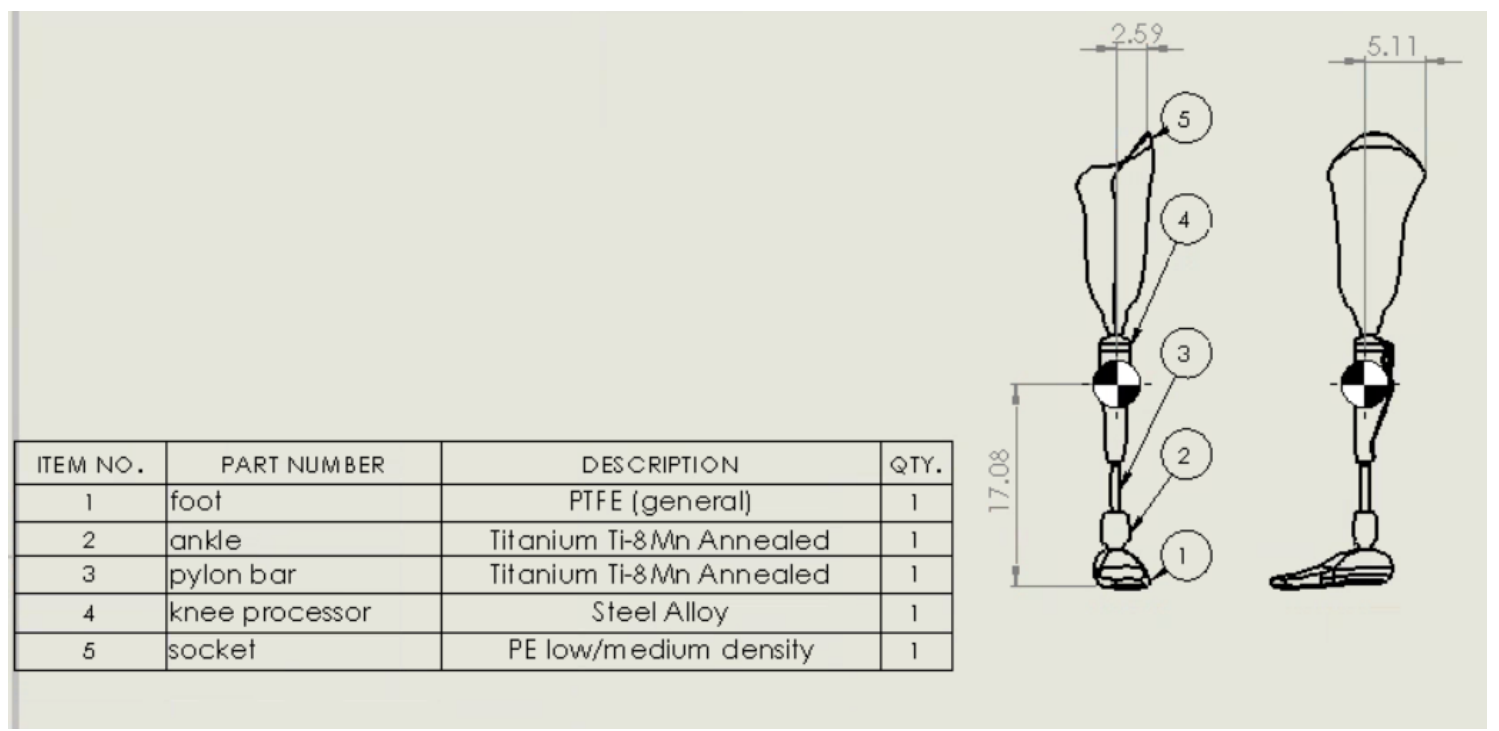

Figure 51: Solidworks drawing of prosthetic leg with center of mass and leg dimensions, and a bill of materials, combination 2 .

\begin{tabular}{|c|l|c|c|}
\hline ITEM NO. & PART NUM BER & DESCRIPTION & QTY. \\
\hline 1 & foo & PTFE (general) & 1 \\
\hline 2 & ankle & $\begin{array}{c}\text { AlsI316 Stainless Steel } \\
\text { Sheet }\end{array}$ & 1 \\
\hline 3 & pylon bar & Aluminum 6061 T6 & 1 \\
\hline 4 & knee processor & PTFE (general) & 1 \\
\hline 5 & socket & Aluminum 6061 T6 & 1 \\
\hline
\end{tabular}
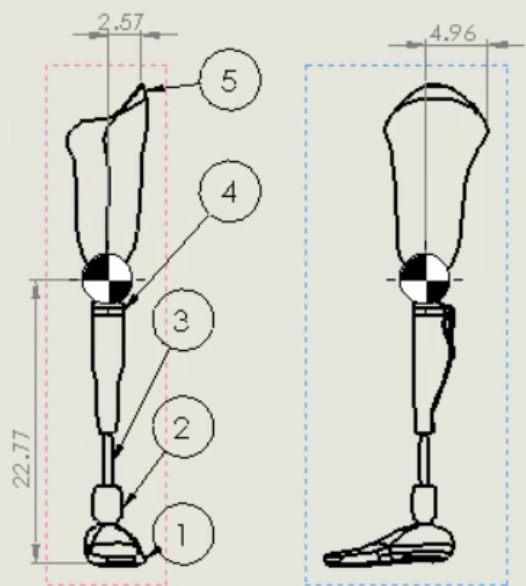

Figure 52: Solidworks drawing of prosthetic leg with center of mass and leg dimensions, and a bill of materials, combination 3 . 
The major change and value of concern was the y direction center of mass number since the previous study comparing combination 1 and the natural leg center of mass demonstrated a significant difference. In Figures $50-52$, the overall height, width and length of the prosthesis remain the same. These mentioned figures test a combination of the materials typically used to manufacture these prosthesis attributes, combination 1,2, and 3, to study how the center of mass locations changed. The center of mass ratio calculations and locations are as shown in the compilation in Table 10. Interestingly, the location of the center of mass shifted in all directions with each combination of materials tested as shown in each of their respective bills of materials.

The bill of materials in combination 1 consisted primarily of steels and plastic forms, where the steel elements are on the ankle and pylon bar. Steel (AISI 316) has a density of $0.289 \mathrm{lbs} / \mathrm{in}^{3}$, while PE high density and PTFE have densities of $0.035 \mathrm{lb} / \mathrm{in}^{3}$ and $0.079 \mathrm{lbs} / \mathrm{in}^{3}$, respectively [36-37]. The location of the steel elements at the lower portion of the leg caused the center of mass to sink lower on the leg than that of the natural leg. After the ratio values for combination 1 and the natural leg were substituted into Eq. 8, the percent change for this comparison is $30.789 \%$, where the natural leg ratio is the original value and the ratio for combination 1 is the new value. To recall, the insignificance of asymmetries is capped at below $10 \%$ for the human body, and the percent change for the prosthesis leg, combination 1 , and the natural leg comparison is significantly higher.

The bill of materials for combination 2 consisted of titanium (Ti-8Mn), steel alloy, and plastic forms (PTFE and PE low/med density), with densities of $0.171 \mathrm{lbs} / \mathrm{in}^{3}$, $0.270 \mathrm{lbs} / \mathrm{in}^{3}, 0.079 \mathrm{lbs} / \mathrm{in}^{3}$, and $0.034 \mathrm{lbs} / \mathrm{in}^{3}$, respectively [37-40]. In this combination, 
the metal components are distributed through to the knee processor joint with steel alloy, contrary to the PTFE knee processor in combination 1. This alteration, in addition with the titanium switch, contributed to the center of mass shift towards the joint bend. Combination 2 presented a y value closer to that of the natural leg, but still is too small of a number to obtain an adequate ratio comparison to achieve near symmetry. Using Eq. 7 to get the ratio, combination 2 has a ratio of 0.4479 or $44.79 \%$. In following the same procedures presented with combination 1, for comparison, combination 2 and the natural leg ratios were inputted in Eq. 8 to get the percent change. The percent change for the combination 2 and natural leg comparison is $28.233 \%$, which is still significantly higher than the acceptable anything below $10 \%$ for human body asymmetry insignificance.

The final test, combination 3, includes PTFE, aluminum (6061-T6), and stainless steel (AISI 316), with densities of $0.079 \mathrm{lbs} / \mathrm{in}^{3}, 0.098 \mathrm{lbs} / \mathrm{in}^{3}$, and $0.289 \mathrm{lbs} / \mathrm{in}^{3}$, respectively [36-37, 41]. Aluminum shows to be significantly lighter than steel and thus decreasing the weight and density of the overall prosthetic. Combination 3 has the center of mass at the knee processor joint bend and provides the most symmetry and easy of mobility if an amputee patient were to wear this combination of materials. Combination 3 proved to be the most successful because the COM ratio was the closest to the $\mathrm{COM}_{\mathrm{NL}}$ ratio at 0.5972 or $59.72 \%$. For the final comparison, Eq. 8 was used to calculate the percent change for the combination 3 and natural leg evaluation, producing a value of 4.310\%. This percent value falls under $10 \%$ thus deeming the ratio difference between the natural leg and the combination 3 of the prosthesis material insignificant asymmetry. 
Table 10: Prosthesis center of mass locations for bill of material combinations.

Material

Combos

Combination 1

Combination 2

Combination 3 x direction

y direction

2.51 in

2.59 in

2.57 in z direction

COM ratio in

$\mathbf{y}$

0.4264

0.4479

17.08 in $\quad 5.11 \mathrm{in}$

4.96 in

0.5972

The analysis conducted demonstrated that the material choices for the prosthetic component alter the center of mass location, and inadvertently affect lower limb mobility symmetry.

\section{MatLab Code}

The MatLab code wrapped up the previous sections with analysis and comparison codes to further bridge the gap between the engineering and art applications. This section will discuss the results of the center of mass percentage calculations and the torque equilibrium results.

\section{$\underline{\text { Center of Mass Percentages }}$}

The center of mass percentages used the information gathered from the Solidworks analysis of the male body (as modeled in Maya) in anatomical position, as shown in Figures 53 - 54. It is important to note the location of the origin in order to establish the correct values for Eq. 7. In this case, the origin is at the center of the body in the $\mathrm{x}$ and $\mathrm{z}$ directions and at the feet location in the $\mathrm{y}$ direction. 


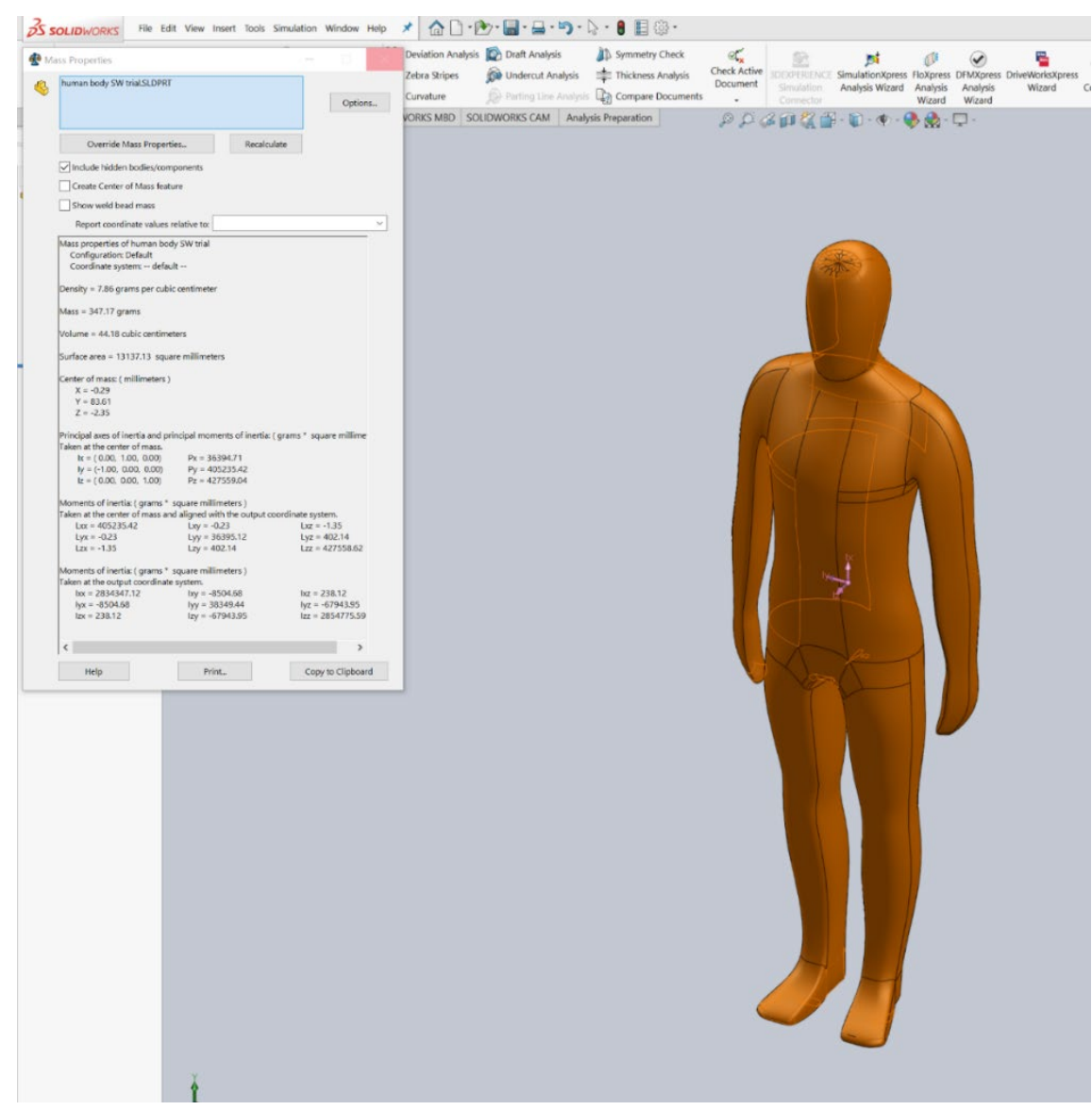

Figure 53: Solidworks Mass Properties analysis results for COM percentages. 


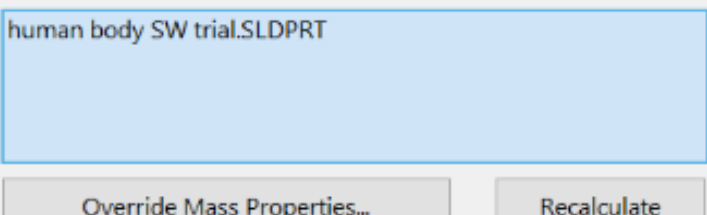

$\checkmark$ Include hidden bodies/components

$\square$ Create Center of Mass feature

$\square$ Show weld bead mass

Report coordinate values relative to:

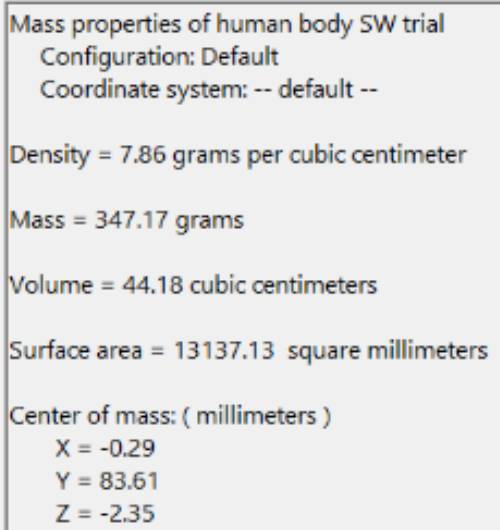

Figure 54: Solidworks Mass Properties analysis results, close-up of the engineering data from Figure 53. 
The center of mass locations, as shown in Figure 54, are compiled in a Table 11, along with the total length, width, and height of the male model in Figure 53 for ease of comparison and analysis.

Table 11: Center of mass and total body dimensions of male figure in anatomical position.

\begin{tabular}{r|lcc}
\multicolumn{2}{c}{$x(\mathrm{~cm})$} & $y(\mathrm{~cm})$ & $z(\mathrm{~cm})$ \\
\hline Center of mass & -0.029 & 8.361 & -0.235 \\
Total dimensions & 2.40 & 14.83 & 1.77
\end{tabular}

Since the $y=0$ location is at the feet of the Solidworks model, Eq. 7 was arithmetically applied without any additional alterations where $\mathrm{x}_{\mathrm{A}}=8.361 \mathrm{~cm}$ and $\mathrm{x}_{\mathrm{B}}=14.83 \mathrm{~cm}$, thus giving a ratio of 0.5638 or $56.38 \%$. This percentage is relatively close to the center of mass percent logics given in the biomechanics textbook, as mentioned in Chapter 2 Literature Review. In Chapter 2, biomechanics states that the center of mass location in the $y$ direction is about $57 \%$ of the height of a male in anatomical position. With these results given from the MatLab and Solidworks combination, it can be assumed that the center of mass calculations of a Maya model are accurate based on the closeness of the values. Knowing this, the calculations of the $\mathrm{x}$ and $\mathrm{z}$ direction ratios can also be executed, since these percentages are not given in biomechanics reference information. For the $\mathrm{x}$ and $\mathrm{z}$ directions, it is important to remember that these values are the distance from the origin. It is known that the origin is exactly half of the $\mathrm{x}$ and $\mathrm{z}$ dimensions because this 
figure was modeled in Maya to be perfectly symmetrical. To find the ratio, Eq. 7, with slight modifications, was applied as follows in Eq. 11:

$$
\text { center of mass ratio from origin }=\frac{\left(\frac{x_{B}}{2}\right)+x_{A}}{x_{B}}
$$

Using Eq. 11, the ratio in the $\mathrm{x}$ direction is 0.4879 or $48.79 \%$, where $\mathrm{x}_{\mathrm{A}}=-0.029$ and $\mathrm{x}_{\mathrm{B}}$ $=2.40$. Implementing the same equation, the ratio in the $\mathrm{z}$ direction is 0.3672 or $36.72 \%$, where $\mathrm{x}_{\mathrm{A}}=-0.235$ and $\mathrm{x}_{\mathrm{B}}=1.77$.

\section{Equilibrium and Rotational Torque}

This code is meant to achieve the following purposes:

a. Input Maya Output Data - test the torque and equilibrium on the output data from the Maya animation from Table 7.

b. Given Data: Test Joint Angles - test torque and on given output data from a previous study, shown in Table 12 and Figure 49. 

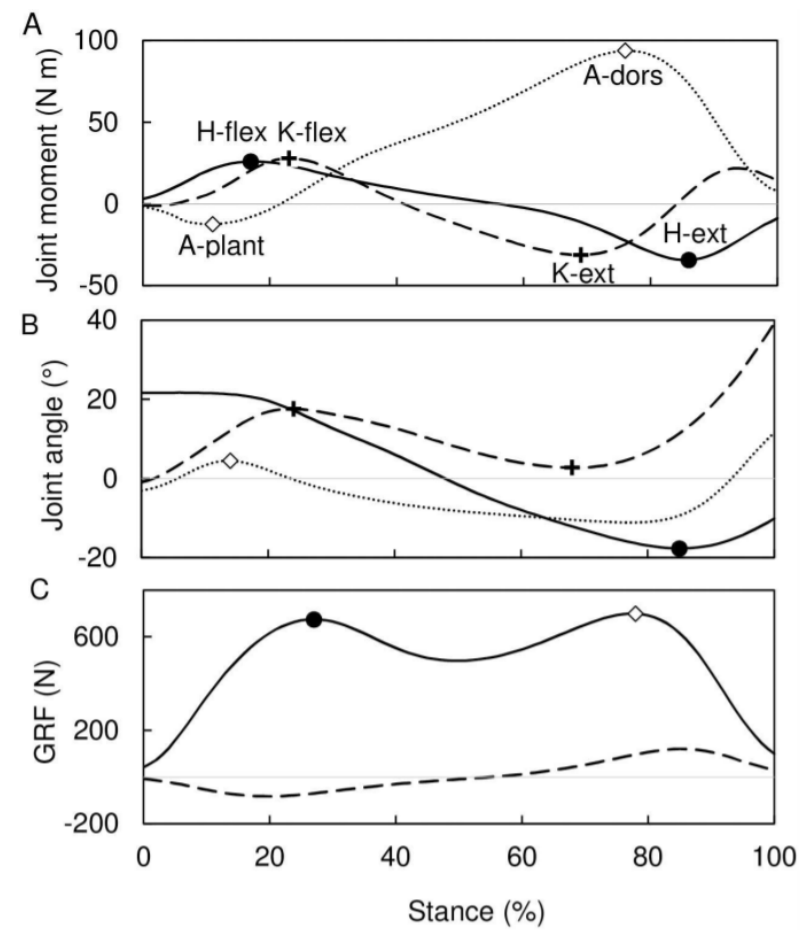

Figure 55: Joint moments data, where solid line $=$ hip, dashed line $=$ knee, and dotted line $=$ ankle - moment of inertia $\left(\mathrm{N}^{*} \mathrm{~m}\right)$, joint angle (degrees), and GFR (ground reaction forces in Newtons) [35].

Table 12: Given data, in degrees, from a previous gait study shown in Figure 55.

\begin{tabular}{|c|c|c|c|}
\hline Stance & Hip & Knee & Ankle \\
\hline$\%$ & angle & angle & angle \\
\hline 0 & 22 & 0 & -3 \\
\hline 10 & 22 & 10 & 5 \\
\hline 20 & 21 & 20 & 2 \\
\hline 30 & 15 & 19 & -3 \\
\hline 40 & 10 & 15 & -9 \\
\hline 50 & 0 & 10 & -10 \\
\hline 60 & -8 & 5 & -10 \\
\hline
\end{tabular}




\begin{tabular}{c|ccc}
70 & -15 & 2 & -10 \\
80 & -18 & 6 & -10 \\
90 & -18 & 36 & -5 \\
100 & -10 & 40 & 10
\end{tabular}

c. Input Patient Data and Inverse Dynamics Method - to create a user-friendly version, potentially for a clinical setting, that utilizes patient input data.

For the code to function, data was given to initiate the function of the respective codes: weight in pounds, height in inches, and gender, where $0=$ female and male $=1$. For the sake of testing the code's functionality, the given data values, Table 13, were chosen constants for all the above purposes. The gender varied to verify both parts of the if/else statement conditions.

Table 13: Given data for weight and height for purposes a $-\mathrm{c}$.

\begin{tabular}{|l|l|}
\hline Weight & $175 \mathrm{lbs}$ \\
\hline Height & $70 \mathrm{in}$ \\
\hline
\end{tabular}

\section{Input Maya Output Data}

The first purpose, in addition to the parameters given by Table 13, addressed the obtained Maya MEL code output from Table 7. The opening of the excel file allowed for the analysis of the left and right attributes of each joint at each keyframe time. The output of the looped MatLab code was designed to display the patient gender, determine if the moment is stable or unstable based on equilibrium testings, choose which leg is unstable, and the torque difference, as shown in Table 14. The data in Table 14 demonstrated that 
the animated Maya walk cycle experiences a great deal of instability at all selected keyframe times. The two negative torque differences stated an instability in the right leg on keyframe times 7 and 19. As shown in Figure 25, keyframes 7 and 19 are considered the passing poses in the animation walk cycle lingo. The passing pose is generally when the hips transition from the lowest position on the figure eight (down pose) to the tallest point (up pose). The torque difference value ranges, -2500 to 1300 , could be due to the constraint that the input data experienced with the IK handle, as mentioned in the MEL code section. In comparing the Maya output data from Table 7 with given data from a previous study in Table 12, the Maya output data values do have abnormally small magnitudes overall. The range of motion that the LEG_R and LEG_L values should have reached in Table 7, should have been closer to 40 degrees at some point, as presented in Table 12. At the very least, from this segment of the study, combined the efforts of the Maya animation, MEL code, and the overall analysis of the torque and equilibrium.

Table 14: MatLab output for Maya joint $\mathrm{z}$ direction rotations for set keyframes from Table 7.

Keyframe time Stable/Unstable L/R Leg Torque Difference $(l b * i n)$

\begin{tabular}{c|ccc}
\hline 1 & Unstable & L & 1349.5 \\
4 & Unstable & L & 577.1 \\
7 & Unstable & R & -1406.4 \\
10 & Unstable & L & 418.3 \\
13 & Unstable & L & 415.1 \\
\hline
\end{tabular}




\begin{tabular}{c|ccc}
16 & Unstable & $\mathrm{L}$ & -2312.5 \\
19 & Unstable & $\mathrm{R}$ & 732.4 \\
22 & Unstable & $\mathrm{L}$ & 57.3 \\
25 & Unstable & $\mathrm{L}$ & 1349.5
\end{tabular}

Based on the data from Table 14, the question arises: Is it possible to achieve equilibrium (stability) when in a dynamic state, such as gait?

\section{Given Data: Test Joint Angles}

This section demonstrates the calculation of torque for the given joint angles to test the functionality of the written code for a modified purpose. Since this study does not calculate joint rotation on the left leg and right leg, performing the equilibrium exam becomes infeasible. For the sake of this section, the torque of each STANCE \% presented in Table 12 was calculated, where the torque results are as presented in Table 15 for a male.

Table 15: MatLab torque calculations for Table 12 joint angles.

\section{STANCE \% HIP TORQUE KNEE TORQUE}

\section{ANKLE \\ TORQUE}

\begin{tabular}{|c|ccc}
\hline $\mathbf{0}$ & -10.7 & 0.0 & -3.7 \\
$\mathbf{2 0}$ & -10.7 & -148.5 & -24.9 \\
$\mathbf{3 0}$ & 1014.1 & 249.12 & 23.6 \\
$\mathbf{4 0}$ & 788.2 & 40.9 & -3.7 \\
& -659.4 & 177.5 & -10.7 \\
\hline
\end{tabular}




\begin{tabular}{l|ccc}
$\mathbf{5 0}$ & 0.0 & -148.5 & 14.1 \\
$\mathbf{6 0}$ & -1199.2 & -261.7 & 14.1 \\
$\mathbf{7 0}$ & -788.2 & 248.2 & 14.1 \\
$\mathbf{8 0}$ & 910.3 & -76.3 & 14.1 \\
$\mathbf{9 0}$ & 910.3 & -270.7 & 24.9 \\
$\mathbf{1 0 0}$ & 659.4 & 203.4 & -14.1 \\
\hline
\end{tabular}

The calculated torque data from the given joint angles fluctuate between very small negative numbers and very large positive torques. These values justify the magnitude of the values presented in Table 14, since the original torque values in Table 15 are in the 1000s magnitude. The rotational torque values correlate with the amount of forward force and effort it takes for a human to walk with an intended direction and force.

\section{Input Patient Data and Inverse Dynamics Method}

This section focuses on constructing an interface that requires patient interaction and input information that can easily be gained from observation and traditional physical check-ups, such as weight, height, and gender. The joint angles would be obtained from inverse dynamics, such as through video or a series of pictures observation of the patient's gait, similar to a compilation of gait phases as presented in Figures 5, 6, or 25. The video or series of pictures will allow for the collection of accurate angles of rotation on the hip, knee, and ankle joints without disrupting or inadvertently influencing the patient's walking pattern with intermittent measuring. Utilizing the preset, constant parameters from Table 13, a range of joint angles were chosen to test the interface intended for patient use, as presented in Table 16. 
Table 16: Data for tested angles and gender for purpose 2.

\begin{tabular}{|c|c|c|c|c|c|}
\hline \multicolumn{3}{|c|}{ Input } & \multicolumn{3}{|c|}{ Output } \\
\hline Joints & $\begin{array}{c}\text { Angle } \\
\text { (Degrees) }\end{array}$ & Male/Female & Stable/Unstable & $\begin{array}{l}L / R \\
L e g\end{array}$ & $\begin{array}{c}\text { Torque } \\
\text { Difference } \\
\left(l b *^{\text {in })}\right.\end{array}$ \\
\hline $\mathbf{L}: \mathbf{H} \boldsymbol{\theta}, \mathbf{K} \boldsymbol{\theta}, \mathbf{A} \boldsymbol{\theta}$ & $0,0,0$ & Female & Stable & $\mathrm{N} / \mathrm{A}$ & 0.0 \\
\hline $\mathbf{R}: \mathbf{H} \theta, \mathbf{K} \theta, \mathbf{A} \theta$ & $0,0,0$ & & & & \\
\hline $\mathrm{L}: \mathbf{H} \theta, \mathbf{K} \boldsymbol{\theta}, \mathbf{A \theta}$ & $70,0,0$ & Female & Unstable & $\mathrm{L}$ & 1009.3 \\
\hline $\mathrm{R}: \mathbf{H} \theta, \mathbf{K} \theta, \mathbf{A} \theta$ & $0,0,0$ & & & & \\
\hline $\mathrm{L}: \mathbf{H} \boldsymbol{\theta}, \mathbf{K} \boldsymbol{\theta}, \mathbf{A} \boldsymbol{\theta}$ & $10,-10,0$ & Female & Unstable & $\mathrm{R}$ & -721.2 \\
\hline $\mathrm{R}: \mathbf{H} \theta, \mathbf{K} \theta, \mathbf{A} \theta$ & $0,-40,-5$ & & & & \\
\hline $\mathrm{L}: \mathbf{H} \boldsymbol{\theta}, \mathbf{K} \boldsymbol{\theta}, \mathbf{A} \boldsymbol{\theta}$ & $0,-40,-5$ & Male & Stable & N/A & 0.0 \\
\hline $\mathrm{R}: \mathbf{H} \theta, \mathbf{K} \theta, \mathbf{A} \theta$ & $0,-40,-5$ & & & & \\
\hline $\mathrm{L}: \mathbf{H} \boldsymbol{\theta}, \mathbf{K} \boldsymbol{\theta}, \mathbf{A} \boldsymbol{\theta}$ & $170,0,0$ & Male & Unstable & $\mathrm{L}$ & 248.0 \\
\hline $\mathrm{R}: \mathbf{H} \theta, \mathbf{K} \theta, \mathbf{A} \theta$ & $0,-10,20$ & & & & \\
\hline $\mathbf{L}: \mathbf{H} \theta, \mathbf{K} \theta, \mathbf{A} \theta$ & $0,-40,-5$ & Male & Unstable & $\mathrm{R}$ & -435.5 \\
\hline $\mathrm{R}: \mathbf{H} \theta, \mathbf{K} \theta, \mathbf{A} \theta$ & $0,-80,10$ & & & & \\
\hline
\end{tabular}

In Table 16, $\mathrm{L}$ and $\mathrm{R}$, represent left leg and right leg respectively, while $\mathrm{H} \theta, \mathrm{K} \theta, \mathrm{A} \theta$, stands for hip angle, knee angle, and ankle angle respectively. The angles were chosen based on the maximum range of motion that each joint experiences in normal, healthy movements. The data demonstrated the code's ability to switch between male and female 
patient analysis information as well as adequately calculate torque and equilibrium based on joint angles.

The results of all the codes are as follows, similar to the example shown in Figure 56:

1. Use given information, such as weight, height, and gender, to establish limb length and weight for torque evaluation

2. Provide $\mathrm{z}$ rotational data, either via the patient's gait observation, Maya MEL code output, given input joint angles

3. Execute the series of if/else statements and/or for loops to calculate torque and/or equilibrium

4. The output provided the gender, as well as tell if the position is stable or unstable. Stable means the left and the right torques equal each other and unstable means that the two sides do not match. The output also stated which side the instability exists in, left or right leg and the value difference.

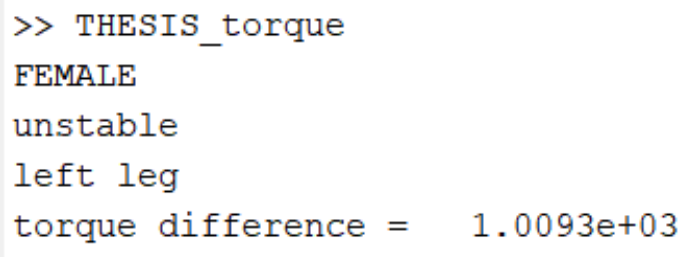

Figure 56: Sample MatLab output for one set of joint rotations in the $\mathrm{z}$ direction.

These codes' complete functionality is multipurpose and autonomously written so data can be switched out and functions modified, as was done for points a-c. 


\section{CHAPTER 5 - CONCLUSION}

The goal of this thesis was to (1) create a framework that assists in the transfemoral prosthesis fitting process by the quantification of balance in relation to patient comfort in lower limb prosthesis users and (2) analyze patient gait using the methods depicted in Figure 57. Due to the novelty of this topic, it is difficult to compare the results obtained from this thesis with previous studies. It was established that balance is a tradeoff between mobility and stability, so it is almost impossible to achieve both simultaneously. Balance and posture are dependent on the center of mass location, while symmetry is closely related to total body equilibrium. The idea of patient comfort is difficult to quantify, for these values are dependent on one another and the overall equilibrium that exists within the human body.

The choice to work with Maya may be foreign to the engineering world, but this software allows functions that engineering modeling software applications do not. With Maya, modeling the figures to be close to real life in basic features are more feasible than in a software, such as Solidworks. Also, with Maya, accessing the coding language has made it possible to analyze the animation on an engineering application and level. The Maya models and animation changed the game by providing countless positions and versions of the models to submit for Solidworks testings, specifically for center of mass location movements and comparisons.

The study of center of mass with Solidworks demonstrated that the change in position and the removal of a limb altered the location of the center of mass, no matter how minute these alterations may be. Symmetry and balance are such fragile elements within the human body that these seemingly minute changes can cause magnified 
problems to the body over time, problems that may appear as posture, spine pain, and joint pain, etc. The gait analysis of the center of mass modifications demonstrated a potential relationship between center of mass location and base of support size. As the gait cycle steps were analyzed, the center of mass constantly moved showing the redistribution of weight and hip movements the body ensues during locomotion. As the base of support transformed with every step, so did the center of mass location as it shifted forward and back in the $\mathrm{z}$ direction. The comparison of natural human and amputee anatomies showed that the center of mass tended to shift towards the natural limb in an amputee, while fluctuating depending on stump length.

An additional center of mass Solidworks analysis revealed that product choice impacted the location of the center of mass on the prosthesis. The ultimate goal of any prosthesis is for it to resemble the intended human function, such as a knee bend. When choosing a product, it is important to note if the material is lightweight and durable, because the comfort of the patient is most vital. Disregarding affordability, the primary goal should be to reestablish symmetry not only visually, but also physically by choosing products that present center of mass values that nearly mirror that of the patient's natural leg. The study comparing the center of mass of the natural leg and the prosthesis material combinations showed that the natural leg ratio was $\mathrm{COM}_{\mathrm{NL}}=0.6241$, while the prosthesis combination ratio trials varied depending on material. Combination 3 produced the best COM y ratio results because the ratio was the closest to the knee joint bend and also was the closest in mirroring the natural leg $\mathrm{COM}_{\mathrm{NL}}$ value at 0.5972 . The percent change of the combination 3 and natural leg comparison was $4.31 \%$, thus deeming the asymmetry 
insignificant. This solidified that combination 3 presented the best results in replicating the natural leg center of mass properties.

The MatLab code had multiple functions and uses. Due to its autonomous design, it was easy to switch out data information and modify intended outputs. With the Solidworks center of mass calculations, the Matlab algorithms were able to establish an $\mathrm{x}$ and $\mathrm{z}$ axis percentage for the center of mass location at $47.49 \%$ of the patients measurements in the $\mathrm{x}$ direction and $36.72 \%$ of the $\mathrm{z}$ parameters of the patient. The extracted Maya MEL code provided data to run the created MatLab analysis codes for the torque and equilibrium testings. The MEL code extracted $\mathrm{z}$ direction joint angles that are rather small in magnitude because of the constraints the IK handles placed on the joint's movements and rotations. This directly affected the equilibrium and torque output this input data created. When compared to the torque data produced by the given data from the previous study, the torque magnitudes in Table 15 proved to be close to that of the equilibrium values presented in Table 14. The MatLab code also showed the possible function of working with patient input data, such as gender, weight, and height, and inverse dynamics measurements method to establish the joint rotation of the patient in the $\mathrm{z}$ direction of movements.

This thesis showed that testing equilibrium on a patient in dynamic movement may not be possible since the center of mass is constantly shifting and the base of support is constantly changing sizes, both balance contributors, during natural locomotion. The body's form of balance in the dynamic phases requires the constant movement of the hips and weight shifts, and center of mass moves with the change of the body's form. The center of mass alteration contributors were established as the stump length, prosthesis 
weight, and body position and anatomy. Overall, this thesis approached the topics of center of mass, balance, and symmetry during gait in a novel method while utilizing software applications present in the visual arts, biomedical engineering, and mechanical engineering fields. The findings of this thesis show promise in positively impacting the present prosthesis fitting process by individualizing the methods with a newfound comprehension of the effects of center of mass, balance, and symmetry on the human body in different positions.

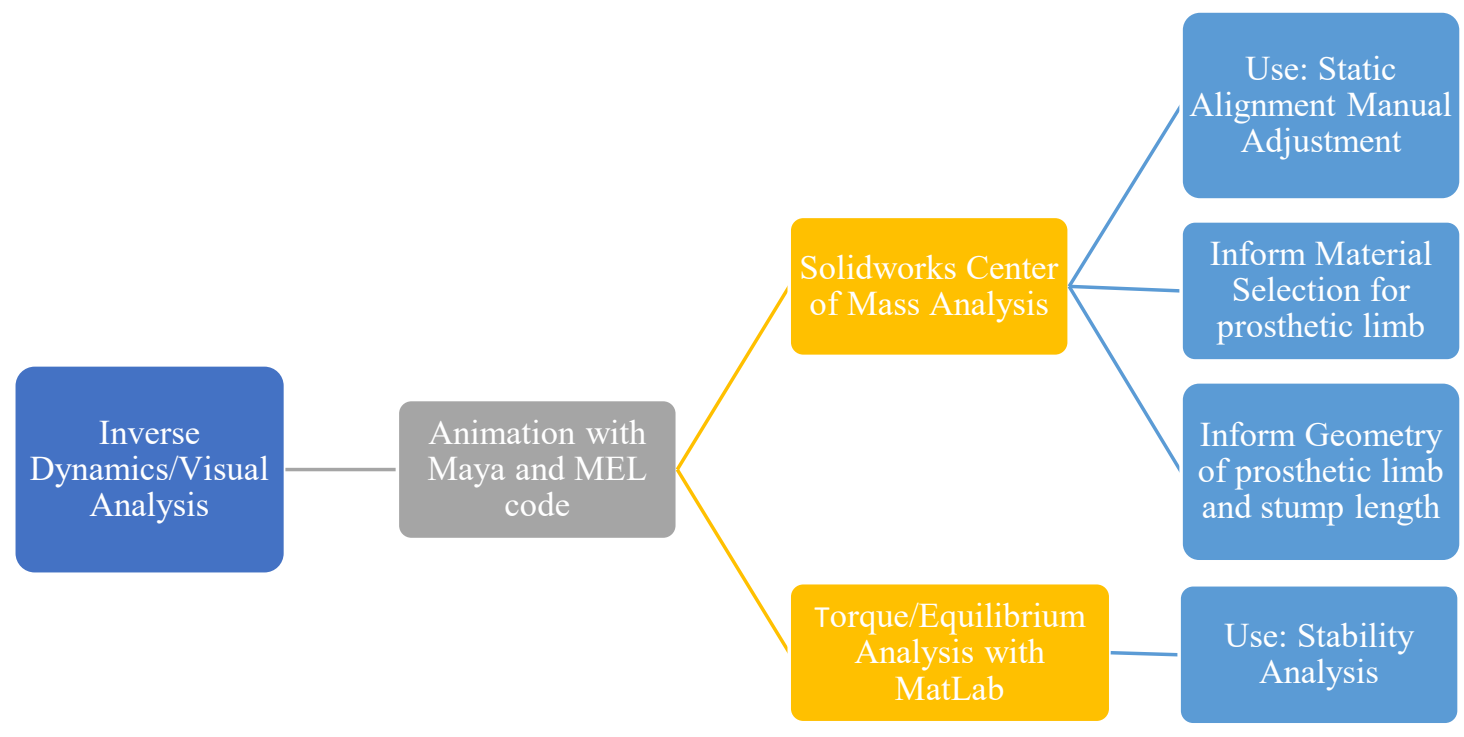

Figure 57: Thesis summary flow chart diagram. 


\section{CHAPTER 6 - FUTURE WORK}

\section{Maya Models and MEL code}

The default function for joints placement and movement is a method called FK or forward kinematics. Forward kinematics moves the joints depending on the created, default hierarchy. For the future, a further study on the joint rotation on the same walk cycle with the created rotation identification code will be used on FK joints instead of IK constraints. This analysis will determine if the $\mathrm{z}$ direction angles are truly affected by the IK handle constraints. An additional aspect of future studies will be to model and animate the female anatomy in Maya with the same constraints that were implemented on the male figure during the testings exhibited in this thesis. Furthermore, establishing the correct way to store values in a text file using MEL code will tremendously assist with the future goals of converting to an autonomous, simultaneous analysis of animated gait.

\section{Other Studies}

The end goal will be to have a modified version of this system implemented in prosthetics and orthotics clinics to help in patient prosthesis fittings. To achieve this goal, the future path includes patient participation and clinical shadowing to gain more firsthand experience and knowledge of the current fitting process. The analysis of the stump socket relationship from the patient information will prompt investigation of the stump pressure study during standing and walking. A pressure sensor study will prompt the creation of a pressure map system to collect stump socket relationship data. Future patient participation will assist in creating an autonomous system that is capable of gathering pressure information, gait, and center of mass to modify and/or add to the current prosthesis fitting method for the advanced ease and comfort of the patient. To assist in 
creating a fully autonomous system, establishing a method to have Maya MEL code and MatLab communicate seamlessly regarding the joint rotations of the legs will further advance and ease the existing process. An additional idea I would like to incorporate during the developments of this research, is to see how my thesis can help or grown into the robotics realm of humanoids and rovers. 


\section{REFERENCES}

[1] Pasquina, Colonel Paul F., et al. "Ethics in Rehabilitation: Access to Prosthetics and Quality Care Following Amputation." American Medical Association Journal of Ethics, vol. 17, no. 6, June 2015, pp. 535-546., journalofethics.amaassn.org/article/ethics-rehabilitation-access-prosthetics-and-quality-care-followingamputation/2015-06\#: :text=Increased\%20prosthetic\%20usage \%20is\% 20associated,general $\% 20$ psychiatric $\% 20$ symptoms $\% 20 \% 5 \mathrm{~B} 24 \% 5 \mathrm{D}$.

[2] Rajt'kova, V., et al. Biomechanics of Lower Limb Prostheses. Elsevier Ltd., 2014, pp. 383-391, Biomechanics of Lower Limb Prostheses.

[3] Luengas, L. A., et al. "Prosthetic Alignment and Biomechanical Parameters in Transtbial Amputees Due to Landmines." Prosthetic Alignment and Biomechanical Parametes in Transitial Amputees Due Landmines, Apr. 2017, 10.1007/978-98110-4086-3_192.

[4] Obiegbusi, Samuel Chigbo, et al. "Prosthetic Alignment: Part1. The Basics." Artlimb, Church WordPress Theme, 2019, www.artlimb.com/more-details/lower-limbarticles/prosthetic-alignment-part1-basics/.

[5] Radcliffe, C. W. Above-Knee Prosthetics. vol. 1, Prosthetics and Orthotics International, 1977, pp. 146-160, Above-Knee Prosthetics.

[6] Clark, Ross A., et al. "Validity and Reliability of the Nintendo Wii Balance Board for Assessment of Standing Balance." Gait and Posture 31, 15 Nov. 2009, pp. 307310., doi:10.1016/j.gaitpost.2009.11.012.

[7] "Prosthetic Fitting and Comfort." ProActive Prosthetics: Making More Possible, 2016, www.proactiveprosthetics.co.uk/service/prosthetic-fitting/.

[8] Shiel Jr., William C. "Medical Definition of Prosthetic." MedicineNet, 12 July 2017, www.medicinenet.com/script/main/art.asp?articlekey=15985.

[9] Myers, Mitchell, and Brad J. Chauvin. "NCBI." NCBI, StatPearls Publishing LLC, 2020, www.ncbi.nlm.nih.gov/books/NBK544350/.

[10] Service, Oxford Prosthetic, and Oxford University Hospitals NHS. Transfemoral Prosthesis, Information for Patients. Transfemoral Prosthesis, Information for Patients, August, 2018.

[11] Knudson, Duane. Fundamentals of Biomechanics. 2nd ed., Springer, 2007, pp. $169-190$.

[12] Bergmann, Thomas, and David Peterson. "Chapter 2: Joint Anatomy and Basic Biomechanics.” Chiropractic Technique, 3rd ed., Elsevier, 2010, pp. 11-23. 
[13] Ottobock. Prosthetics: Lower Limbs. Prosthetics: Lower Limbs.

[14] "Biomechanics." The Free Dictionary, Farlex, medicaldictionary.thefreedictionary.com/biomechanics.

[15] Admin. "What Is The Difference Between Kinetics and Kinematics? - Tabular Format." BYJUS, BYJU'S, 8 Aug. 2019, byjus.com/physics/difference-between kinetics-and-kinematics/.

[16] “Joints Types, Protection \& Location.” Ptdirect, 2010-2020, www.ptdirect.com/training-design/anatomy-and-physiology/joints-types-jointprotection-joint-location.

[17] “Gliding Joint - Pivot Joints.” Innerbody, 1999-2020, www.innerbody.com/image_skel07/skel32.html.

[18] Development, Web. "Microprocessor Technology For Leg Prostheses." Amputee Coalition, 2 Oct. 2019, www.amputee-coalition.org/microprocessor-technologyfor-leg-prostheses/.

[19] "Microprocessor Controlled Knees." Ottobock., 2013, www.ottobock.co.uk/prosthetics/info_for_new_amputees/prosthetic-technologyexplained/computer_controlled_knees/.

[20] "Computer Controlled Knees." Ottobock., 2020, www.ottobockus.com/prosthetics/info-for-new-amputees/prosthetics101/computer-controlled-knees/.

[21] "Artificial Limb." How Products Are Made, 2020, www.madehow.com/Volume1/Artificial-Limb.html.

[22] Shasmin, Hanie Nadia, et al. "A New Pylon Materials in Transtibial Prosthesis: A Preliminary Study.” Journal of Biomechanics, vol. 40, no. 2, 2007, p. 297. , https://www.researchgate.net/publication/233388171_A_NEW_PYLON MATRIALS_IN_TRANSTIBIAL_PROSTHESIS_A_PRELIMINARY_STUDY.

[23] Oleiwi, Jawad Kadhim, and Shaymaa Jumaah Ahmed. "Tensile and Buckling of Prosthetic Pylon Made from Hybrid Composite Materials.” Eng \& Tech Journal, vol. 34, no. 14, 2016, pp. 2642-2653., https://www.researchgate.net/publication/316317262_Tensile_and_Buckling_of_ Prosthetic_Pylon_Made_from_Hybrid_Composite_Materials.

[24] "Finding the Best Foot for You." Ottobock., 2020, www.ottobockus.com/prosthetics/infofor-new-amputees/prosthetics-101/finding-the-best-foot-for-you/. 
[25] Zawada, Jerome, and Luis Tissone. "Advanced Sealing Systems Improve Prosthetics' Performance.” Orthopedic Design \& Technology - Covering the Specialized Field of Orthopedic Product Development and Manufacturing, 13 Sept. 2016, www.odtmag.com/contents/view_online-exclusives/2016-0913/advanced-sealing-systems-improve-prosthetics-performance/.

[26] Kingsley, Jim. "Prosthetic Knee Options." Scheck \& Siress, Scheck and Siress, 24 Mar. 2020, www.scheckandsiress.com/patient-information/care-and-use-of-yourdevice/prosthetic-knee-options/.

[27] "Multifunction Ankle Joints: AFO - Ankle Foot Orthosis: Custom Orthotics: Orthotics: Ottobock US B2B Site." Multifunction Ankle Joints | AFO - Ankle Foot Orthosis | Custom Orthotics | Orthotics | Ottobock US B2B Site, shop.ottobock.us/Orthotics/Custom-Orthotics/AFO---Ankle-FootOrthosis/Multifunction-Ankle-Joints/c/4021.

[28] Human Body Part Weights, robslink.com/SAS/democd79/body_part_weights.htm.

[29] Krishnan, R. Hari, et al. "Estimation of Mass Moment of Inertia of Human Body, When Bending Forward, for the Design of a Self-Transfer Robotic Facility." Journal of Engineering and Science Technology, vol. 11, no. 2, 2016, pp. 166176.

[30] Williams, Richard. Animator's Survival Kit. 2nd ed., Faber and Faber, 2001.

[31] Moses, Scott. "Hip Range of Motion.” Family Practice Notebook, Terms | Privacy (EHS) | About | Site Map | Blog, 3 May 2020, fpnotebook.com/Ortho/Exam/HpRngOfMtn.htm.

[32] "Hip Anatomy.” Physiopedia, 2020, www.physio-pedia.com/Hip_Anatomy.

[33] McClure, Grace. "Range of Motion After Joint Replacement Surgery." PeerWell's PreHab and ReHab Blog: All Things Joint Replacement Surgery, PeerWell's PreHab and ReHab Blog: All Things Joint Replacement Surgery, 19 Nov. 2018, www.peerwell.co/blog/2017/01/13/range-of-motion-after-joint-replacementsurgery/.

[34] Roaas, Asbjorn, and Gunnar B. J. Andersson. "Normal Range of Motion of the Hip, Knee, and Ankle Joints in Male Subjects, 30-40 Years of Age." Acta Orthopaedica Scandinavica, vol. 53, 1982, pp. 205-208., https://www.tandfonline.com/doi/pdf/10.3109/17453678208992202.

[35] Hora, Martin, et al. "Body Size and Lower Limb Posture During Walking in Humans." PLOS One, vol. 12, no. 2, 13 Feb. 2017, pp. 1-16., doi:10.1371/journal.pone.0172112. 
[36] “AISI Type 316 Stainless Steel, Annealed Sheet.” ASM Aerospace Specification Metals Inc., asm.matweb.com/search/SpecificMaterial.asp?bassnum=MQ316A.

[37] Engineers Edge, LLC. "Properties of Plastic Materials." Engineers Edge Engineering, Design and Manufacturing Solutions, 25 Sept. 2018, www.engineersedge.com/plastic/properties_of_plastic_materials_14630.htm.

[38] AZoM. “Grade Ti 8Mn Alloy (UNS R56080).” AZoM.com, 5 July 2013, www.azom.com/article.aspx?ArticleID=9389.

[39] "Metals and Alloys - Densities." The Engineering ToolBox, www.engineeringtoolbox.com/metal-alloys-densities-d_50.html.

[40] "Polyethylene (PE)." Polyethylene (PE) Plastic: Properties, Uses \& Application, https://omnexus.specialchem.com/selection-guide/polyethylene-plastic.

[41] "Chemical Composition and Properties of Aluminum Alloys." United Aluminum, www.unitedaluminum.com/chemical-composition-and-properties-of-aluminumalloys/.

[42] Uermura, Keisuke, et al. "Hip Rotation during Standing and Dynamic Activities and the Compensatory Effect of Femoral Anteversion: AN in-Vivo Analysis of Asymptomatic Young Adults Using Three Dimensional Computed Tomography Models and Dual Fluoroscopy.” HHS Public Access, vol. 61, Mar. 2018, pp. 276281., doi:doi:10.1016.

[43] Rudroff, Thorsten, and Felix Proessl. "Effects of Muscle Function and Limb Loading Asymmetries on Gait and Balance in People with Multiple Sclerosis." Frontiers in Physiology, vol. 9, 15 May 2018, doi:10.3389/fphys.2018.00531. 


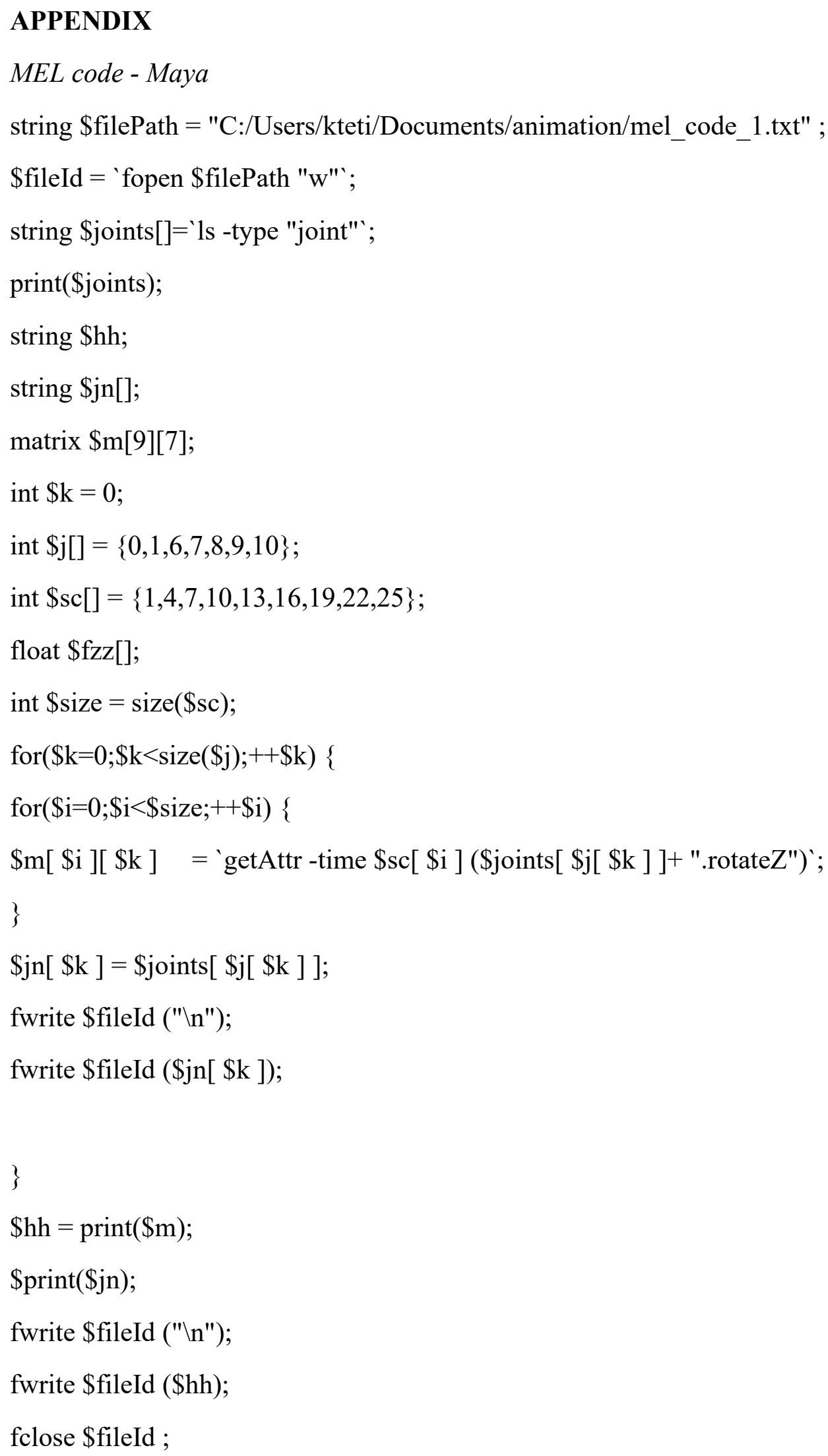




\section{MatLab Code}

Center of mass percentages from $(0,0,0)$

$\mathrm{h}=14.83$; \%centimeters (y)

$\mathrm{w}=2.40$; \%centimeters ( $\mathrm{x}$ )

$1=1.77$; \%centimeters (z)

$\mathrm{cmy}=8.361 ;$ \%centimeters $(y)$

$\mathrm{cmx}=-0.029$; \%centimeters (x)

$\mathrm{cmz}=-0.235$; \%centimeters $(z)$

$\mathrm{cm} \times 1=(\mathrm{w} / 2)+\mathrm{cmx}$;

$\mathrm{cmzl}=(1 / 2)+\mathrm{cmz}$;

$\mathrm{py}=(\mathrm{cmy} / \mathrm{h}) * 100$;

$\mathrm{px}=(\mathrm{cm} \times 1 / \mathrm{w}) * 100$;

$p z=(c m z 1 / 1) * 100$;

fprintf('center of mass percentage for $\left.y={ }^{\prime}\right)$;

disp(py);

fprintf('\ncenter of mass percentage for $x=$ ');

$\operatorname{disp}(p x)$;

fprintf(' \ncenter of mass percentage for $z=$ ');

$\operatorname{disp}(p z)$;

MatLab - with Maya output

clear a11;

open MEL code data for z rotation

data $=x$ 1sread ('MEL_code_rot_data. $x 1 s x$ ') ;

ktime=data $(:, 1)$;

ank1e_L=data $(:, 2)$;

ank1e_R=data $(:, 3)$;

hips=data $(:, 4)$;

knee_L=data $(:, 5)$;

knee_R=data $(:, 6)$;

leg_L=data $(:, 7)$;

1eg_R=data $(:, 8)$;

figure();

plot (ktime, ankle_L);

hold on;

plot (ktime, knee_L) ;

hold on;

plot (ktime, (1eg_L).*-1);

hold off;

title('Left Leg Joint Movements, z-axis');

xlabel('keyframe time');

ylabel('degree of rotation'); 


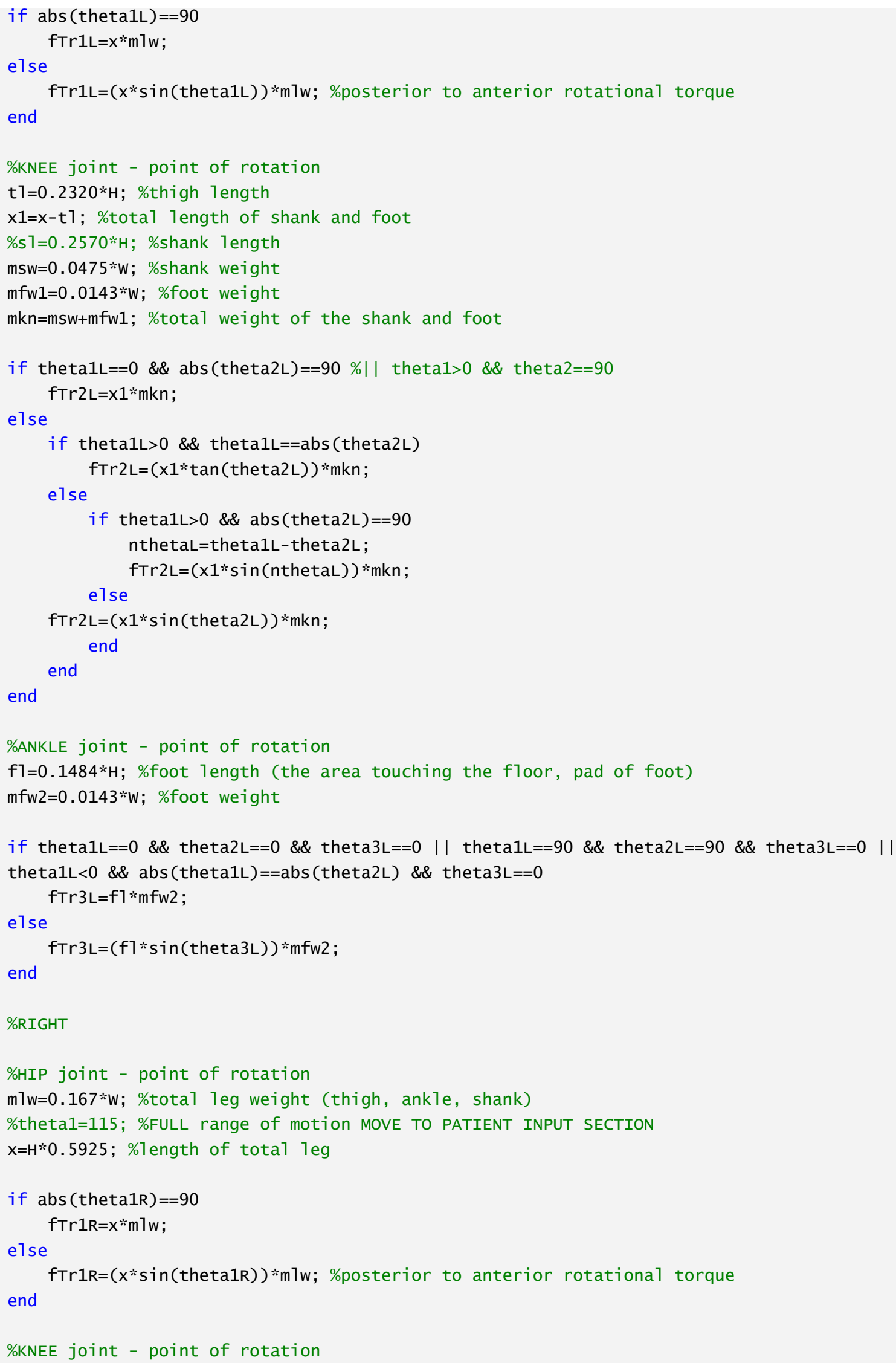




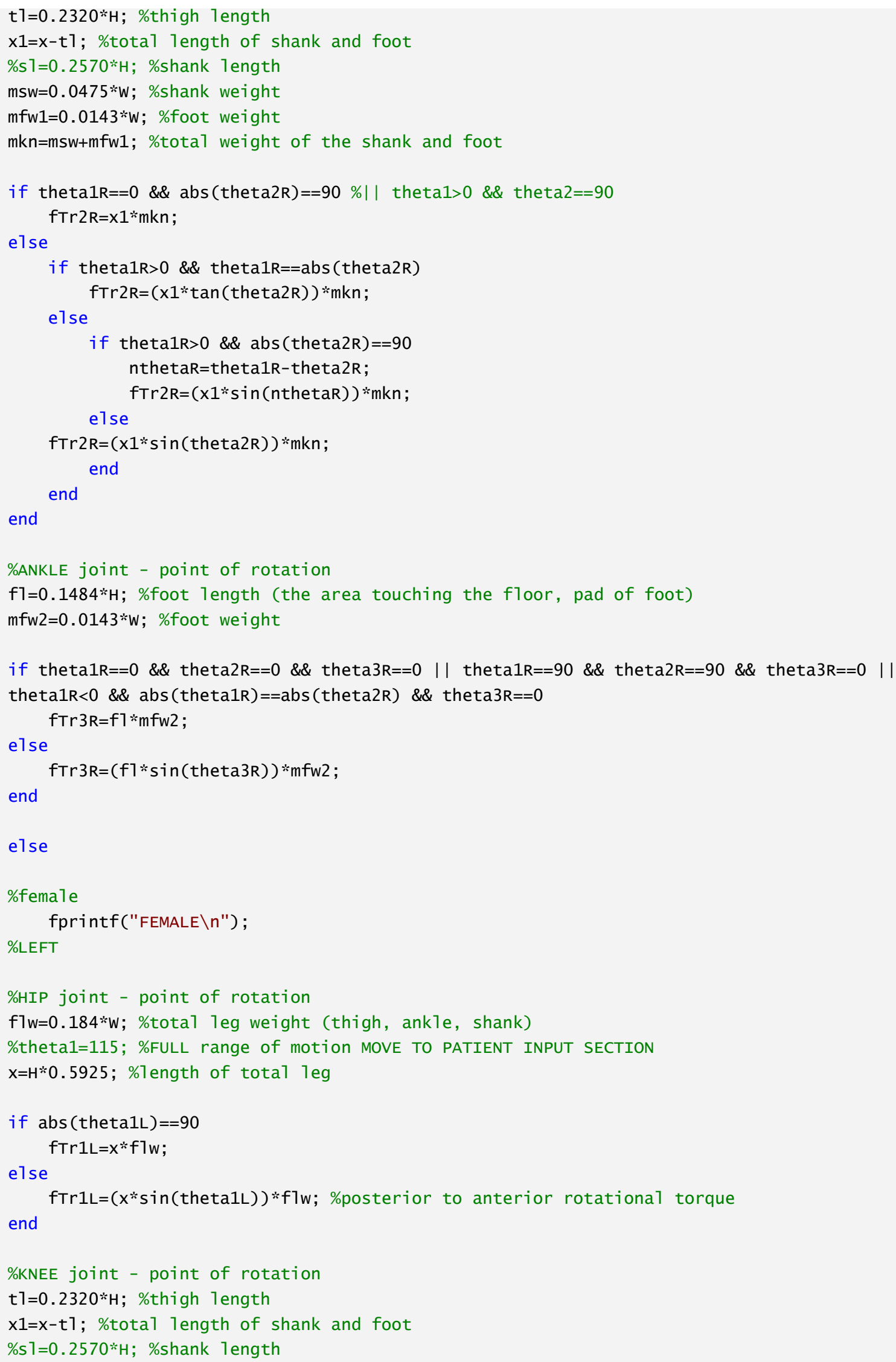


$f s w=0.0535 \%$; \%shank weight

ffw $1=0.0133 * w$; \%foot weight

$f k n=f s w+f f w 1 ;$ \%total weight of the shank and foot

if theta $1 \mathrm{~L}==0 \& \&$ abs $($ theta $2 \mathrm{~L})==90 \%||$ theta $1>0 \& \&$ theta $2==90$

$\mathrm{fTr} 2 \mathrm{~L}=\mathrm{x} 1 * \mathrm{fkn}$;

e1se

if theta1L $>0$ \&\& theta $1 \mathrm{~L}==\operatorname{abs}$ (theta2 $\mathrm{L}$ )

$\mathrm{fTr} 2 \mathrm{~L}=(\mathrm{x} 1 * \tan ($ theta $2 \mathrm{~L})) * \mathrm{fkn}$;

else

if theta1L $>0$ \&\& abs (theta2L) $==90$

nthetaL $=$ theta $1 \mathrm{~L}-$ theta $2 \mathrm{~L}$;

$\mathrm{fTr} 2 \mathrm{~L}=(\mathrm{x} 1 * \sin (\mathrm{nthetaL})) * \mathrm{fkn}$;

else

$\mathrm{fTr} 2 \mathrm{~L}=(\mathrm{X} 1 * \sin ($ theta $2 \mathrm{~L})) * \mathrm{fkn}$;

end

end

end

\%ANKLE joint - point of rotation

$\mathrm{fl}=0.1484 \% \mathrm{H}$; \%foot 1ength (the area touching the floor, pad of foot)

ffw2 $=0.0133 \% \mathrm{w} ; \%$ foot weight

if theta $1 \mathrm{~L}==0$ \&\& theta $2 \mathrm{~L}==0$ \&\& theta3 $\mathrm{L}==0 \quad||$ theta $1 \mathrm{~L}==90$ \&\& theta $2 \mathrm{~L}==90$ \&\& theta3 $\mathrm{L}==0||$

theta $1 \mathrm{~L}<0 \quad \& \&$ abs $($ theta $1 \mathrm{~L})==\mathrm{abs}($ theta $2 \mathrm{~L}) \& \&$ theta $\mathrm{L}==0$

$\mathrm{fTr} 3 \mathrm{~L}=\mathrm{f}\rceil * \mathrm{ffw} 2$;

else

$f \operatorname{Tr} 3 L=(f\rceil * \sin ($ theta $3 L)) * f f w 2 ;$

end

\%RIGHT

\%HIP joint - point of rotation

flw=0.184*w; \%tota1 1eg weight (thigh, ank1e, shank)

\%theta1=115; \%FULL range of motion MOVE TO PATIENT INPUT SECTION

$\mathrm{X}=\mathrm{H} * 0.5925$; \%1ength of total 1 eg

if $\operatorname{abs}($ theta1R $)==90$

$\mathrm{fTr} 1 \mathrm{R}=\mathrm{x} * \mathrm{fl} w$;

e1se

$\operatorname{fTr} 1 \mathrm{R}=(\mathrm{X} * \sin ($ theta1R $)) * \mathrm{flw}$; \%posterior to anterior rotational torque

end

\%KNEE joint - point of rotation

$\mathrm{t} 1=0.2320 * \mathrm{H}$; \%thigh 1ength

$\mathrm{x} 1=\mathrm{x}-\mathrm{t} 1$; \%tota 1 1ength of shank and foot

$\% \mathrm{~s} 1=0.2570 * \mathrm{H} ; \%$ shank 1ength

$\mathrm{fsw}=0.0535 * \mathrm{w}$; \%shank weight

ffw1 $=0.0133 * w$; \%foot weight

$f k n=f s w+f f w 1 ; \%$ total weight of the shank and foot

if theta $1 R==0 \& \&$ abs $($ theta2R) $==90 \%||$ theta $1>0 \& \&$ theta $2==90$

$\mathrm{fTr} 2 \mathrm{R}=\mathrm{x} 1 * \mathrm{fkn}$;

e1se 


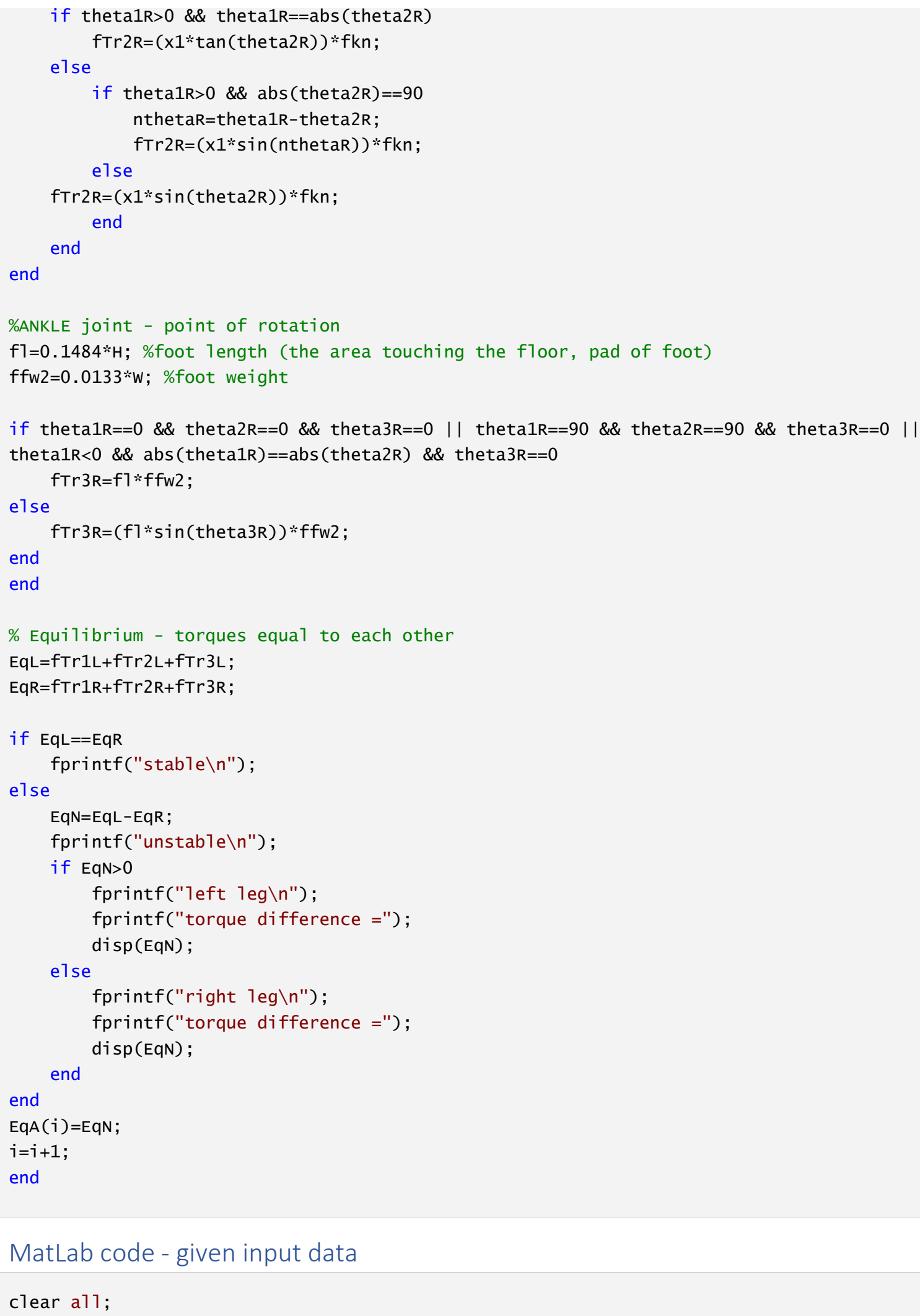


open data for joint rotation

data $=x 1$ sread('Given data_joint angles.x1sx');

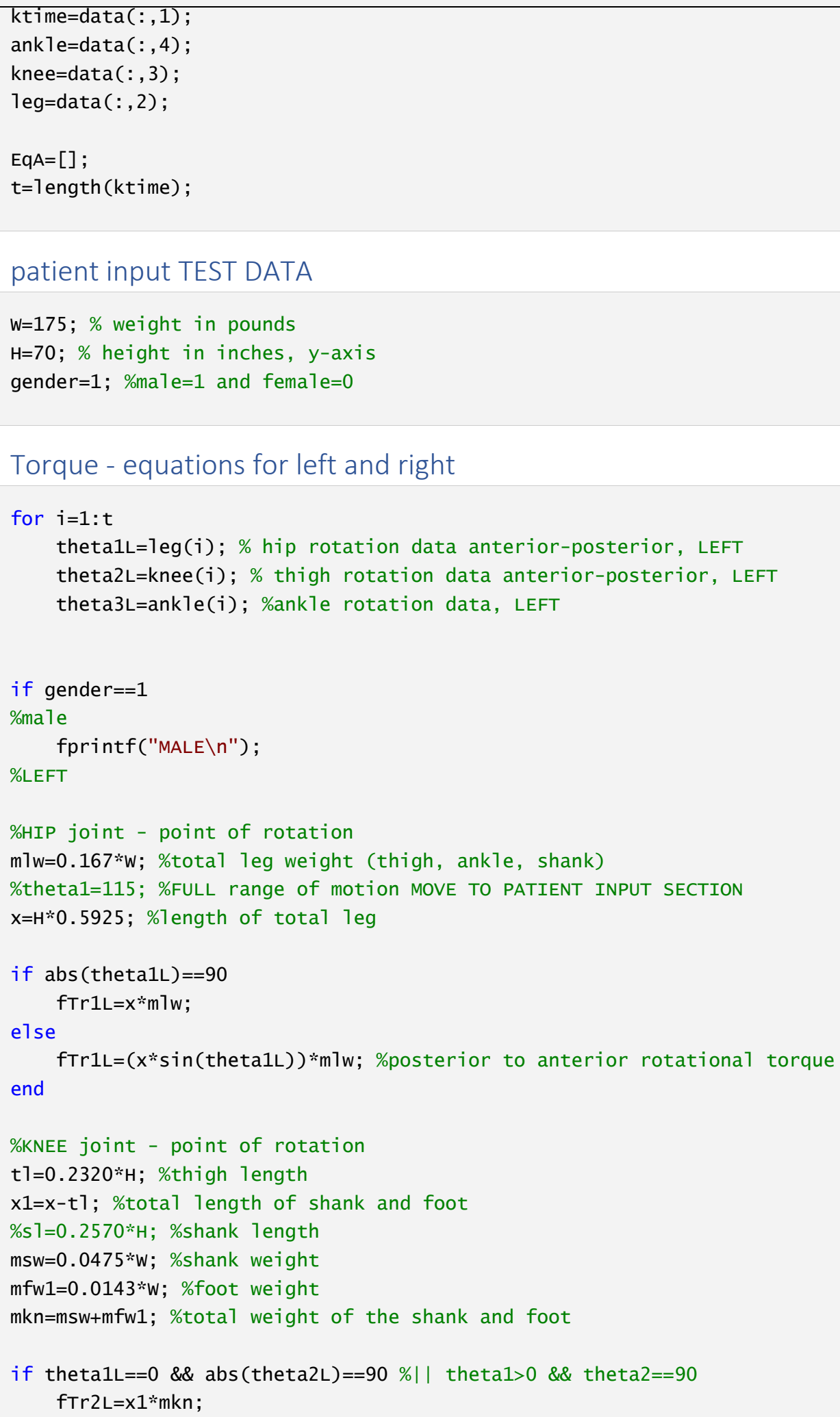




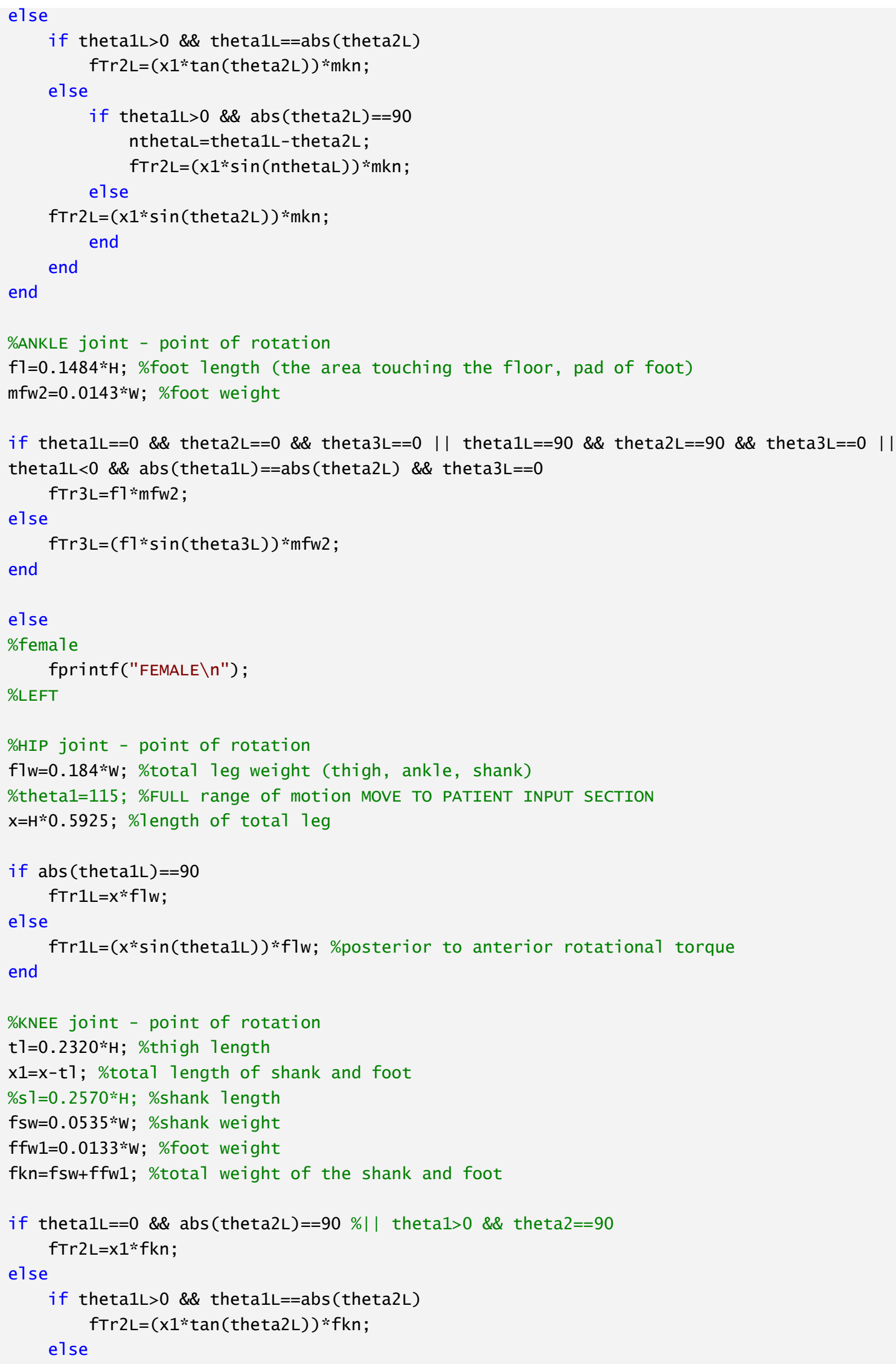




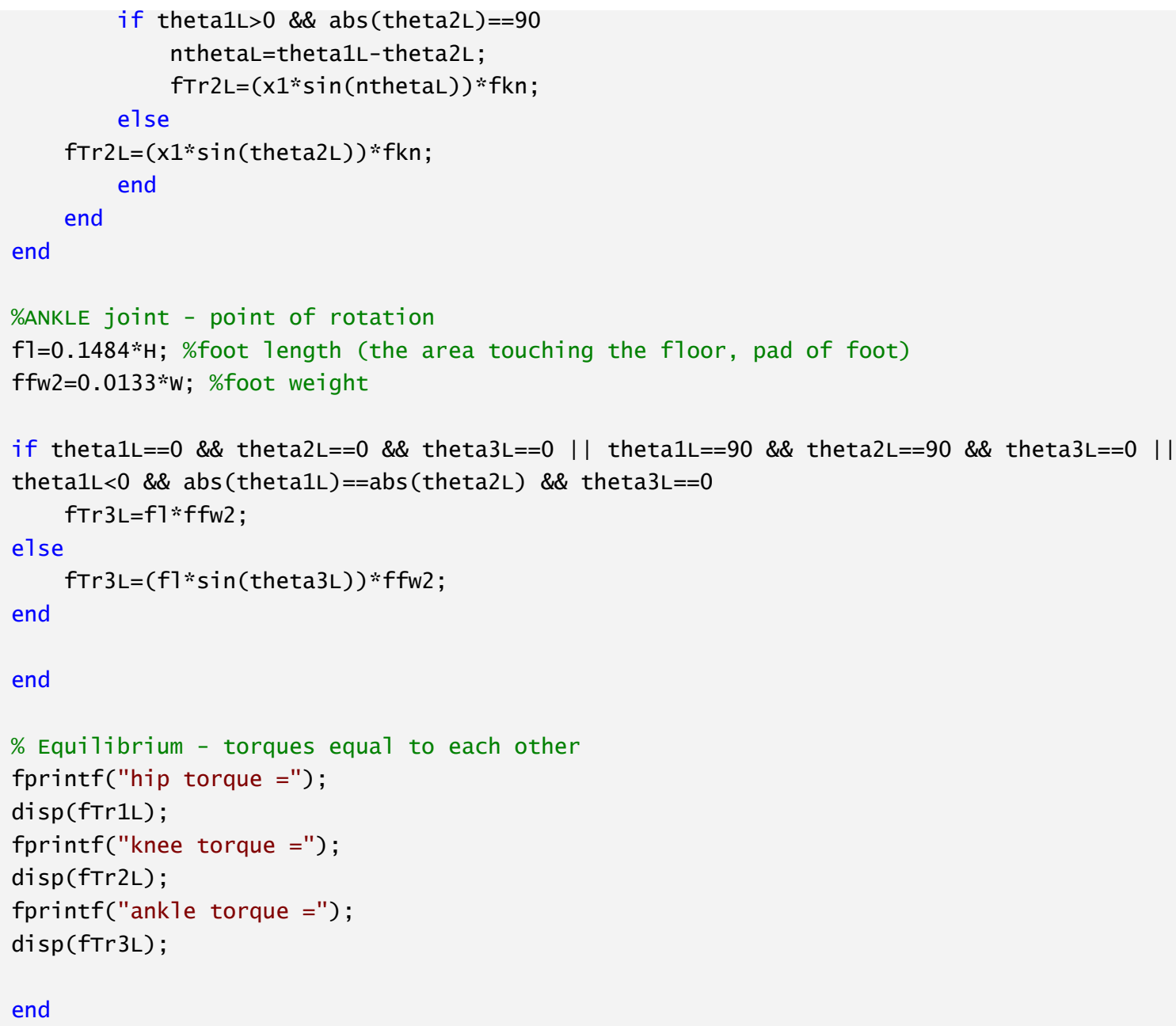

angle rotations along z-axis - patient input based on leg position, LEFT

theta1L=70; \% hip rotation data anterior-posterior theta $2 \mathrm{~L}=-10.006$; $\%$ thigh rotation data anterior-posterior theta $3 \mathrm{~L}=1.5$; \%ankle rotation data 
angle rotations along z-axis - patient input based on leg position, RIGHT

theta1R=0; \% hip rotation data anterior-posterior

theta2R=0; \% thigh rotation data anterior-posterior

theta3R=0; \%ankle rotation data

Torque - equations for left and right

if gender $==1$

$\%$ male

fprintf("MALE $\backslash n ")$;

$\%$ LEFT

\%HIP joint - point of rotation

m7w=0.167*w; \%tota1 1eg weight (thigh, ank1e, shank)

\%theta1=115; \%FULL range of motion MOVE TO PATIENT INPUT SECTION

$\mathrm{X}=\mathrm{H} * 0.5925$; \% 1ength of total 1 eg

if $\operatorname{abs}($ theta1L $)==90$

fTr1L=x*m1w;

else

fTr $1 L=(x * \sin ($ theta $1 L)) * m 1 w$; \%posterior to anterior rotationa 1 torque end

\%KNEE joint - point of rotation

$\mathrm{t} 1=0.2320 \% \mathrm{H} ; \%$ thigh 1ength

$\mathrm{x} 1=\mathrm{x}-\mathrm{t} 1$; \%tota 1 1ength of shank and foot

$\% \mathrm{~s} 1=0.2570 * \mathrm{H}$; \%shank 1ength

$\mathrm{msw}=0.0475 * \mathrm{w}$; \%shank weight

mfw1 $=0.0143 * w$; \%foot weight

$m k n=m s w+m f w 1 ; \%$ total weight of the shank and foot

if theta $1 \mathrm{~L}==0 \quad \& \&$ abs $($ theta $2 \mathrm{~L})==90 \%||$ theta $1>0 \& \&$ theta $2==90$

$\operatorname{fTr} 2 \mathrm{~L}=\mathrm{x} 1 * \mathrm{mkn}$;

else

if theta $1 \mathrm{~L}>0$ \& \& theta $1 \mathrm{~L}==\operatorname{abs}$ (theta $2 \mathrm{~L}$ )

$\mathrm{fTr} 2 \mathrm{~L}=(\mathrm{x} 1 * \tan ($ theta $2 \mathrm{~L})) * \mathrm{mkn}$;

else

if theta1L>0 \&\& abs (theta2L) $==90$

nthetaL $=$ theta $1 \mathrm{~L}-$ theta $2 \mathrm{~L}$;

fTr $2 L=(x 1 * \sin (n$ thetaL $)) * m k n$;

else

$\operatorname{fTr} 2 \mathrm{~L}=(\mathrm{X} 1 * \sin ($ theta $2 \mathrm{~L})) * m k n$;

end

end

end

\%ANKLE joint - point of rotation

$\mathrm{fl}=0.1484 * \mathrm{H}$; \%foot length (the area touching the floor, pad of foot)

$\mathrm{mfw} 2=0.0143 * \mathrm{w} ; \%$ foot weight

if theta $1 \mathrm{~L}==0 \quad \& \&$ theta $2 \mathrm{~L}==0 \quad \& \&$ theta $3 \mathrm{~L}==0 \quad||$ theta $1 \mathrm{~L}==90 \quad \& \&$ theta $2 \mathrm{~L}==90 \quad \& \&$ theta $3 \mathrm{~L}==0 \quad||$ 


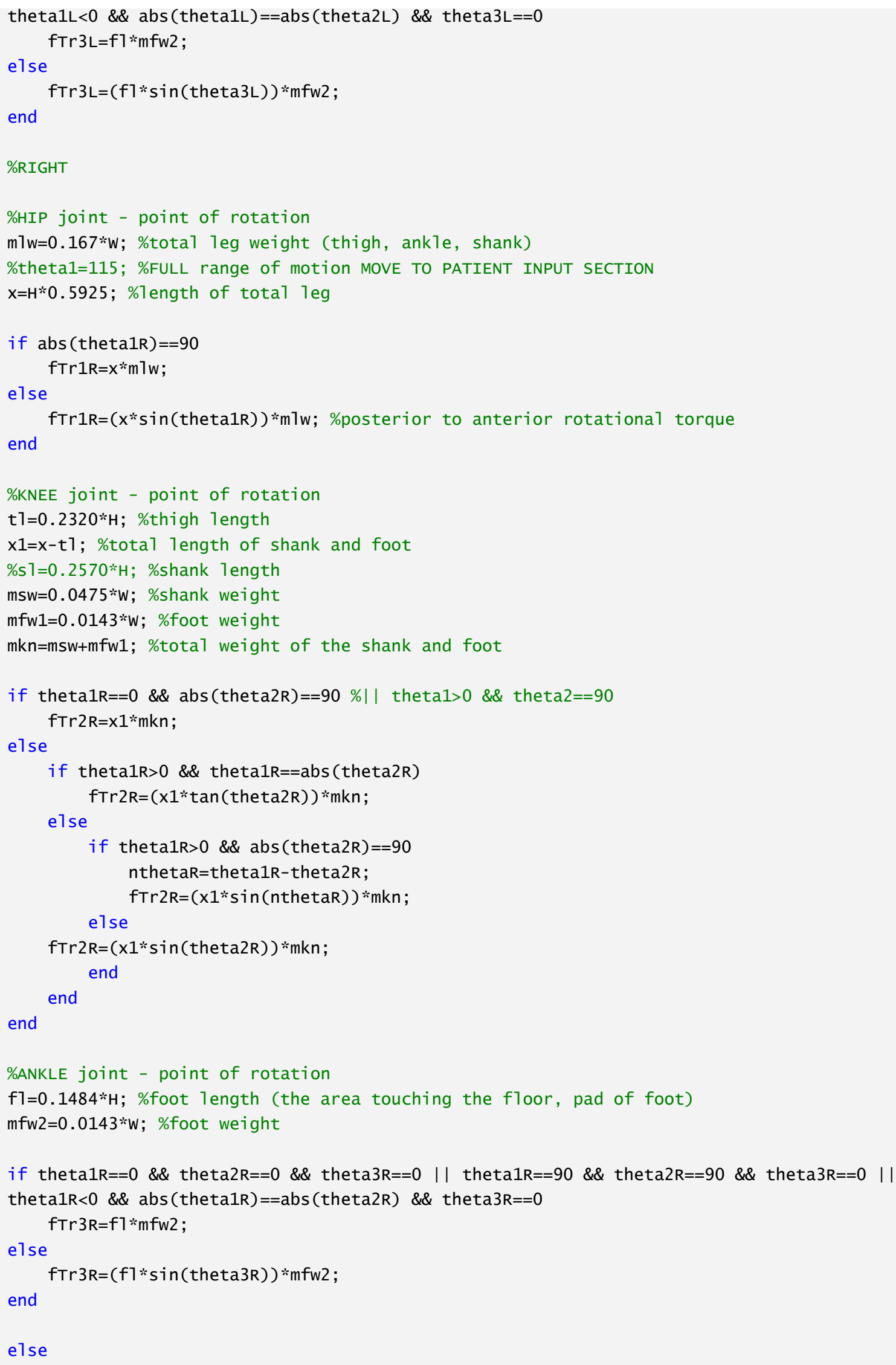




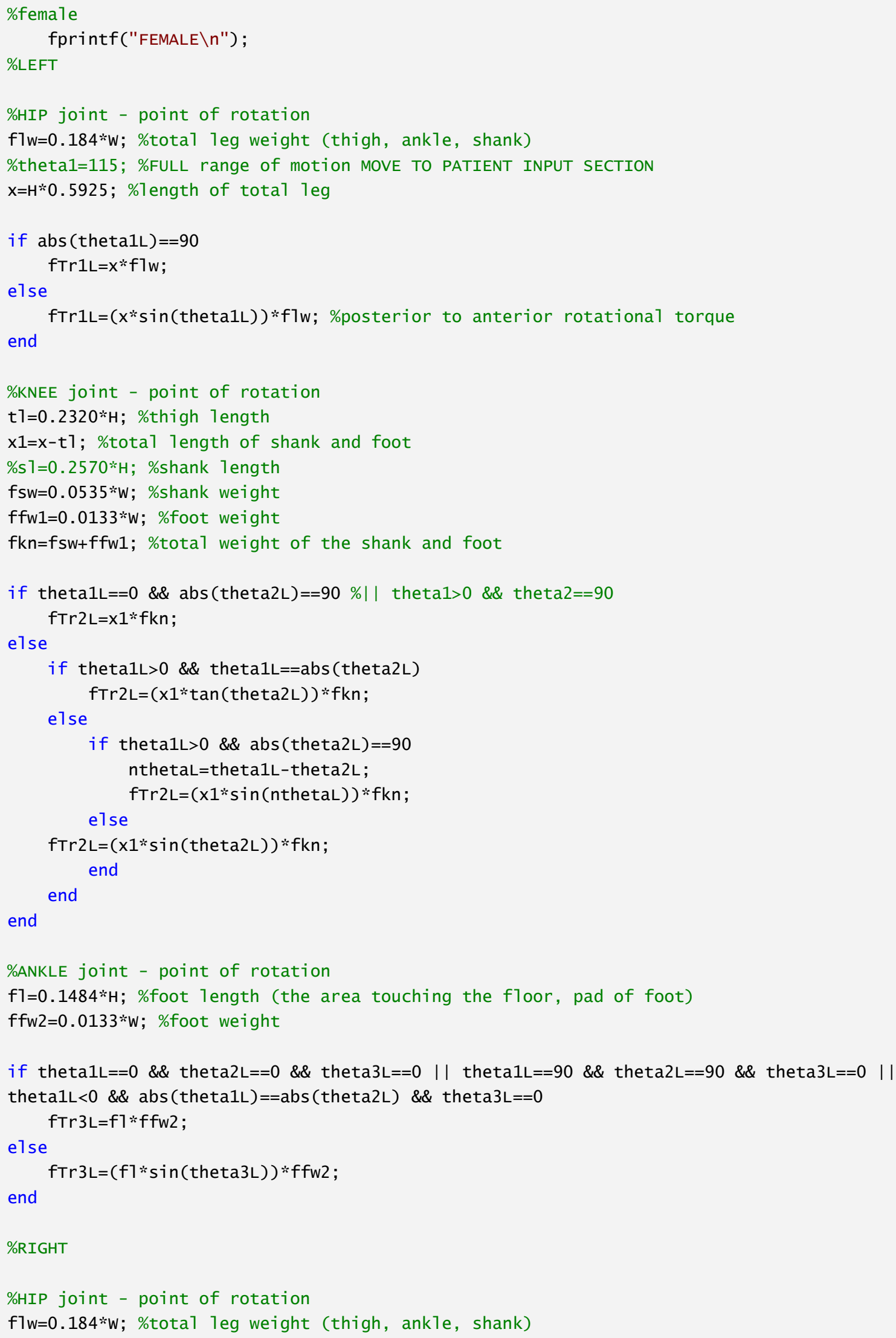




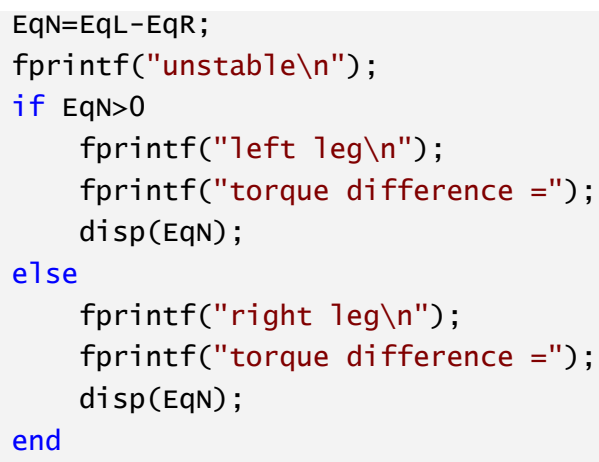

Published with MATLAB ${ }^{\circledR}$ R2019b 